\title{
Hal Foster e a crítica ao primitivismo vanguardista
}

\author{
Larissa Costa da Mata*
}

\section{Resumo:}

O texto que se segue apresenta alguns conceitos utilizados pelo crítico norteamericano Hal Foster, cuja produção recebeu apenas esparsas traduções para a língua portuguesa até o momento em revistas acadêmicas brasileiras e um livro completo. Hal Foster é atualmente professor do departamento de Arte e Antropologia na Universidade de Princeton e co-editor do periódico OCTOBER. Segue-se a esta apresentação a tradução de "Blinded insights", um dos capítulos do seu Prosthetic Gods (MIT Press, 2004), sobre a relação estética dos artistas Jean Dubuffet, Paul Klee e Max Ernst com a coleção de Prinzhorn de obras de artistas com problemais mentais.

\section{Palavras-chave:}

Hal Foster; vanguardas; real; primitivismo

Embora Hal Foster se ocupe de uma série de temas caros à crítica e à história da arte contemporâneas, seria um trabalho pouco produtivo desenvolver, aqui, uma genealogia de todos os seus interesses sem se estabelecer um vínculo com o ensaio que segue esta apresentação. Atenho-me, portanto, a algumas considerações presentes em "Blinded insights" ("Iluminações cegas") que percebo remeterem aos seus textos anteriores, como a relação do real com a imagem e a noção surrealista de colagem, que colaboram para a sua crítica ao primitivismo vanguardista europeu, de artistas surrealistas como os mencionados em seu ensaio (Max Ernst, Paul Klee e Jean Dubuffet), mas também de Paul Gauguin e de Pablo Picasso, responsáveis, segundo ele, por constituir uma cena originária para a aproximação vanguardista do primitivo (FOSTER, 2004). Os artistas de que ele trata em Prosthetic Gods (Deuses protéticos, 2004) - Paul Gauguin e Pablo Picasso, F. T. Marinetti e Wyndhan Lewis, Adolf Loos e Max Ernst, Paul Klee e Jean Dubuffet - estão fascinados por ficções de origem e buscam estabelecer um projeto de alteridade próprio -

*Doutoranda em Teoria da literatura pela Universidade Federal de Santa Catarina. 
esteja ele baseado nos inícios primordiais ou na antecipação de um futuro tecnológico. Como veremos, Hal Foster é capaz de propor uma noção própria de primitivo, com base no equívoco vanguardista que ele aponta.

Nesse sentido, considero que a aproximação da vanguarda da arte dos alienados acompanha o interesse da mesma pelo que Hal Foster denomina de uma "tríade estranha", que incorpora no sentido de "primitivo" a arte dos alienados, das crianças e das culturas não-ocidentais. Além de Cesare Lombroso e de Prinzhorn, podemos citar, por exemplo, G. H. Luquet, autor de $A$ arte primitiva, de 1930, resenhado por Bataille na Documents do mesmo ano no verbete homônimo. Luquet procura uma definição de arte primitiva considerando-a como a gênese do figurativismo ocidental, por ter como princípio o que ele denomina "realismo intelectual". ${ }^{1}$ A sua concepção abrangia as crianças e o homem pré-histórico, visto que considerava especialmente a espontaneidade da arte "primitiva" e o sentido cronológico linear. Devemos mencionar, ainda, a publicação no Brasil de uma obra semelhante à de Prinzhorn por Osório César (1896-1980), psiquiatra do Juqueri em São Paulo, em 1929, a Expressão artística dos alienados. Estudos dos Símbolos na Arte.

Doutor em História da arte pela Universidade da Cidade de Nova York, o crítico norte-americano Hal Foster começou a sua carreira colaborando com periódicos proeminentes na área, como a revista Artforum e Art in America (que editou até 1987). Em 1990, o mesmo ano em que se vincula ao grupo da OCTOBER, da qual se torna editor, defende a sua tese sobre o surrealismo, orientada por Rosalind Krauss e depois transformada no livro Compulsive beauty (Beleza compulsiva, 1993). Algumas das colaborações de Hal Foster à OCTOBER foram posteriormente incorporadas aos seus livros, como é o caso de "Iluminações cegas", que teve uma versão publicada nesse periódico antes de compor Deuses protéticos ${ }^{2}$.

\footnotetext{
1 "Primitive art is that which, whatever the age and milieu of the artist, is guided in the rendering of forms by the same conception of figurative art and thus of resemblance that guides our children's art, insofar as they draw in their own way, which is different from the style of adults they will become" (LUQUET, 2003, p. 222). Georges Bataille critica a opção de Luquet em: L'art primitif, Documents, v. 7, 1930.

Outro leitor da obra de Luquet é o escritor Mário de Andrade, que questiona diversas definições de primitivo, inclusive a do próprio Luquet, em seu ensaio "Primitivos" (Rev. da Academia Paulista de Letras, São Paulo, $\mathrm{n}^{\circ} 27$, set 1944, p. 21-28).

$2 \mathrm{O}$ texto foi publicado com o título de "Blinded insights: on the modernist reception of the art of the mentally ill" ["Iluminações cegas: sobre a recepção modernista da arte dos alienados". OCTOBER, $\mathrm{n}^{\circ}$ 97, 2001 (p. 3-30). Segundo o autor menciona em nota de rodapé, o texto da revista é uma versão revisada de um primeiro ensaio denominado "No man's land" (Terra de ninguém), escrito para acompanhar a exposição "The Prinzhorn collection: traces upon the Wunderblock" [A coleção de Prinzhorn: rabiscos sobre o Wunderblock [bloco mágico]], com a curadoria de Catherine de Zegher, que ocorreu no Drawing Center em Nova York em 2001. Além dos livros mencionados nesta apresentação, Hal Foster também é autor de Pop Art (2005); Art since 1900: Modernism, antimodernism, postmodernism (2004, em co-autoria com Krauss, Bois, Buchloh) e Design and crime
} 
A OCTOBER procura reabrir o debate nos diversos campos das artes, introduzindo o pós-estruturalismo francês e conduzindo o debate artístico pósmoderno seguinte ao formalismo greenberguiano. Hal Foster compartilha com o grupo em torno da OCTOBER - uma geração intelectual anterior e muito citada por ele, à qual pertencem Rosalind Krauss e T. J. Clark - o interesse especial pela obra de Georges Bataille e de outros surrealistas dissidentes, ligados ao Colégio de Sociologia. É o caso, por exemplo, de Roger Caillois, cuja teoria do mimetismo alimentou a sua leitura da obra de Marx Ernst no texto que segue esta apresentação. Vale mencionar, ainda, que esse mesmo periódico teve um número dedicado a uma série de ensaios sobre o intelectual alemão Carl Einstein, bem como à tradução para o inglês de algumas de suas contribuições à revista Documents ${ }^{3}$ e a periódicos alemães como Die Aktion.

Hal Foster vê a psicanálise como uma forma de desconstruir o sujeito e o seu ego, ambos já fraturados, e por isso a necessidade de se utilizar uma prótese, percebida pelo Freud de O mal-estar da civilização (1930), que Ihe serve de epígrafe em Deuses protéticos. Além disso, Hal Foster acredita ser necessário enfatizar a existência de uma implicação mútua entre a arte e a psicanálise, visto ambas se ocuparem, simultaneamente, da crise no processo de subjetificação e de suas conseqüências na representação. ${ }^{4}$

Em The return of the real (O retorno do real, 1996), Hal Foster sistematiza o eixo diacrônico (ou histórico) e o sincrônico (ou social) na arte e na teoria por meio da paralaxe ("o deslocamento aparente de um objeto causado pelo movimento real do observador", p. xii, minha tradução) e da noção freudiana de ação diferida, segundo a qual os acontecimentos traumáticos são registrados apenas em seu retorno. Na pintura, o "trauma" aparece como efeito de fissura na tela, como a abertura em que se insere o engano do observador, o trompeI'oeil. É também na "tela-imagem" de ordem simbólica que se inserem os códigos de reconhecimento visual, como os da história da arte e as imagens da arte pop.

(and other diatribes) (2002) e editou os livros Richard Serra (2000); Vision and visuality (1988); Discussions in contemporary culture (1987); The anti-aesthetic: essays on postmodern culture (1983).

${ }^{3}$ Como os ensaios de Sebastian Zeidler, "Totality against a subject: Carl Einstein's Negerplastik" (OCTOBER, $\mathrm{n}^{\circ} 107,2004$, p. $\left.14-46\right)$ e de Rainer Rumold, "'Painting as a language. Why not?' Carl Einstein in Documents" (OCTOBER, $\mathrm{n}^{\circ}$ 107, 2004, p. 75-94) e de Charles Haxthausen, Reproduction/Repetition: Walter Benjamin/Carl Einstein (OCTOBER, $\left.\mathrm{n}^{\circ} 107, \mathrm{p} .47-74\right)$.

4 "For the most part, my methodological ambition is to set modernist works and psychoanalytic notions to resonate with one another - not to impose theory on art, but to see how one might implicate the other. [...] I do not read my artists by the book by Freud; rather, I focus on points of connection, conscious and not, between modernism and psychoanalysis - on common interests in origin stories and heroic fictions, in moments of regression and reaction, in imbrications of enigma and desire, in relays between traumatic events and psychological defenses (fetishistic and apotropaic representations appear frequently in this book" (p. xii). 
Esse é o caso, por exemplo, do artista pop Andy Warhol, em cuja obra o choque e o trauma são demarcados pelos momentos de lapso, em que se perde o encontro com o real pelo adiantamento ou pelo atraso. Para Hal Foster, a repetição de imagens em Andy Warhol não consiste na reprodução no sentido de representação, mas serve como tela em que o real se mostra pelo trauma, com a ruptura do sujeito entre a percepção e a consciência tocada pela imagem. Hal Foster retoma aqui a distinção de Freud entre reprodução e repetição da qual Lacan se vale, segundo a qual a repetição só se refere à reprodução na ordem da ação. ${ }^{5}$ Ou seja, o real se insere na lógica da repetição serial onde a novidade surge como a própria evasão do significado e do sujeito como referente, visto ele ser captado pelo real inconscientemente: "Um pensamento adequado enquanto pensamento, no nível em que estamos, evita sempre ainda que para se reencontrar em tudo - a mesma coisa. O real é aqui o que retorna sempre ao mesmo lugar - esse lugar onde o sujeito, na medida onde ele cogita, onde res cogitans, não o encontra" (LACAN, 1993, p. 62). Contudo, Hal Foster não retoma simplesmente as considerações de Lacan sobre o real no seminário sobre o olhar, onde define a contemplação estética, sobretudo, como uma domesticação do olhar, um dompe-regard por meio do uso do anteparo. Para o crítico americano, o efeito contrário acontece com alguns artistas do póspop: a recusa de valer-se do anteparo para neutralizar a violência do olhar, e a sugestão de que o anteparo já se encontra rompido:

É como se essa arte quisesse que o olhar brilhasse, que o objeto sustentasse, que o real existisse, em toda a glória (ou horror) de seu desejo pulsante, ou ao menos que evocasse essa condição sublime. Com esse objetivo, ela não somente se move para atacar a imagem, mas para romper o anteparo, ou sugere que este já se encontra roto. (FOSTER, 2005, p. 171)

Como veremos em "Iluminações cegas", a principal característica da arte dos alienados parece ser, justamente, a falta dessa mediação - a do anteparo - que domestica o olhar, e por isso ela produz uma cintilação do real, demarca o negativo de uma ordem simbólica que ela não é capaz de sustentar. É o que vemos quando Foster trata da Imagem de custódia no texto a seguir: "uma imagem que, por mais que nos pareça obscura, é também muito aberta e

\footnotetext{
5 "[...] repetição não é reprodução. Jamais qualquer oscilação sobre esse ponto - Wierderholen não é Reproduziren. Reproduzir é o que se acreditava fazer no tempo das grandes esperanças da catarse. [...] Só que, o que Freud nos indica quando dá os passos seguintes, [...] é que nada pode ser pego, nem destruído, nem queimado, senão de maneira, como se diz, simbólica, in effigie, in absentia. A repetição aparece primeiro numa forma que não é clara, que não é espontânea, como uma reprodução, ou uma presentificação, em ato [...]" (LACAN, 1993, p. 52).
} 
transparente para a 'visão religiosa' de um criador paranóico, e nela brilha algo da intensidade indomável do real lacaniano".

Recodings. Art, spetacle, cultural politics (Recodificação: Arte, espetáculo, política cultural), de 1984, consiste na primeira coletânea de ensaios de Hal Foster, ${ }^{6}$ anterior, inclusive, à incorporação dele ao grupo da OCTOBER. Nessa obra, Foster procura colocar em crise as práticas culturais contemporâneas, apontando, assim, os limites do (pós)modernismo, em um momento em que a crítica de arte européia e a norte-americana confluem para uma conjunção entre pós-modernismo e pós-estruturalismo. Dessa forma, Hal Foster questiona o intuito de romper com a tradição de práticas artísticas e culturais. Em textos como "Subversive signs" ("Signos subversivos"), por exemplo, o autor trata de alguns artistas americanos do início da década de 1980 (como Martha Rosler, Sherrie Levine, Barbara Kruguer, etc.) que teriam uma relação com a cópia e a obra, o texto e a imagem, de forma a repetir, em parte, a unicidade implicada pela noção benjaminiana da aura e a pôr em xeque, ao mesmo tempo, a instituição da arte. ${ }^{7}$ A partir das noções de imaginário e de simbólico de Lacan e das considerações de Barthes sobre o caráter fascista da linguagem (em O grau zero da escrita e em Aula), Foster conclui que somente é possível haver uma relação crítica do artista com a instituição quando ele se torna capaz de pensar a imagem e a linguagem em seu caráter disjuntivo.

Contudo, interessa mais para esta apresentação outro ensaio do mesmo livro, "Black skins, White masks" ("Peles negras, máscaras brancas"), onde vemos como o MOMA parece prosseguir na década de 1980 com o projeto de regular as fronteiras da arte moderna, em uma postura que Hal Foster denominou de imperialista e, baseado em Homi Bhabha, de colonial fetichista. Esse ensaio trata de uma exibição de arte que aconteceu no MOMA em 1984, denominada "The 'primitivism' in the twentieth century art. Affinity of the tribal and the modern" ("O 'primitivismo' na arte do século vinte. Afinidades entre o tribal e o moderno"), com a curadoria de William Rubin e de Kirk Varnedoe. ${ }^{8}$

\footnotetext{
${ }^{6}$ Trata-se, até o momento, do único livro completo do autor publicado no Brasil, com a tradução de Duda Machado, pela Casa Editorial Paulista em 1996. Além disso, é possível contar com algumas traduções esparsas como a de um capítulo de $O$ retorno do real (com o mesmo nome do título do livro) pela revista Concinnitas, da Universidade Estadual do Rio de Janeiro (ano 6, vol. 1, n 8, jul. 2005).

${ }^{7}$ Esse é o caso, por exemplo, da relação entre texto e imagem sobre a qual Krugue reflete em sua obra:

"Aware of these problems, Kruger has suggested that image appropriation, rather than question 'the 'original' use and exchange value' of representations, contradict 'the surety of our initial readings' and strain 'the appearance of naturalism,' may in fact confirm them" (FOSTER, 1989, p. 112).

${ }^{8} \mathrm{O}$ catálogo, uma compilação de dois volumes, conta com textos de Jack Flan, Rosalind Krauss, William Rubin, Kirk Varnedoe, etc.
} 
O discurso acerca das afinidades estéticas dessa mostra sobrepõe-se ao da influência estética que a arte primitiva exerceu sobre os artistas vanguardistas por meio do obscurecimento das referências históricas dos objetos expostos alguns deles artefatos e máscaras - junto às obras de artistas como Pablo Picasso, Paul Gauguin, Giacometti, Paul Klee, Fernand Léger, Brancusi e Henry Moore. ${ }^{9}$ Para Hal Foster, o problema de uma noção vaga como a de afinidade está no fato de que ela faz com que o "primitivo seja absorvido pelo primitivismo", ou seja, pelo próprio fenômeno da recepção das culturas nãoocidentais pelo Ocidente, baseado em uma contradição real. ${ }^{10}$ Dessa maneira, a mostra pauta-se em coincidências morfológicas e não reflete acerca do deslocamento conceitual da apropriação vanguardista da estética primitiva, nem opera uma mudança na noção de primitivismo:

Inocuous enough, these statements nevertheless suggest how primitivism is conceived to absorb the primitive, in part via the concept of affinity. The renaissance of antiquity is an intrawestern event, the very discovery of westerness: to pose it as an analogy is almost ipso facto to inscribe the tribal as modern-primitivist, to deny its difference. (FOSTER, 1985 , p. 184)

Hal Foster utiliza como exemplo Pablo Picasso, cuja visita ao museu do Trocadéro, em 1907, teria inspirado Deimoseilles d'Avignon (1907), peça central da mostra. Para o autor, o primitivo em Deimoseilles é utilizado em favor da própria cultura falocêntrica ocidental que pretendia questionar. ${ }^{11}$ Dessa maneira, Hal Foster percebe que o uso do "primitivo" para operar uma ruptura na estética vanguardista acaba por enfatizar a decadência e as ruínas das sociedades não ocidentais.

Como alternativa ao primitivismo vanguardista e da exposição, Hal Foster sugere recuperarmos, por um lado, o conceito de bricolagem (de Lévi-Strauss, lido por Derrida em $A$ escritura e a diferença), como genealogia historicamente enigmática que se dá em um processo de jogo, contra o mito, ou o

\footnotetext{
9 "When such ahistorical juxtaposition are visually convincing, they illustrate affinities rather than influences. Affinities are far from unimportant, however, and in the long run, the multiplicity of them may tell us something more essential about twentieth century art than do the far rarer instances of direct influence (which might be thought of as confirming the propinquity involved)" (RUBIN, 1984, p. 24).

10 Segundo a definição de Lévi-Strauss, citada por Hal Foster (1985, p. 198).

11 "This, too, was essentially the argument of the 'Primitivism' show: that modern art was 'becoming other' prior to the 1907 Picasso visit to the Trocadéro. Thus the heroes of the show were artists who 'prepared' the primitive (Gauguin) and/or incorporated it (Picasso) - artists who turned the 'trauma' of the other into an 'epiphany' of the same" (FOSTER, 1985, p. 192).
} 
favorecimento de uma única direção, de uma afinidade universal e humanista. ${ }^{12}$ Por outro, nos incita a relembrar o modelo da transgressão do Bataille de Foucault, para que vejamos, assim, o primitivo como ruptura, e não como forma abstrata e universalista; como uma figura fantasmática que escapa aos sistemas classificatórios e que somente pode se manifestar na diferença.

O procedimento de colagem, ao qual Hal Foster se refere em "Iluminações cegas", possui um efeito semelhante ao da bricolage, entendida como a atividade artesanal de recompor uma forma nova a partir de fragmentos. ${ }^{13}$ Como sabemos, esse procedimento foi compartilhado pelos artistas vanguardistas - em especial, os ligados ao dadaísmo, como o próprio Ernst, Jean Arp e Kurt Schwitters - e pela etnografia. A colagem também parece ser o procedimento básico da definição de imagem de Pierre Reverdy, citada por André Breton no primeiro manifesto do movimento:

A imagem é uma criação pura do espírito. Ela não pode nascer da comparação, mas da aproximação de duas realidades mais ou menos remotas. Quanto mais longínquas e justas forem as afinidades de duas realidades próximas, tanto mais forte será a imagem - mais poder emotivo e realidade poética ela possuirá... etc. (REVERDY, apud BRETON, 1985 , p. 52)

Portanto, a força da aproximação de duas realidades distintas evocada por Reverdy se torna possível, para André Breton, pelo seu valor de acaso, ou seja, pela escolha alucinatória do material e das figuras justapostas, mas também pela diferença ressaltada na aproximação das duas realidades. ${ }^{14}$

James Clifford, em um ensaio que recupera a relação dos surrealistas dissidentes - do Colégio de Sociologia e da revista Documents - menciona a imagem da mesa de dissecação de Lautréamont, evocada por Marx Ernst em Além da pintura e citada por Hal Foster. Para ele, a colagem exemplifica o fato de que os procedimentos surrealistas também se encontram em obras

\footnotetext{
12 "However compromised by its appropriation as an artistic device in the West (superficially, bricolage has become the 'inspiration' of much primitivist art), bricolage remains a strategic practice, for just as the concept of myth demystifies 'natural' modes of expression and 'neutral' uses of the cultural forms, so to the device of bricolage deconstructs such notions as a modern/tribal 'affinity' or modernist 'universality' and such constructs as a fixed primitive 'essence' or a stable western 'identity'" (p. 202)

13 "Ora, é peculiar ao pensamento mítico, assim como ao bricolage no plano prático, a elaboração de conjuntos estruturados utilizando resíduos e fragmentos de fatos - odds and ends, diria o inglês ou, em francês, des debris et des morceaux - testemunhos fósseis da história de um indivíduo ou de uma sociedade" (LÉVI-STRAUSS, 1997, p. 37)

14 "É da aproximação, por assim dizer, fortuita dos dois termos que fulgiu uma luz especial, a luz da imagem, à qual somos infinitamente sensíveis. O valor da imagem depende da beleza da centelha obtida; é, por conseguinte, função da diferença potencial entre os dois condutores. Se esta diferença mal existe, como na comparação, a centelha não se produz" (BRETON, 1985, p. 70).
} 
etnográficas. Ela consiste, para James Clifford, em uma forma de inserir uma voz além da do etnógrafo em seu ensaio e de evocar uma realidade distinta da sua, evitando discursos culturais homogeneizadores. É nesse sentido que o etnógrafo se torna também um inventor, ${ }^{15}$ um bricoleur, que constitui também a si próprio com os resíduos das culturas primitivas que coleciona. Uma aproximação crítica da arte dos alienados como a de Hal Foster - ou da arte primitiva, de acordo com certa concepção - também favorece um projeto de alteridade baseado na diferença e na pluralidade de vozes, além de enfatizar a fissura instaurada nas formas de representação.

\section{Referências bibliográficas:}

BRETON, André. Manifestos do surrealismo. Trad: Luiz Forbes. Apresentação: Cláudio Willer. São Paulo: Brasiliense, 1985.

CLIFFORD, James. On ethnographic surrealism. Comparative studies in society and history, vol. 23, $\mathrm{n}^{\circ}$ 4, out. 1981 (p. 539-564).

FOSTER, Hal. The return of the real. Cambridge: MIT Press, 1996.

O retorno do real. Rio de Janeiro, Concinnitas, ano 6 , vol. $1, \mathrm{n}^{\circ} 8$, jul. 2005.

. Recodings. Art, spectacle, cultural politics. $3^{\text {a }}$ ed. Seattle: Bay Press, 1989.

Prosthetic Gods. Cambridge, Massachusetts; Londres, Inglaterra: MIT Press, 2004.

Blinded insights: on the modernist reception of the art of the mentally ill. OCTOBER, $\mathrm{n}^{\circ}$ 97, 2001 (p. 3-30).

KRAUSS, Rosalind. MICHELSON, Annette. About OCTOBER. OCTOBER, $\mathrm{n}^{\circ} 102$, 1976 (p. 3 - 5).

LACAN, Jacques. O seminário, livro 11: Os quatro conceitos fundamentais da psicanálise. $2^{a}$ ed. Texto estabelecido por Jacques Alain-Miller. Trad.: M. D. Magno. Rio de Janeiro: Jorge Zahar, 1993.

LÉVI-STRAUSS, Claude. O pensamento selvagem. Trad. Tânia Pellegrini. $2^{a}$ ed. Campinas: Papirus, 1997.

\footnotetext{
15 "The surrealist elements of modern ethnography tend to go unacknowledged by a science that sees itself engaged in the reduction of incongruities rather than, simultaneously, in their production. But it is not every ethnographer something of a surrealist, a reinventor and reshuffle of realities? Ethnography, the science of cultural jeopardy, presupposes a constant willingness to be surprised, to unmake interpretative synthesis, and to value - when it comes - the unclassified, unsought Other" (CLIFFORD, 1981, p. 564).
} 
LUQUeT, G. H. Primitive art. In: FLAM, Jack. DEUTCH, Miriam. Primitivism and twentieth century art. A documentary history. London; Los Angeles: University of California Press, 2003 (p. 219 - 223).

RUBIN, William. Modernist primitivism. An introduction. In: "Primitivism" in 20th Century Art. Affinity of the tribal and the modern. v. I. Nova York: Museum of Modern Art, 1984 (p. 1 - 79).

\section{Title:}

Introduction to "Blinded insights". Hal Foster and the criticism of avant-garde primitivism

\section{Abstract:}

The following text presents some concepts applied on the work of Hal Foster, American art critic and art historian, which has been translated to Portuguese only in some scattered texts and in a single whole book. Nowadays, Hal Foster is the chair holder of Art and Anthropology at Princeton University and co-editor of OCTOBER. This introduction is followed by the translation of "Blinded insights", which is one chapter of Prosthetic Gods, 2004, about the aesthetic relation of artists as Jean Dubuffet, Paul Klee and Max Ernst with the Prinzhorn collection of mentally ill artists' work.

\section{Keywords:}

Hal Foster; avant-garde; real; primitivism 


\section{Iluminações cegas* Hal Foster ${ }^{* *}$}

A reavaliação da arte dos doentes mentais seguiu a reaproximação das artes dos "primitivos" e das crianças com relação ao tempo e à lógica. Sendo antes vista como sem sentido e sintomática, passou a ser reconsiderada em meados da década de 1910 e início da década de 1920. Como também ocorreu com essas outras artes, os modernistas que por ela se interessaram a viram de acordo com os seus próprios objetivos, ou seja, como se expressasse certa essência da arte, uma pureza da visão ou um desafio às convenções. Entretanto, não possuía, na maioria das vezes, nenhum desses sentidos. $\mathrm{Na}$ verdade, essas três leituras, que chamarei de expressionista, visionária e transgressiva, respectivamente, sinalizam as fantasias modernistas de uma origem simplista da arte ou de uma alternativa absoluta à cultura e, ao invés de iluminar a arte dos doentes mentais, tendem a obscurecê-la.

Os românticos viam a arte dos doentes mentais como um epítome do gênio criativo, mas focaram mais as produções textuais do que as visuais. Entretanto, o valor dessa arte reduziu-se dramaticamente após o romantismo, a tal ponto que, no final do século dezenove, havia quase se tornado um sintoma de "degeneração" psicológica. Como mencionado no capítulo 2, uma figura muito importante para o discurso da degeneração foi o psiquiatra italiano Cesare Lombroso quem, com o seu seguidor húngaro Max Nordau, expandiu a sua noção ideológica da prática psiquiátrica para a interpretação da cultura. Lombroso compreendia a loucura como o retorno a um estágio primitivo de desenvolvimento, e o seu julgamento fomentou a associação fóbica entre o alienado, o primitivo e a criança que perdurou até o século $X X$, quando passou a concorrer com a associação idílica dos três elementos com visionários inocentes, uma herança dos românticos. ${ }^{1}$ Em Gênio e loucura (1864), um estudo feito com

\footnotetext{
* O presente texto corresponde à tradução de: FOSTER, Hal. Blinded insights. In: Prosthetic Gods. Cambridge, Massachusetts; Londres, Inglaterra: MIT Press, 2004 (p. 193-223) por Larissa da Costa Mata.

** Crítico e professor de Arte e Arqueologia da Universidade de Princeton (EUA).

${ }^{1}$ Hoje esse trio pode nos parecer particularmente esquisito, mas naquela época foi visto como um critério necessário em meio à busca modernista pelo "começo primário da arte" (Paul Klee). Assim
} 
107 pacientes, dos quais a metade desenhava ou pintava, Lombroso detectou essa degeneração nas representações que ele considerou "atávicas" e/ou "absurdas". 2

Embora o discurso da degeneração não seja forte na psicanálise, ele sobrevive como resíduo na noção de "regressão". Da mesma forma, persistiu a abordagem de diagnóstico da arte dos doentes mentais no discurso psicanalítico. Como o seu professor francês Jean Martin Charcot, Freud seguiu a abordagem de diagnóstico da maneira inversa, ou seja, ele buscou sinais de distúrbios psicológicos na arte de artistas sãos como Leonardo e Michelangelo (as suas análises datam de 1910 e 1914, respectivamente). A abordagem de diagnóstico da arte dos doentes mentais foi compensada apenas gradualmente com as considerações que se ajustaram às qualidades intrínsecas das obras. Nesse sentido, podemos destacar como referências as obras L'art chez les fous (1907) de Marcel Réja, pseudônimo do psiquiatra francês Paul Meunier, que examinou a arte dos doentes mentais para compreender a natureza de uma atividade artística enquanto tal, e Bildnerei der Geisteskranken (Introdução à produção de imagens dos doentes mentais, 1922) do historiador da arte alemão Hans Prinzhorn, que expandiu a sua pesquisa aos fundamentos da "configuração" (Gestaltung) de forma a influenciar diretamente muitos modernistas.

Essa última reavaliação da arte dos doentes mentais surgiu durante um grande debate acerca da definição das psicoses. Em 1898, o psiquiatra alemão Emil Kraepelin apresentou a sua tipologia de "demência precoce", que incluiu as variações catatônica, paranóica e hebefrênica. Em 1911, o psicanalista suíço Eugen Bleuler introduziu a sua categoria de "esquizofrenia", definida como uma relação interrompida entre o eu e o mundo que se manifesta por meio da dissociação de pensamento, ação ou afeto - ou seja, um transtorno de subjetividade freqüentemente marcado, por sua vez, por um transtorno de representação (a raiz grega de "esquizofrenia" significa "mente dividida"). Bleuler encontrou um ajuste entre as posições de Kraepelin e de Freud: como Kraepelin, ele ligou a paranóia à esquizofrenia e, como Freud, ressaltou a fragmentação (Spaltung) da mente como fundamental. Contudo, Freud criou um termo próprio, "parafrenia", como alternativa à "esquizofrenia" e como complemento da "paranóia" (obviamente, prevaleceu "esquizofrenia"). Apesar

nos deparamos, imediatamente, com o velho paradoxo modernista segundo o qual a prioridade artística e o imediatismo expressivo são buscados pelo intermédio de representações verdadeiramente complexas como as imagens psicóticas, os objetos tribais e os desenhos infantis.

2 Ver a obra de Cesare Lombroso Genio e follia (Milão, 1864); traduzida ao francês em 1889, ao inglês em 1891 e ao alemão em 1894. Sobre a recepção histórica da arte dos alienados, consulte John MacGregor (1989). 
de ter encontrado, algumas vezes, a esquizofrenia e a paranóia combinadas, no seu célebre estudo de caso do juiz Schreber (1911), Freud tratou delas como sintomaticamente distintas: na sua perspectiva, o esquizofrênico é dominado por alucinações que apenas aprofundam a sua sensação de catástrofe interior e exterior, ao passo que o paranóico constrói ilusões de grandeza pessoal para conter a crise interna e projeções de ordem global para conter a crise externa. ${ }^{3}$ Essa distinção entre a esquizofrenia e a paranóia é fundamental para a minha própria leitura da arte dos doentes mentais, cuja recepção modernista se centra na obra de Prinzhorn.

\section{A configuração segundo Hans Prinzhorn}

Prinzhorn estudou história da arte na Universidade de Viena antes de se interessar pela psiquiatria e, posteriormente, pela psicanálise. A sua formação peculiar levou Karl Wilmanns, diretor da Clínica Psiquiátrica de Heidelberg entre 1916 e 1933, a indicá-lo em fevereiro de 1919 para organizar a coleção de arte dos doentes mentais. Iniciada entre 1890 e 1903, enquanto Kraepelin dirigia a clínica, a coleção se desenvolveu sob a supervisão de Wilmanns e, mais tarde, de Prinzhorn, chegando a cerca de 4.500 obras de aproximadamente 453 pacientes - dos quais $75 \%$ foram diagnosticados como esquizofrênicos - de diversas instituições, em sua maioria localizadas na Alemanha. (Embora as mulheres fossem mais numerosas do que os homens nessas instituições, elas não os superavam na coleção, visto que apenas $16 \%$ das obras eram de mulheres - Figura 1).

\footnotetext{
3 É claro que a distinção entre interno e externo também entra em questão na paranóia. Ver os textos de Sigmund Freud (1963), Emil Kraepelin (1971) e Eugen Bleuler (1950). Em O anti-Édipo Deleuze e Guattari também opõem a esquizofrenia à paranóia, que eles relacionam aos limites (ou às crises) na ordem social, embora haja nesse ótimo texto um voluntarismo anti-freudiano - resíduo do movimento anti-psiquiátrico dos anos 1960 - que não compartilho com eles.
} 


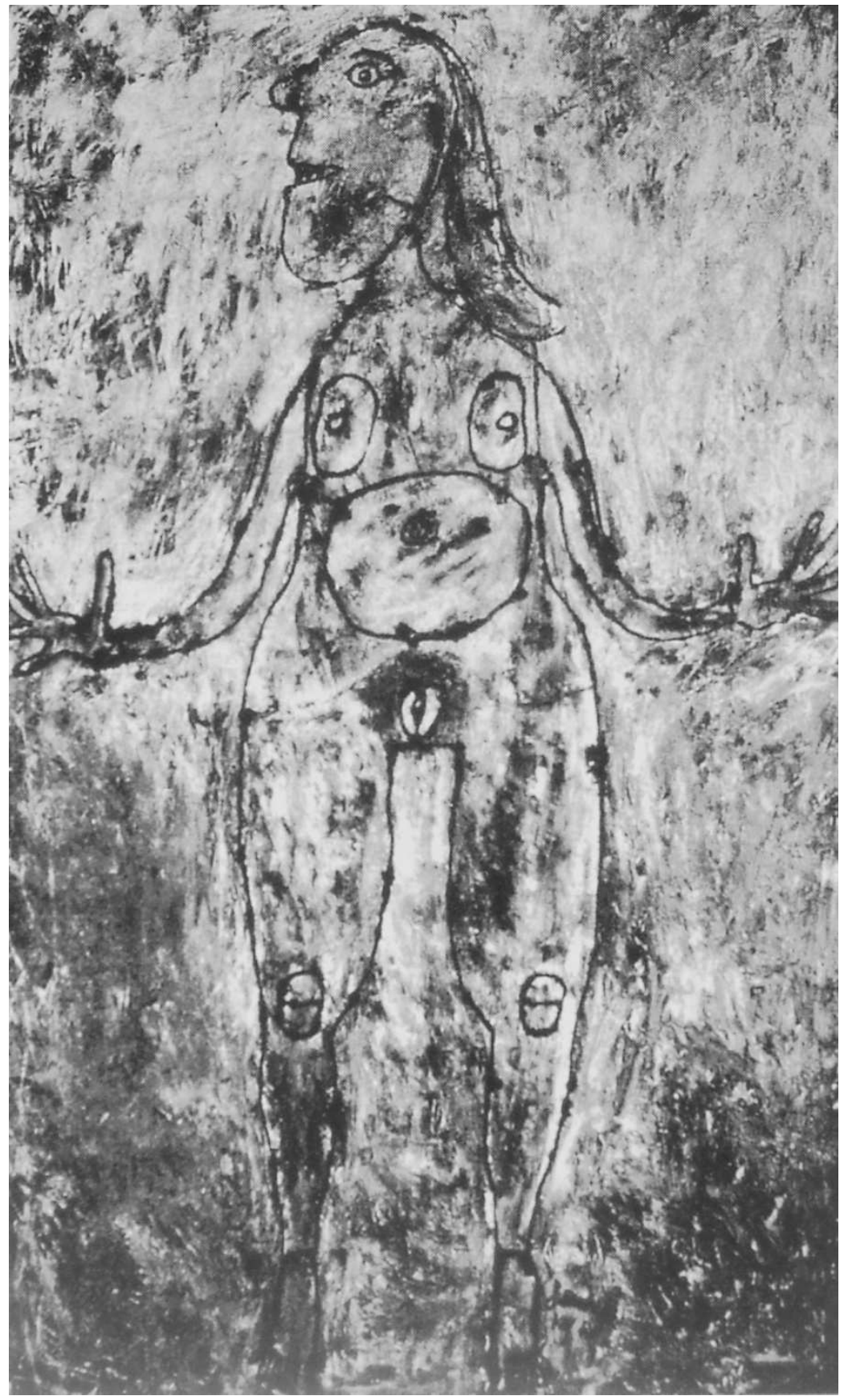

Figura 1 - Jean Dubuffet, Grand nu charbonneux, 1944.

Prinzhorn deixou a clínica repentinamente, em julho de 1921, antes mesmo de publicar a Introdução à produção de imagens, obra que para ele representava um projeto ambicioso. A partir de então, ele proferiu diversas palestras acerca do tema, inclusive um seminário na Sociedade Psicanalítica de Viena, presidida por Freud, bem como muitas conferências na Alemanha, acompanhadas por diversos artistas modernistas.

A Introdução à produção de imagens se divide em uma "parte teórica", dez estudos de caso de "artistas esquizofrênicos", e um resumo dos "resultados 
e problemas"; conta, ainda, com 187 reproduções, cuidadosamente selecionadas da coleção completa (PRINZHORN, 1972). Ainda que muitas obras mostrem certas afinidades com o simbolismo e o expressionismo, poucos pacientes eram interessados em arte. Algumas vezes eram estimulados a desenhar por razões terapêuticas ou para que fossem diagnosticados, o que pode ter conferido à coleção resultados menos espontâneos do que os atribuídos por Prinzhorn. De qualquer modo, a coleção é tão heterogênea quanto ao material, à técnica e ao estilo empregados que se torna impossível encaixá-la em uma teoria, e a teoria que Prinzhorn apresenta é contraditória em alguns aspectos.

Por um lado, Prinzhorn não quer simplesmente estabelecer um diagnóstico com a sua interpretação ("uma abordagem puramente psiquiátrica não é suficiente" - 1972, p. 240) e, de fato, ele não vê as obras como expressões diretas de uma doença. E, embora ele proponha seis pulsões predominantes na representação psicótica, também as considera atuantes em outras artes. De fato, ele afirma que "os componentes do processo configurativo" permanecem "intactos" nessa obra (Idem, p. 269) ${ }^{4}$. Por outro lado, ele não quer que a sua interpretação seja apenas estética e se previne contra meras equivalências entre os "quadros" e a arte. Ainda que nomeie os seus dez "mestres" favoritos, Prinzhorn emprega o termo arcaico Bildnerei - literalmente, "produção de imagens" - ao invés da expressão usual Kunst ou "arte". Ao mesmo tempo, se refere a Van Gogh, Rousseau, Ensor, Kokoschka, Nolde (quem conhecia pessoalmente), Max Pechstein, Eric Heckel e Alfred Kubin (o único artista importante do período a ver a coleção em pessoa), e enfatiza "a relação particularmente próxima entre um grande número dos nossos quadros e a arte contemporânea", principalmente o expressionismo (Ibid., p. 270). Obviamente, os modernistas que se interessavam pela arte desse tipo também estabeleceram essa relação, bem como os inimigos do modernismo. "A arte degenerada", exposição nazista de 1937, atacou modernistas como Paul Klee e Max Ernst exatamente por meio da associação com os doentes mentais e se valeu de imagens da coleção de Prinzhorn para isso (ironicamente, a mostra também consistiu na maior exposição da arte modernista e dos doentes mentais na Alemanha do período). ${ }^{5}$ Dessa forma,

\footnotetext{
${ }^{4}$ Para Prinzhorn, esse "processo configurativo" é universal, mas muitas das obras da Introdução à produção de imagens são historicamente específicas - com roteiro e personagens alemães singulares (ex. Wilhelm II), instituições, etc.

${ }_{5}$ Ainda em 1921, um professor de Hamburgo chamado Wilhelm Weygrandt utilizou-se de uma
} 
a reavaliação modernista da arte dos doentes mentais é assombrada pelo seu reverso: pois se a arte dos doentes mentais poderia se revelar, de algum modo, como modernista quanto à afinidade, a arte dos modernistas também pode ser rotulada, nessa perspectiva, como tendente ao patológico. ${ }^{6}$

Prinzhorn estudou com o historiador da arte August Schmarsow, famoso pela sua abordagem ontológica da arte (ele preferia, por exemplo, definir cada disciplina de acordo com o seu vetor essencial: a horizontalidade da pintura, a verticalidade da escultura, a profundidade da arquitetura, etc.). Naquele momento, Prinzhorn escreveu a sua tese sob a orientação do psicólogo Theodor Lipps, cuja idéia de "empatia" alimentou toda uma geração de historiadores da arte alemães (ver o capítulo 3). Na Introdução à produção de imagens, Prinzhorn também se inspirou na estética formalista do historiador da arte Conrad Fiedler, bem como na psicologia da expressão do filósofo Ludwig Klages. De fato, ele tentou conciliar a autonomia da forma visual, fundamental para Fiedler, com a expressividade da psique enfatizada por Klages. ${ }^{7}$ Como as suas alusões artísticas também sugerem, o expressionismo instigou Prinzhorn e, apesar de suas próprias restrições, exaltou uma profunda afinidade entre a "atitude emotiva" desse movimento e a arte dos doentes mentais e entre a sua "renúncia ao mundo exterior" e o "retorno ao eu interior" (1972, p. 271). ${ }^{8}$

A combinação dessas influências o levou à teoria das seis pulsões que, para Prinzhorn, regulavam a arte dos doentes mentais - embora também se refiram a qualquer arte - e que se relacionam à expressão, ao jogo, à elaboração ornamental, à ordem desenhada, à cópia obsessiva e aos sistemas simbólicos. Entretanto, também quanto a isso ele foi contraditório, pois as pulsões relacionadas à expressão e ao jogo implicariam um sujeito aberto ao mundo, o que não se pode dizer das outras pulsões.

justaposição condenatória entre a arte dos insanos e a modernista, que se estendeu a Paul Schultze-Naumburg em Kunst und Rasse (1935) e, obviamente, em Entartete "Kunst", de 1937. Em 1933 os nazistas designaram Carl Schneider para a direção da clínica de Heidelberg; foi ele quem obteve o material da exibição de 1937. Schneider se tornou o diretor científico do programa nazista de extermínio de pacientes mentais, e muitos dos pacientes da coleção de Prinzhorn tiveram esse destino. Ver Bettina Brand-Claussen, "The collection of works of art in the psychiatric clinic, Heidelberg - from the beginnings until 1945" (In: BRAND-CLAUSSEN et al, 1996).

${ }^{6}$ Prinzhorn já percebe esse perigo na Introdução à produção de imagens: "Tais comparações... são vulgares e sensacionalistas... é errado e superficial inferir uma equivalência entre as condições psíquicas subjacentes e as semelhanças externas" (1972, p. 271).

7 Essa tensão entre os imperativos kantianos e os hegelianos - entre, digamos, a "configuração" e a "pulsão" - foi sentida ao longo da disciplina da história da arte. Casualmente, Prinzhorn concluiu o seu doutorado em 1908, o mesmo ano em que um colega de Lipps, Wilhelm Worringer, publicou a sua tese influente intitulada Abstração e empatia (ver o capítulo 3).

${ }^{8}$ Nesse sentido, Brand-Claussen é rigorosa, mas exata: "A noção de Prinzhorn de criatividade inconsciente acaba por revelar-se um caso de ilusão expressionista (1996, p. 12). 
Contrariamente, a ornamentação compulsiva, a ordenação, a cópia e a construção de um sistema implicam um sujeito em uma defesa rígida, até mesmo paranóica, contra o mundo. Talvez Prinzhorn percebesse essa contradição, já que ele chegou a propor que pulsões de jogo expressivo corrigiam os impulsos de ordenação obsessiva (como veremos, a sua cegueira inicial pode levar a uma eventual iluminação acerca dos imperativos opostos, freqüentemente em operação nessa arte) ${ }^{9}$ Além disso, Prinzhorn admitiu, afinal, esta diferença fundamental entre o artista e o esquizofrênico:

Mesmo o artista mais solitário ainda permanece em contato com a humanidade, ainda que apenas por meio do desejo e da ansiedade, e o desejo de manter esse contato nos é transmitido por todos os quadros de pessoas "normais". Por sua vez, o esquizofrênico está desvinculado da humanidade e, por definição, nem almeja, nem está apto a restabelecer o contato com ela. Se a sua vontade mudasse ele estaria curado. Percebemos nesses quadros um isolamento autista completo e um solipsismo repulsivo que ultrapassa, e muito, os limites da alienação psicopática. Creio que encontremos nisso a essência da configuração esquizofrênica. (1972, p. 266).

Ainda que Prinzhorn nos previna contra uma equação entre a imagem e a psique, ele a admitiu com frequência (como na passagem acima), e essa falta de mediação entre ambas permitiu que ele reivindicasse a existência de "características essenciais" da configuração artística em si na arte dos doentes mentais (1972, p. 11). ${ }^{10}$ A sua insistência na estética formalista, na teoria da empatia e na psicologia expressiva (incluindo as noções de urgências expressivas, pulsões intrínsecas e imagens eidéticas) o tornaram predisposto a esse tipo de essencialismo estético. Uma equivalência semelhante entre a imagem e a psique também permitiu que os modernistas influenciados por Prinzhorn - em particular Klee, Ernst e Dubuffet - vissem "características essenciais" da arte na arte dos doentes mentais. Todos eles conheciam bem a Introdução à produção de imagens, mas não a própria coleção de Prinzhorn. Klee, que conheceu a arte dos doentes mentais já no início de sua carreira,

\footnotetext{
${ }^{9}$ A noção de uma iluminação que se origina de uma cegueira é traçada, obviamente, a partir de Blindness and insight de Paul de Man (1971).

${ }^{10}$ Como vimos, Prinzhorn nos adverte contra a equação entre a imagem e a psique no final de $A$ introdução da produção de imagens (ver a nota 7). No entanto, no início ele afirma que: "aceitamos, portanto, o campo dos fatos expressivos, no qual os elementos psíquicos aparecem e são apreendidos diretamente, sem a justaposição de qualquer aparato intelectual" (1972, p. 12). Em outras passagens ele parece menos seguro: "o que e quanto da psique se expressa nesse mundo autocrático da forma?" (1972, p. 72). Essa incerteza se torna irredutível em muitas das considerações psicanalíticas sobre a arte - talvez, inclusive, na minha própria aqui.
} 
assistiu a uma palestra de Prinzhorn antes que o seu livro aparecesse. Como vimos no capítulo 4, Ernst descobriu essa arte independentemente, talvez durante os seus estudos, antes da guerra, na Universidade de Bonn. Mais jovem que os outros, Dubuffet conheceu a Introdução à produção de imagens em 1923, apenas um ano após a sua publicação, quando ainda não era um artista ativo. Embora a arte dos doentes mentais seja apenas uma das influências desses modernistas, ela afetou claramente a elaboração do estilo deles, bem como os seus modelos estéticos.

\section{A visão segundo Paul Klee}

Klee começa o seu "Credo criativo" (1920) com este período famoso: "A arte não reproduz o visível, ela faz visível" (KLEE, P., 1959, p. 5). Nesse texto, que surge no auge do seu engajamento com a arte dos doentes mentais, Klee atribui o papel de tornar visível às "crianças, [a]os loucos e selvagens" com um poder especial, pois eles "ainda podem, ou novamente, examinar" o "mundo intermediário" que "existe entre os mundos percebidos pelos nossos sentidos" (KLEE, F., 1962, p. 184). ${ }^{11}$ Claramente, esse poder é visionário para Klee - pois se refere "ao domínio dos não-nascidos e dos mortos" - e já em 1912, em uma resenha sobre os expressionistas do Blaue Reiter (com quem ele se associaria em breve), ele considera esse mesmo poder necessário para qualquer "reforma" modernista da arte (Idem; KLEE, P., 1988, p. 320-322).

Alguns estudiosos percebem a influência da arte dos doentes mentais no trabalho de Paul Klee entre os anos 1904-05. Outros supõem que ele tenha conhecido a arte hoje apreciada de Adolf Wölffli, um paciente de uma instituição próxima a Berna, enquanto Klee ainda vivia lá. No entanto, as imagens de Wölffli não foram publicadas até 1921, e Klee jamais mencionou qualquer encontro nesse período. Sabemos por meio de Oskar Schlemmer, seu colega na Bauhaus, que Klee conheceu a coleção antes da palestra de Prinzhorn em um local próximo a Stuttgart em julho de 1920 (SCHLEMMER, 1972, p. 83). ${ }^{12}$ Nesse período, o seu trabalho mostra claramente os efeitos mais marcantes da arte dos doentes mentais, com os traços heteroglóssicos e as ordenações obsessivas que Prinzhorn atribuiu à representação dessa arte. Além disso, Lothar Schreyer, outro colega de Klee também da Bauhaus, nos relata sobre a identificação profunda de Klee com a Introdução à produção de

\footnotetext{
${ }^{11}$ A ambigüidade entre o "ainda" e o "novamente" nos mostra a dificuldade de situar essa visão no tempo.

${ }_{12}$ Klee também deve ter visto uma parte da coleção em janeiro de 1921 no Zinglers Kabinett, em Frankfurt, onde fez uma exibição no ano seguinte.
} 
imagens em 1922, no momento de sua publicação (ele possuía uma cópia do livro no seu atelier). E isso aconteceu na Bauhaus, uma instituição que se tornaria em breve famosa pelo seu racionalismo. "Você conhece esse livro excelente de Prinzhorn, não?", foi o comentário de Klee para Schreyer enquanto folheava a Introdução à produção de imagens: "Este quadro é um ótimo Klee. E também este, e este aqui. E veja estas pinturas religiosas. Têm uma profundidade e um poder de expressão que eu jamais atinjo nos temas religiosos. É, de fato, uma arte sublime. Uma visão espiritual direta" (KLEE, F., 1962, p. 183). ${ }^{13}$

Há muito que desconstruir nessa retórica de celebração que circula entre a arrogância ("um ótimo Klee") e a humildade ("eu jamais atingiria..."), uma retórica que praticamente se torna própria da aproximação modernista da arte primitiva. O mais importante é que a arte dos doentes mentais é praticamente transportada ao registro do sublime, como uma questão de "visão espiritual direta". Porém, Klee é cuidadoso no seu auto-elogio: quando simplesmente ilustra os "temas religiosos" - com os seus vários "anjos" e demônios, "fantasmas" e "profetas", - afirma não atingir o "poder expressivo" encontrado com frequência na Introdução à produção de imagens; mas, quando evoca a "visão espiritual direta", se aproxima em alguns momentos desse poder, como em Angelus Novus, a sua célebre aquarela de 1920 (Figura 2).

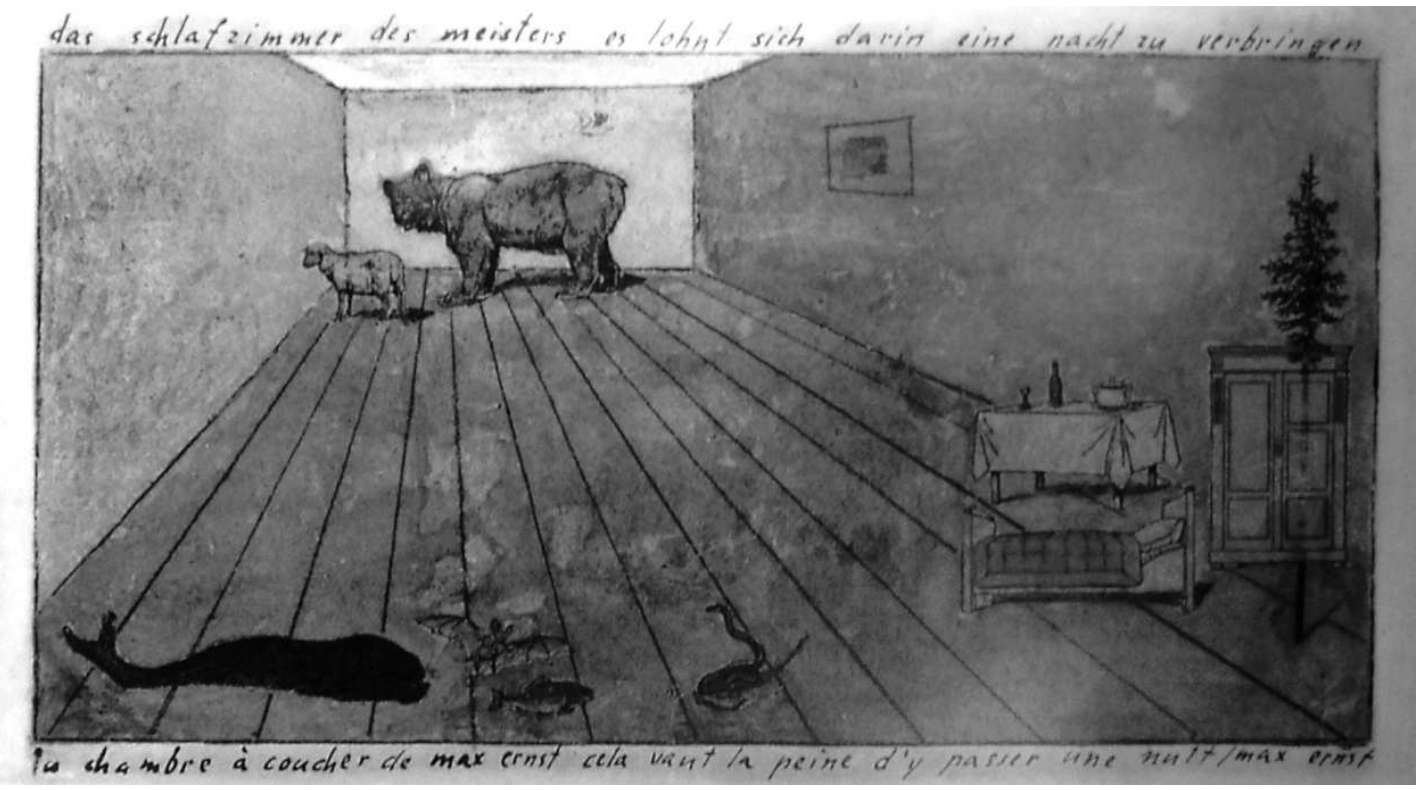

Figura 2 - Max Ernst, O quarto do mestre, 1920

Esse desenho quase esquizofrênico, com a sua estranha elaboração de coroas

\footnotetext{
${ }^{13}$ É questionável até que ponto podemos confiar na lembrança dessa conversa.
} 
de flores como cabelos e de rolos como dedos, com a imensa cabeça com o olhar distante e a boca indecifrável, essa figura que avança em nossa direção parece realmente "tornar visível", como se tivesse o poder de nos fazer ver. Ao menos foi assim que essa imagem pareceu a Walter Benjamin, o seu antigo dono, para quem consistia em um anjo alegórico da história-como-catástrofe que "preferiu libertar os homens thes tomando algo" (BENJAMIN, 1978, p. 273). ${ }^{14}$ Mas em que consiste exatamente essa "visão espiritual direta" que Klee evoca? Será que ela corre o risco de ser um estado mental nada inocente, mas alucinatório e até mesmo horrendo - uma visão que vem para possuir o seu sujeito com uma anunciação repentina, como a que Klee e Benjamin vislumbram no olhar desse anjo? Esse estado demasiado direto, demasiado sublime, é evocado por algumas representações da Introdução à produção de imagens semelhantes ao Angelus Novus, como a Imagem de custódia, de Johan Knopf (Figura 3),

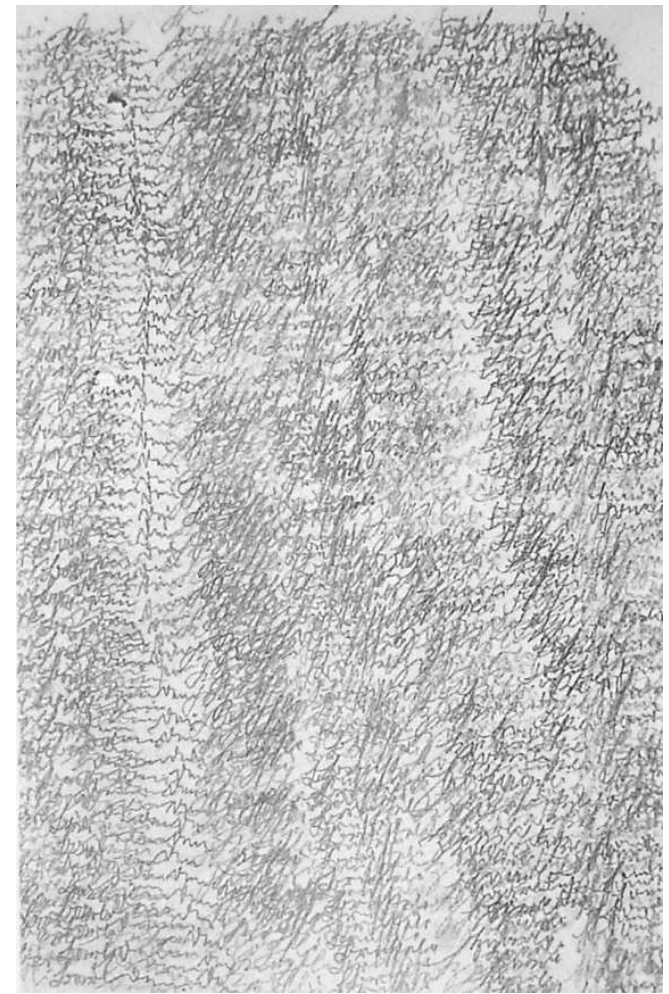

Figura 3 - Emma Hauck, Querido venha (carta ao marido), 1909

um dos dez mestres esquizofrênicos cuja obra Klee teria conhecido (Prinzhorn Ihe atribuía o pseudônimo de "Knüpfer", e o seu diagnóstico é descrito como

\footnotetext{
${ }^{14}$ A sua descrição alegórica aparece em "Theses on the philosophy of history" [Sobre o conceito de história, 1940] (In: BENJAMIN, 1969, p. 257-258). Existem muitos relatos sobre esse anjo, dentre os quais encontramos o de O. K. Werckmeister: "Ele o considerava primeiramente uma alegoria da experiência metafísica, depois da sobrevivência em meio a uma catástrofe histórica onde os textos e as imagens se tornaram inúteis" (1982, p. 115).
} 
"forma paranóica de demência precoce"). ${ }^{15}$ Uma custódia é, de fato, algo que "torna visível": na Igreja Católica Romana, é um véu perfurado e transparente no qual a hóstia é disposta para a adoração. Mas essa "imagem de custódia" é também monstruosa:* uma imagem que, por mais que nos pareça obscura, é também muito aberta e transparente para a "visão religiosa" de um criador paranóico, e nela brilha algo da intensidade indomável do real lacaniano (ver o capítulo 7).

Klee capta um vislumbre dessa intensidade em muitas de suas obras da época, como O homem é a boca do Senhor (1918), título que por si só sugere uma visão paranóica, e O santo da luz interior (1920), figura cuja "luz interior" é evocada por um semblante cego. O jogo irônico com os sistemas pictográficos, ativo em outras obras de Klee, mas que não pertence à arte dos doentes mentais, não se manifesta aqui também. ("A ironia é totalmente excluída por sua própria natureza", escreveu Prinzhorn, "visto ela pertencer às convenções normalmente aceitas que consistem, exatamente, no que o esquizofrênico exclui da sua mente" - 1972, p. 245). Fundamentalmente, essas obras excluem a idéia de que arte dos doentes mentais seja inocente, tão apreciada por Klee. Assim como Prinzhorn gostaria de ver essa arte como expressiva, somente para concluir que era radicalmente inexpressiva, ou seja, expressiva apenas do retraimento esquizofrênico, Klee pretendia ver nessa arte uma inocência da visão apenas para descobrir a intensidade que às vezes se aproxima do terror paranóico: um Angelus Novus da catástrofe. A cegueira inicial de Klee e de Prinzhorn em torno da concepção de arte dos doentes mentais nos permite uma eventual iluminação, por meio da qual a visão artística projetada nesses pacientes se revela como o terror psicológico em que geralmente consiste.

\section{A transgressão segundo Jean Dubuffet}

A dimensão horrenda dessa visão alucinatória não a tornava menos imediata para Klee, pelo contrário, tornava-a ainda mais. É essa proximidade intensa que permite que ele busque o graal modernista da visão pura na arte dos

\footnotetext{
15 Essa obra em particular não se encontra na Introdução à produção de imagens, mas algumas imagens relacionadas foram incluídas. Para uma delas, Knüpfer criou esta interpretação (que Prinzhorn compreendeu): "O círculo grande com a coroa de raios pretende ser uma custódia, como sabemos a partir de outros desenhos, e o corpo minúsculo o seu cabo. Ao mesmo tempo, o círculo pode ser a frente de um relógio, o sol ou a face do homenzinho que de acordo com a inscrição representa o cordeiro de Deus, ou seja, Cristo, com quem Knüpfer costumava se identificar. Dessa forma, devemos admitir pelo menos cinco ou seis significados" (1972, p. 174). Como sabem os leitores do juiz Schreber, os raios normalmente representam a influência paranóica, como os pássaros que falam na imagem com o homenzinho. A identificação do Cristo também é tipicamente paranóica, como veremos adiante.

Há aqui um trocadilho formado pelas palavras "monstrance" (custódia) e "monstruous" (monstruoso/a) impossível de se traduzir para o português [N. T.].
} 
doentes mentais. Dubuffet projeta um tipo diferente de imediação e desenvolve um modelo transgressivo de arte modernista baseado, parcialmente, na arte dos doentes mentais. Ele também se deparou com a Introdução à produção de imagens no início de sua formação; ganhou a obra em 1923, enquanto estudava outras publicações a respeito da arte visionária. Porém, o seu trabalho não se desenvolveu nessa linha até o início de 1940, e a sua primeira inspiração foi o desenho de crianças: os desenhos desse período relembram os homenzinhos de palitos [stick-people], representados frontalmente ou de perfil, ou, paradoxalmente, das duas formas ao mesmo tempo. Contudo, durante esse intervalo Dubuffet se correspondeu com pacientes e doutores em vários manicômios, e o contato se tornou mais intenso em 1945, em uma viagem de três semanas por hospitais psiquiátricos na Suíça, onde encontrou a obra de Wölffli, entre outras. Essa experiência Ihe inspirou dois atos significativos: destruir a maioria da sua arte anterior a 1942 e começar uma coleção de arte "incomum" (incluindo a primitiva, a ingênua [naïve] ou tribal e a produção dos doentes mentais) sob o título de art brut brut como "cru", "bruto", "não-civilizado". Dubuffet formou em 1948 a Compagnie de I'Art Brut - com André Breton, Jean Paulhan, Charles Ratton, Henri-Pierre Roché e Michel Tapié - que, em 1949, exibiu pela primeira vez as suas aquisições (com um total de aproximadamente duas mil obras de 63 artistas) na Galeria René Drouin em Paris. A mostra foi acompanhada por um texto importante sobre o tema, "L'art brut préferé aux arts culturels", no qual Dubuffet apresenta, em princípio, o artista brut como uma versão radical do gênio romântico liberto de qualquer convenção:

Entendemos por esse termo as obras produzidas por pessoas que não foram lesadas pela cultura artística, onde o mimetismo tem um papel pequeno ou nulo (contrário às atividades de intelectuais). Esses artistas deduzem tudo - temas, escolha de materiais, meios de transposição, ritmos, estilos de escrita, etc. - de suas próprias profundezas, e não das concepções da arte clássica ou da arte da moda. Somos testemunhas, aqui, de uma operação artística completamente pura, e totalmente reinventada em todas as suas fases somente por meio dos impulsos do próprio artista (DUBUFFET, 1967; DUBUFFET, 1988, p. 33).

Em um ensaio subseqüente, Dubuffet transforma essa categoria de brut em um critério para toda a arte modernista: "uma obra de arte não me interessará se não for uma projeção absolutamente imediata e direta das profundezas do indivíduo" (DUBUFFET, 1967, p. 213). 
A sua idealização da arte dos doentes mentais é semelhante às de Prinzhorn e Klee, pois também pressupõe as noções de uma "expressão" essencial e de uma visão "direta". Embora, para Dubuffet, a natureza dessa arte seja menos formal (como é para Prinzhorn) ou espiritual (como é para Klee) do que transgressiva: "Acredito muito nos valores da selvageria, ou seja, em instinto, paixão, inconstância, violência, loucura" (DUBUFFET, 1967, p. 94; 1960, p. 2). Portanto, também como com os outros artistas, a sua idealização é um tipo de primitivismo: Dubuffet também acredita em um retorno às "profundezas". Conduto, diferente dos outros, ele não define essas profundezas como a origem da arte, que alguém poderia reivindicar como redenção, mas como um exterior para a arte, que invade e desestabiliza os seus espaços culturais. No entanto, como outros primitivistas antes dele, Dubuffet se dirige única e exclusivamente à arte acadêmica; nesse sentido, a sua lógica estrangeira [outsider] é também um movimento interior que, intencionalmente ou não, pretende construir um espaço entre as linhagens vanguardistas. ${ }^{16}$ Além disso, mesmo que ele tente desfazer a oposição entre normal e anormal ("a distinção entre o normal e o anormal é, de fato, insustentável: quem é normal, afinal?"), Dubuffet sustenta uma oposição entre brut e culturel, entre civilizado e não-civilizado (Dubuffet, 1988 , p. 33). Dessa maneira, a sua transgressão sustenta-se exatamente sobre a regra que se propunha a contestar. Na verdade, como Michel Foucault destacou com relação a Georges Bataille, essa transgressão serve para reimaginar a base "sagrada" da lei que a secularização moderna desgastou: "A profanação, em um mundo que já não reconhece qualquer significado positivo no sagrado", escreve Foucault. "Não é mais ou menos isso o que denominamos transgressão... uma maneira de recompor uma forma vazia, a sua ausência, por meio da qual ela se torna ainda mais cintilante?" (FOUCAULT, 1977, p. 30). ${ }^{17}$

Bem como Prinzhorn e, antes dele, Klee, Dubuffet pôde apontar uma iluminação na arte dos doentes mentais na própria cegueira de sua concepção anti-cultural - ou melhor, duas. A primeira delas envolve a ordem subjetiva: o psicótico está longe de estar "ileso", pois está amedrontado pelo trauma, e o seu distúrbio psíquico se registra nas deformações corpóreas que permeiam a arte dos doentes mentais. Nessa arte, partes significativas do corpo, especialmente os olhos e a boca, são com frequência aumentados grosseiramente e, algumas vezes, cravadas desordenadamente em outras partes do corpo, de forma que

\footnotetext{
${ }^{16}$ De acordo com o que ele próprio admite mais tarde: "Eu acredito muito que não haja nenhuma forma de arte que não seja de algum modo dependente das determinações culturais" (1973, p.439). Sobre essas manobras ver Griselda Pollock (1992).

17 O ensaio foi publicado pela primeira vez em "Hommage à Georges Bataille", Critique, 1963, p. 195196.
} 
olhos se tornem seios, por exemplo, ou bocas substituam vaginas (Figura 4). ${ }^{18}$

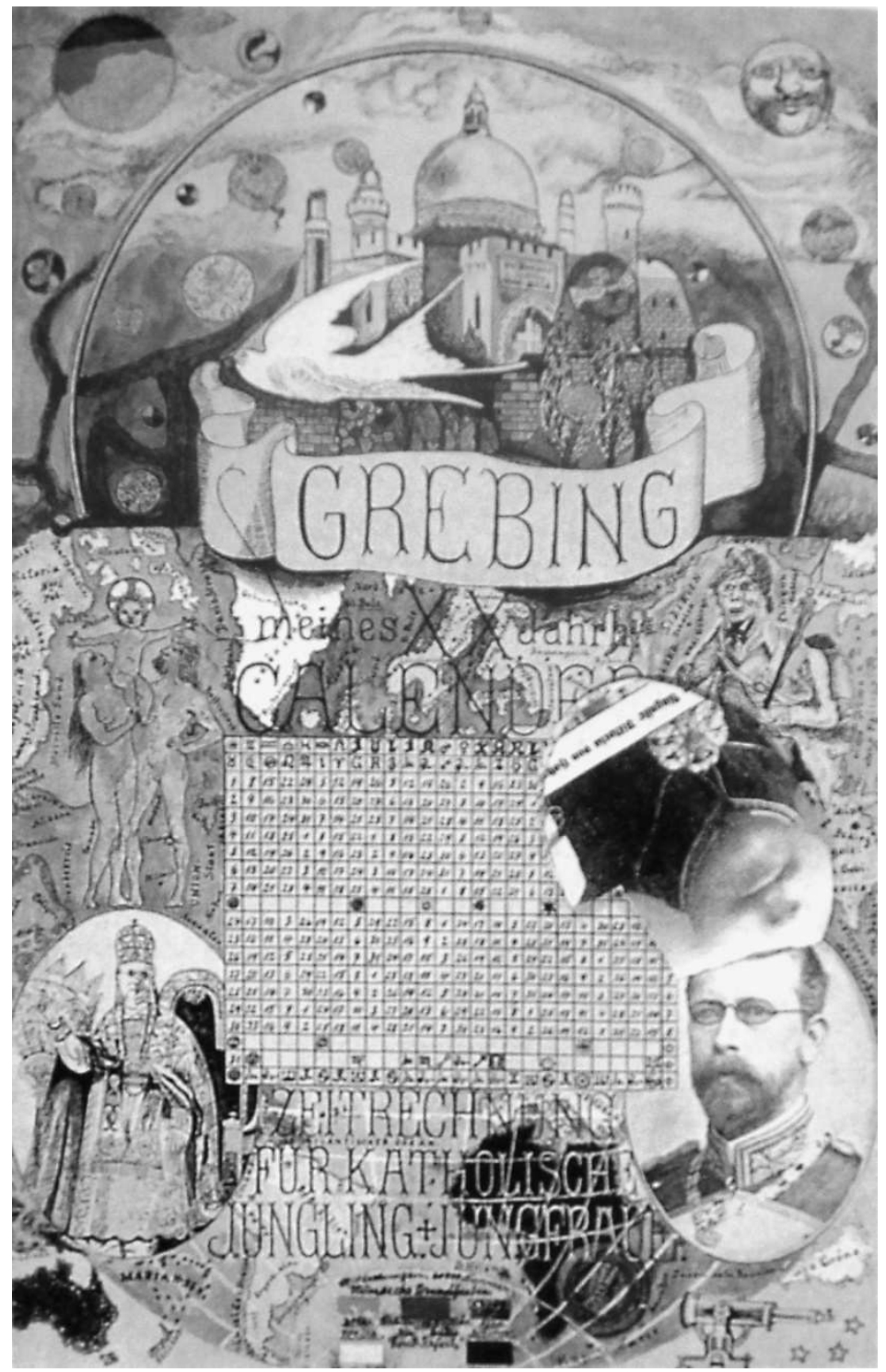

Figura 4 - Josef Heinrich Grebing, Calendário do meu século XX _ Cronologia para jovens católicos e donzelas, Foto Manfred Zentsch.

Klee também experimentou esses desarranjos da imagem do corpo, mas não de forma tão extrema como Dubuffet, que ocasionalmente correspondia às obras da Introdução à produção de imagens (Figura 5).

18 Seja por horror ou por deleite, algumas vezes o corpo é transformado em uma espécie de máquina sexual, geralmente com traços sacramentais ou sacrílegos; outras, com ambos ao mesmo tempo. 


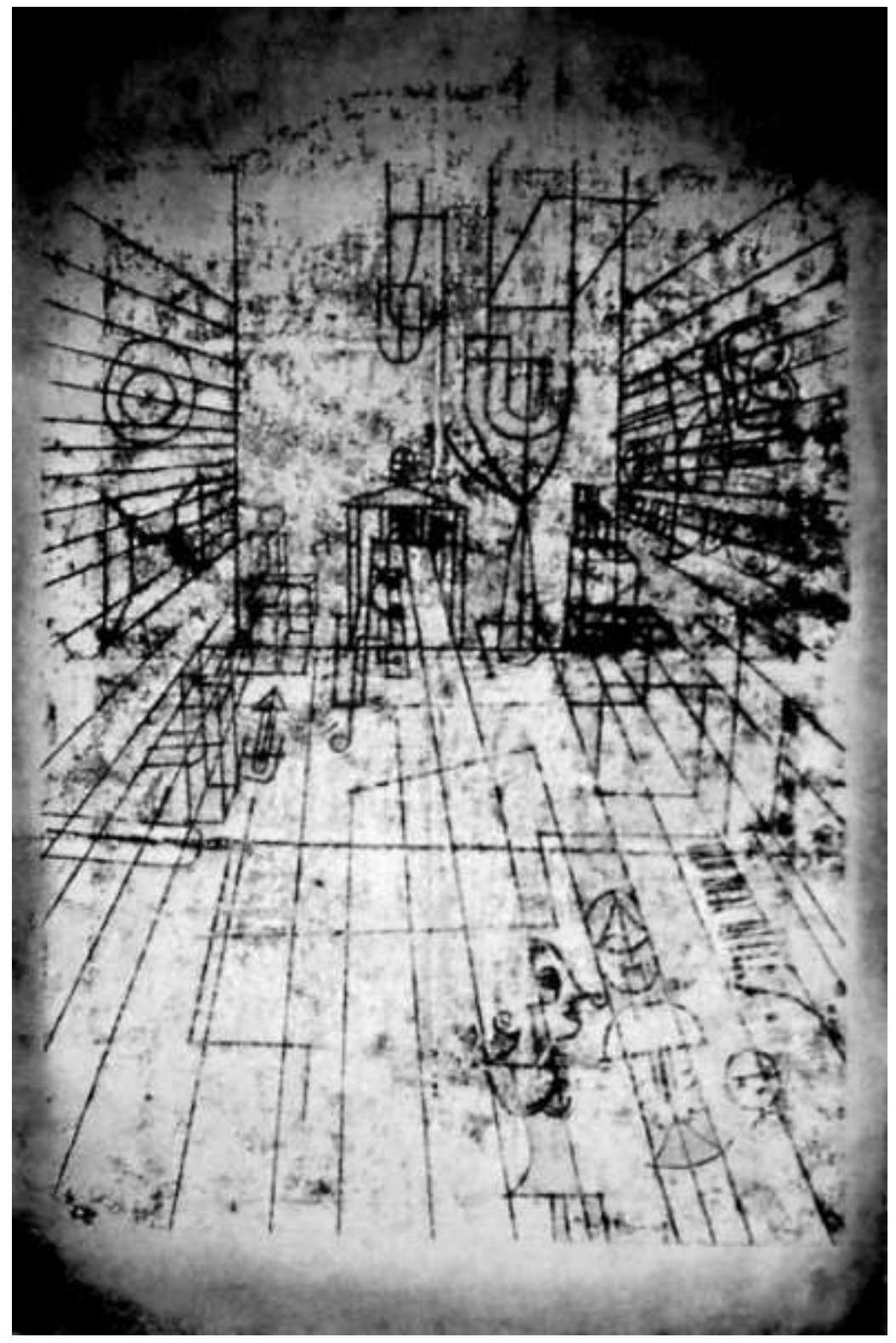

Figura 5 - Paul Klee, Perspectiva de uma sala com habitantes, 1921.

A sua afinidade com Hermann Beehle, conhecido como Beil, é estranhamente (ou conscientemente?) próxima: eles compartilham a representação frontal de nus por vezes reorganizados, geralmente esticados, e sempre fixados no suporte (que, para Beil, costumava ser papel-higiênico). Dubuffet evoca por meio de tais dispositivos um sentido esquizofrênico de auto-deslocamento literal, que em nada se refere à "operação artística completamente pura" que pretendia projetar na arte dos doentes mentais.

Se a sua primeira iluminação se refere à subjetividade, a segunda envolve o status da ordem simbólica atribuída à arte dos doentes mentais. Os desarranjos do corpo nessa arte implicam um mundo mais desesperado, ou mesmo 
debilitado, do que capacitado e, apesar de suas afirmações do contrário, isso também é verdade em Dubuffet algumas vezes. Dessa forma, o conjunto das duas obras aponta um tipo distinto de transgressão, um que se concebe em linhas que não pertencem exatamente à lógica vanguardista de Dubuffet, mas à lógica imanente do Bataille de Foucault. Ou seja, ao invés de atacar as convenções artísticas e a ordem simbólica, a arte dos doentes mentais parece se preocupar em encontrar essas leis estéticas novamente - talvez fundar novamente uma ordem simbólica; ou ao menos, como Foucault afirma, "recompor a sua forma vazia, a sua ausência". Portanto, o que esses artistas parecem ver com frequência, para o próprio terror deles, não é uma ordem simbólica estável demais, que desejam contestar (como se propõe com a lógica vanguardista), mas, na verdade, uma ordem simbólica que não é estável de forma alguma, que está em crise ou corrompida. Esses artistas estão longe de ser heróis contra a civilização, como Dubuffet gostava de imaginá-los ("a insanidade representa a recusa de adotar uma visão da realidade imposta pelo hábito"). Na verdade, eles estão desesperados para construir uma civilização que substitua a sua própria, uma ordem simbólica substituta na falta de uma oficial que, como o Angelus Novus de Klee e de Benjamin, eles percebem em ruínas (DUBUFFET apud MACGREGOR, 1989, p. 303). ${ }^{19}$ Essa hipótese sugere a seguinte especulação: de que as visões paranóicas e esquizofrênicas gravadas na coleção de Prinzhorn podem representar, sintomaticamente, uma crise na ordem simbólica específica à modernidade capitalista do período, ou ainda, que essa crise preparou uma explosão psicótica naquele momento (do qual a coleção de Prinzhorn era apenas um arquivo); e, por fim, que alguns modernistas encontraram na arte dos doentes mentais uma perspectiva dentro dessa crise. ${ }^{20}$

\footnotetext{
${ }^{19}$ Para uma apreciação gráfica da apreensão dessa crise na ordem simbólica, ver o capítulo 7.

${ }^{20}$ Essa especulação foi proposta primeiro no capítulo 4. Devo a minha linha de pensamento ao texto brilhante de Eric Santner (1996). "A estabilidade política e social de uma sociedade, assim como a 'saúde' psicológica de seus membros", de acordo com Santner, "parece ser um correlato da eficácia dessas operações simbólicas - do que podemos chamar de mágica performativa - por meio da qual os indivíduos 'se tornam quem são', admitem a essência social que Ihes foi determinada por meio dos nomes, títulos, graus, cargos, etc. Cruzamos o limiar da modernidade quando a atenuação desses laços sociais efetuados performativamente se torna crônica, quando não podem mais capturar o sujeito por meio de sua auto-compreensão. O assombramento causado por uma análise da paranóia... é que uma 'crise de investidura' não tem apenas o potencial de gerar sentimentos de alienação extrema, anomia, e de um vazio profundo, ansiedades associadas com a ausência: uma das principais lições do caso Schreber é, precisamente, que uma atenuação generalizada do poder simbólico e da autoridade pode ser experimentada pelo mais íntimo da natureza de alguém como o colapso do espaço social e dos ritos institucionais. Como veremos, a sensação que isso gera são ansiedades que não se relacionam à ausência ou à perda, mas à super-aproximação, à perda da distância com relação a uma presença obscena e malévola que possui influência direta no interior de alguém" ( $\mathrm{p}$. xxii). Nesse sentido, a arte dos alienados possui sim um imediatismo, mas um imediatismo com relação ao real (a uma condição primordial em que o simbólico nos é projetado a partir de nós mesmos), mais do que ao simbólico (a uma essência artística). Apesar de tudo, é
} 
Até agora elaborei um esboço das três leituras equivocadas e criativas da arte dos doentes mentais: o modelo da expressão de Prinzhorn, o modelo da visão de Klee e o modelo da transgressão de Dubuffet. Essas três projeções modernistas utilizam-se da arte dos doentes mentais para propor uma essência metafísica da arte. Apesar de cada modelo situar o artista de forma particular, eles pressupõem um ego suficientemente intacto - na verdade, auto-presente o bastante - para ser expressivo, visionário e, acima de tudo, transgressivo. 0 que é ainda mais estranho é que eles imaginam esse ego em um descontentamento radical com a convenção artística e também com a ordem simbólica, ao invés de perceberem o seu "isolamento autista" com relação a ambas. ${ }^{21}$ Dessa maneira, projetam uma ordem simbólica - estável, sólida e determinada - contra a qual justapõem esse descontentamento radical. E nenhuma dessas projeções parece verdadeira na arte dos doentes mentais, mas ajustam-se às ideologias vanguardistas de ruptura, imediação, pureza, etc. 0 artista psicótico está muito longe de ser auto-presente, pois está completamente deslocado e, com muita frequência, perdido no espaço. Além disso, a representação psicótica está longe de ser vanguardista em sua revolta contra a convenção artística e a ordem simbólica, pois atesta um desejo franco de reinstalar a convenção, de reinventar a ordem que o psicótico sente ter sido quebrada e tem, por isso, uma necessidade desesperada de repará-la ou substituí-la. Ou seja, as elaborações obsessivas dessa arte não são feitas para romper a ordem simbólica, mas 0 inverso: elas se constituem nessa brecha aparente. Talvez aqui uma última lição nos seja dada: a aparência obstinada da ordem simbólica não pertence exatamente a uma fixidez estabelecida que the é característica (somos nós os semiparanóicos que projetamos, ao menos parcialmente, essa fixidez), mas à frágil arbitrariedade que ela se esforça, a todo custo, para esconder e que os doentes mentais vislumbram a custa deles. Isso possui implicações significativas para se repensar a transgressão como um objetivo primordial da arte vanguardista.

\section{A alucinação segundo Max Ernst}

Ernst teve poucas ilusões a respeito da inocência da arte dos doentes mentais expressiva, visionária, transgressiva ou de outro tipo. Ao contrário: ele procurou explorar os distúrbios dessa arte com o intuito de "escapar do princípio de

possível que possamos ver essa arte diagnosticamente; mas apenas com relação a uma ordem simbólica debilitada.

${ }^{21}$ Como vimos, Prinzhorn oscila entre essas leituras. De acordo com Brand-Claussen: "todo o conceito vanguardista de violar obstinadamente a convenção pictórica - uma prática que em seu surgimento não era afetada por qualquer comparação com a arte dos alienados - encontra a sua expressão derradeira no modelo de Prinzhorn, de acordo com o qual o artista louco e autista faz ver, na 'unio mystica com o mundo todo', o que determina o artista genuíno" (1996, p.14). 
identidade" (ERNST, 1948, p. 13). ${ }^{22}$ Ernst deparou-se com essa arte quase tão cedo quanto Klee, talvez enquanto estudava psicologia na Universidade de Bonn, antes da guerra, quando leu Kraepelin e Freud (em algum momento ele também deve ter visto o estudo de caso de Schreber, pois se utiliza dos tropos freudianos da paranóia em Além da pintura, a sua extraordinária auto-análisecum-tratado-de-arte). Como mencionado no capítulo 4, Ernst afirma ter visitado a coleção de arte dos doentes mentais em um manicômio próximo a Bonn enquanto era estudante e uma vez planejou um livro sobre o assunto. "Eles comoveram profundamente o jovem rapaz", escreveu sobre essas obras em suas "Notas biográficas". "Entretanto, foi apenas mais tarde que descobriu certos 'procedimentos' que o ajudaram a penetrar nessa 'terra de ninguém"' (ERNST, 1970, p. 20). Da mesma forma, Ernst descobriu tais procedimentos "além da pintura" - as suas versões da colagem chamadas frottage e grattage inspirados pela arte dos doentes mentais.

Como vimos no capítulo 4, as suas primeiras colagens dadaístas de figuras mecânicas, feitas em Colônia antes da publicação da Introdução à produção de imagens, aludem ao dano psicológico causado pela Primeira Guerra Mundial. Imagens como a Pequena máquina auto-construída (1919), relembram um tipo particular de representação esquizofrênica, um gênero de estruturas maquínicas que pretendem funcionar como suportes do ego, mas que servem apenas para tornar o ego ainda mais debilitado (existem inúmeras máquinas disfuncionais na coleção de Prinzhorn). Nos seus retratos doentes mentais, Ernst evoca a regressão às pulsões desordenadas e às funções mortais, uma regressão que repercute os eventos reacionários do período; dessa maneira, ele adapta a arte dos doentes mentais a uma crítica direta à ordem simbólica de sua época.

A sua obra dadaísta impressionou os jovens futuros surrealistas quando foi exibida pela primeira vez em Paris, em maio de 1921, mas André Breton e Louis Aragon se chocaram menos com as suas colagens e figuras desconexas do que com as suas "sobrepinturas" [overpaintings] de ilustrações encontradas (Figura 6).

\footnotetext{
${ }^{22}$ Beyond painting [Além da pintura] consiste em diversos fragmentos publicados pela primeira vez nos periódicos surrealistas entre meados dos anos 1920 e a metade da década de 1930. A frase "escapar do princípio de identidade" é uma citação de uma resenha feita por Breton de uma mostra de 1921 das primeiras colagens de Ernst (ERNST, 1948, p. 177).
} 


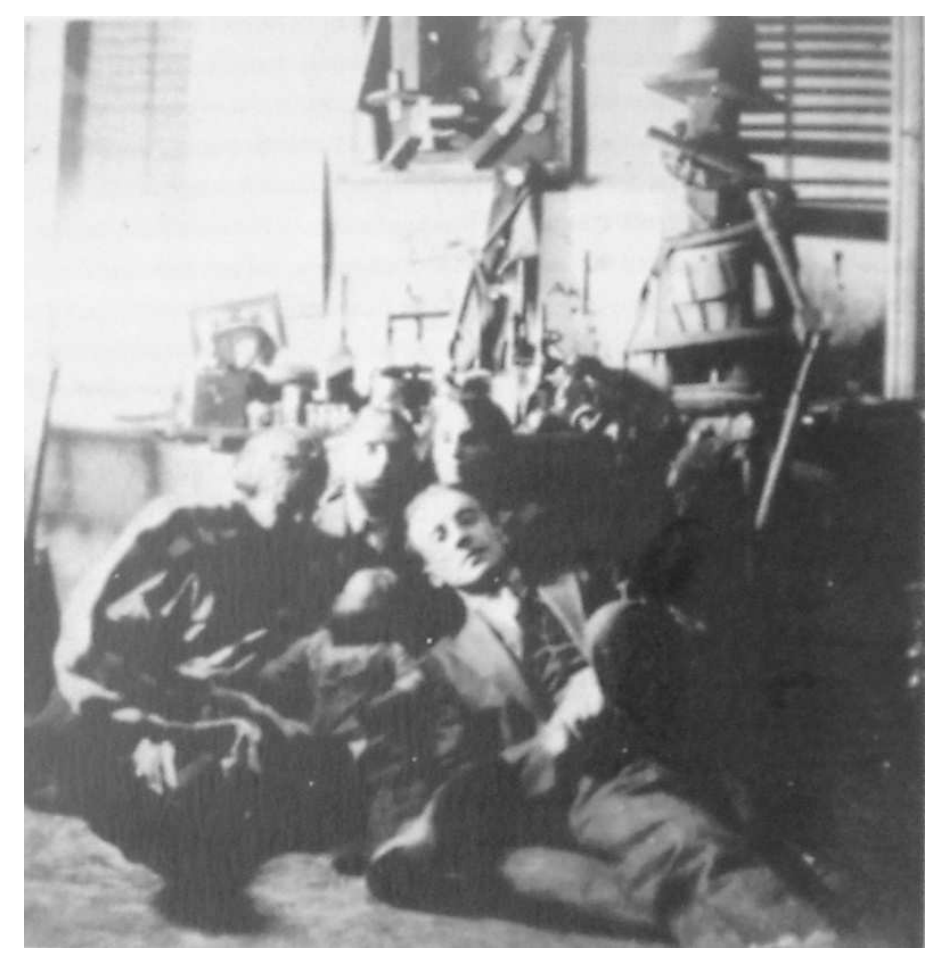

Figura 6 - Louise Straus-Ernst, Max Ernst, e o filho Jimmy com Gala e Paul Eluard no atelier de Ernst, Colônia, Nov. 1921, em frente ao Velho Libertino com um rifle

Esses estranhos palimpsestos de páginas pintadas de materiais didáticos "introduziram um esquema inteiramente original da estrutura visual", Breton afirmou mais tarde, "ao mesmo tempo, corresponderam exatamente às intenções de Lautréamont e Rimbaud na poesia", que foram nomeados precursores do surrealismo (BRETON, 1972, p. 64). ${ }^{23}$ Com efeito, as sobrepinturas demonstraram como a arte visual pôde antecipar a poética surrealista de "combinar duas realidades, aparentemente distantes, em um plano ao qual elas supostamente não pertencem", como Ernst define a colagem em Além da pintura, basicamente em uma paráfrase de Lautréamont e Pierre Reverdy, dentre outros (1948, p. 13). O fundamental aqui é a conexão que Ernst desenvolve entre as perturbações na imagem e na subjetividade, sustentada pelo exemplo da arte dos doentes mentais. Essa arte surge, portanto, como um ponto de mediação necessário entre a estética surrealista e a dadaísta, que freqüentemente desaparece nas considerações sobre essa passagem. Quando Ernst se mudou para Paris em 1922, ele trouxe a Introdução à produção de imagens de presente para Paul Eluard, que no mesmo ano colaborou com Breton em $A$ imaculada

${ }^{23}$ É claro que quando ele alude a Lautréamont refere-se ao "encontro ao acaso entre a máquina de costura e o guarda-chuva em uma mesa de dissecação" dele que o surrealismo adotou como mote, e a alusão a Rimbaud é à sua "alchimie du verbe" em Uma temporada no inferno, que Ernst chama de "milagre da transfiguração total" em Além da pintura. 
concepção, uma simulação poética de loucura que consiste no texto inaugural da escrita surrealista.

Em Além da pintura, Ernst relaciona explicitamente o transtorno da imagem e o da subjetividade. Ele nos conta, em "Alguns dados sobre a juventude de M. E.", as suas primeiras memórias de forma a relacionar a crise simbólica com os distúrbios psíquicos. Em uma delas, a sua irmã mais nova falece no mesmo dia que o seu pássaro de estimação, uma coincidência que ele atribui à sua posterior "confusão de imagens de seres humanos com pássaros e outras criaturas" (1948, p. 26). Entretanto, o mais importante é a sua "visão de vigília" (datada "entre os 5 e os 7 anos") que abre Além da pintura: aqui, o pequeno Max assiste ao seu malicioso pai, um pintor de domingo, fazer marcas "alegremente obscenas" em um painel (1948, p. 3). Eis o seu primeiro encontro com a pintura em termos de uma cena originária, que Freud define como uma fantasia traumática do coito dos pais por meio da qual uma criança desvenda o enigma das origens (ver o capítulo 1). ${ }^{24}$ Ernst evoca o tropo da cena originária na origem das histórias de todos os seus procedimentos "além da pintura" - numa repetição que salienta, mais uma vez, o seu desejo de abrir a ordem estética ao transtorno psíquico. Assim como Freud descreve as cenas psicologicamente fundadoras em termos visuais, Ernst descreve as suas cenas pictoricamente originárias em termos psicanalíticos.

Entretanto, existe mais aqui que o envolvimento de um dispositivo dessublimador, pois Ernst desenvolve essa noção de fantasia traumática em uma teoria da prática estética: "O autor assiste como um espectador... ao nascimento de sua obra", ele afirma em Além da pintura. "O papel do pintor é o de... projetar aquilo que nele se vê a si mesmo" (1948, p. 8, o destaque é do autor). ${ }^{25}$ Aparentemente tendo em mente mais uma vez a cena originária, Ernst posiciona o artista ao mesmo tempo dentro e fora da cena da sua arte, como se fosse simultaneamente o criador ativo da sua fantasia e o observador passivo dessas imagens. O fascínio visual e as confusões sexuais dessa cena originária nos dizem não apenas sobre a sua definição de colagem ("a combinação de duas realidades aparentemente irreconciliáveis"), como também sobre o que concebia como o propósito da colagem (perturbar "o princípio de identidade"). Ele coloca esse modelo na prática bem cedo em O quarto do mestre (1920,

\footnotetext{
${ }^{24}$ Sobre a cena originária em Ernst, ver o meu livro Compulsive Beauty [Beleza compulsiva], do qual adaptei alguns parágrafos aqui.

${ }^{25}$ Compare com Prinzhorn sobre um de seus mestres: "Ele é completamente passivo quando cria, quase como se fosse um espectador" (1972, p. 143). Nessa passagem, encontramos mais uma vez os ecos da passividade de Schreber.
} 
Figura 6), uma célebre sobrepintura de um catálogo que lista cinqüenta objetos usados para instrução elementar básica em percepção, discurso e escrita (note o brilhantismo dessa subversão particular de educação racionalista). Todos os itens originais - exceto dez - foram sobrepintados (mesa, cama, escrivaninha, árvore, baleia, morcego, peixe, cobra, ovelha, urso); tremendamente fora de escala, eles são postos em um quarto bizarro que Ernst esquematiza com linhas e matizes suficientes apenas para evocar um theater mundi esquizofrênico. Os habitantes esquisitos e o espaço distorcido parecem olhar para trás, para o artista-espectador, como se uma fantasia traumática, reprimida por muito tempo, tivesse retornado repentinamente para ameaçar o seu dono, uma alucinação que pode "despossuí-lo" [unmaster] inteiramente. Ainda que o título sugira uma cena originária, são as des/conexões formais da imagem - o seu jogo de justaposição louca, a escala contraditória e a perspectiva inquietante que evocam a fantasia traumática e produzem o efeito paranóico. São esses os "procedimentos" que auxiliaram Ernst a penetrar na "terra de ninguém" da representação psicótica e, dessa forma, passar dos resíduos mais sociais evidentes na colagem dadaísta, aos traços mais psicóticos em operação nas imagens surrealistas.

Os surrealistas gostavam de citar como modelo de imagem surrealista o exemplo usado por Leonardo para descrever como o gênio artístico pode diferenciar, em uma simples mancha sobre a parede, uma paisagem completa, a cena de uma batalha ou qualquer outra invenção. ${ }^{26}$ Freqüentemente, essa ilusão canônica se parece com uma tentativa de obter respeitabilidade artística; o modelo mais insistente de imagem surrealista, como Ernst afirma em Além da pintura, é "a simples alucinação" (1948, p. 12). "Fiquei surpreso", ele escreve em uma versão de sua cena originária da arte, "com a repentina intensificação das minhas capacidades visionárias e com a sucessão alucinatória de imagens sobrepostas, uma sobre a outra, com a persistência e a rapidez características das memórias amorosas" (Idem, p. 14). Embora o "mecanismo" dos seus procedimentos continue sendo "o encontro ao acaso" de imagens, a "técnica" não é materialmente espalhafatosa como na maioria das colagens dadaístas (Ibid., p. 13). Como vimos no capítulo 4, Ernst tendia a obscurecer os seus meios de produção: "ce n'est pas la colle qui fait le collage", ele afirma em Além da pintura (Ibid., p. 13). Ou seja, ele destruía o suporte material para que a imagem resultante pudesse parecer tão imaculada quanto uma visão psíquica.

\footnotetext{
${ }^{26}$ Ernst se refere a isso em Além da pintura (p.7), André Breton em L'amour fou [0 amor louco], e Prinzhorn também trata do tema na Introdução à produção de imagens (p.18-19).
} 
"Os desenhos assim obtidos", segundo ele escreve acerca das frottages, "perde cada vez mais o caráter do material interrogado.... e fica com o aspecto da... primeira causa da obsessão, ou produz um simulacro dessa causa" (Ibid., p. 8). A destruição do suporte material duplica a intensidade onírica da visão psíquica - do sonho, a recordação encobridora, ou a cena originária (como mencionado no capítulo 1, o sonho do Homem Lobo - um outro estudo de caso de Freud que Ernst provavelmente conheceu - engloba os três ao mesmo tempo). Como nessas visões psíquicas, as colagens de Ernst produzem uma intensidade singular por meio das múltiplas camadas da cena visual que parecem "readymades psíquicos". ${ }^{27}$ Com imagens sobrepostas que por vezes se infiltram mutuamente, o meio da sobrepintura serve para evocar esse campo dos readymades psíquicos. De fato, a sobrepintura sugere um correspondente visual da própria "cenografia" da psique: a justaposição de imagens incongruentes como em um sonho, o retorno do familiar tornado estranho pela repressão no sinistro, a fusão no tempo de dois elementos distantes como no trauma. $E$, mais uma vez, esse modelo da arte como visão alucinatória parece ser firmado pela arte dos doentes mentais. ${ }^{28}$

Portanto, em suas primeiras colagens dadaístas Ernst evoca um sujeito prejudicado, à maneira de algumas representações esquizofrênicas, em particular das estruturas maquínicas projetadas como suportes do ego. Logo depois disso, ele desenvolve uma estética surrealista ao modo de algumas representações paranóicas, em particular das reguladas por uma "sucessão alucinatória de imagens contraditórias". Dessa maneira, Ernst não apenas elabora estilisticamente a arte dos doentes mentais, mas a compreende quase diagnosticamente, e a transforma na sintomatologia das suas representações por razões críticas. ${ }^{29}$ Esse entendimento faz com que o seu uso da arte

\footnotetext{
${ }^{27}$ Ver Rosalind Kraus (1989). "O que se projeta aqui é um campo visual que não é latente, uma onda de potencialidade pura do exterior sempre renovada; ao invés disso, temos um campo de antemão preenchido - ou, empregando o termo - ready-made" (p. 65). Sobre um arranjo da imagem de forma que aparentemente destrua o seu suporte, ver BURGIN, 1986. Como vimos no capítulo 1, a suposta destruição do suporte produz uma intensidade onírica (como no Homem Lobo), contudo a imagem permanece como palimpsesto, uma tela constituída por múltiplas telas. Em certo sentido, se a abstração do último modernismo sugere um espaço "estritamente ótico", de acordo com Clement Greenberg, as sobrepinturas sugerem um espaço "estritamente psíquico".

${ }^{28}$ Compare à transformação sem lógica do mestre de Prinzhorn, August Natterer, discutida no capítulo 7. Para Krauss, a recordação encobridora é a analogia mais próxima da sobrepintura, "um aparato por meio do qual a visão é retrojetada, projetada após o acontecimento sobre o fundo totalmente saturado do readymade" (1989, p. 69).

${ }^{29}$ Essa estética se tornou mais tarde programática, quase uma rotina, no "método paranóico-crítico" de Salvador Dali. Além da pintura pode ser lido como uma passagem das estratégias dadaístas que imitam a regressão surrealista pré-edípica às histórias sobre o enigma de Édipo. Nessa obra do início dos anos 1920, Ernst se desloca das últimas colagens dadaístas que algumas vezes evocavam uma cena originária às pinturas do início do surrealismo que freqüentemente possuíam um tema edípico. Ele também parte da personagem autista "Dadamax" à figura híbrida "Loplop", que funciona como um superego aparente (especialmente quando identificado com um pai castrador). Em certo sentido, Ernst se desloca de uma posição de negatividade dadaísta para a redenção surrealista, uma estética mais de auto-criação reconstituinte que de "identidade convulsiva".
} 
dos doentes mentais seja diferente das apropriações vanguardistas de Klee e de Dubuffet. De maneira distinta, Ernst não atribui a essas imagens o caráter de origem redentora da arte nem as situa radicalmente além das fronteiras da civilização; isso significaria projetar novamente uma ordem simbólica intacta e até mesmo sólida. $\mathrm{Na}$ verdade, ele aponta para a percepção mais radical de que a ordem simbólica já está de alguma forma fraturada, e que essa fratura pode precipitar uma crise no sujeito e também preparar um novo tipo de arte crítica, capaz de repensar o lugar e o alcance da transgressão.

\section{Um paciente é Deus, mas varre o chão de bom grado}

Como vimos, tanto Klee como Dubuffet distorcem, muitas vezes, a imagem do corpo, como se mantidos em uma apreensão esquizofrênica do auto-prejuízo ou do auto-deslocamento, e, como Ernst, eles também viam o corpo algumas vezes como um mecanismo disfuncional. ${ }^{30}$ Essas distorções da imagem do corpo também se manifestam na coleção de Prinzhorn e sugerem uma característica comum dessa arte - um tratamento paradoxal das linhas limites e das relações entre a figura e o fundo. Algumas vezes, as margens são retraídas, como na distorção esquizofrênica; em outras, contrariamente, são exageradas como na defesa paranóica. Outras vezes, também, as margens são exageradas ao ponto de se retraírem novamente - como se, na própria tentativa de enfatizar a distinção entre o eu e o mundo necessária a uma idéia de autonomia, essa mesma diferença se desfizesse. As falhas nas margens dessa arte assumem tantas formas quanto às pulsões propostas por Prinzhorn: as relações entre a imagem e o fundo se confundem com a ordenação ornamental, com a cópia obsessiva, com as fantasias sistemáticas, etc. Em todos esses modos, o desejo de ordenar é geralmente tão insistente que domina o dispositivo que deveria libertá-lo, e a imagem é lançada de volta ao caos.

Um exemplo recorrente desse des/ordenamento paradoxal entre a figura e o fundo é a inscrição compulsiva de números e/ou letras, de palavras e/ou frases no campo pictórico. Parece se manifestar aqui uma ânsia por qualquer diferença na demarcação primordial de uma figura contra um fundo e também na natureza fundamental dos signos utilizados. Assim, essas marcas são, mais uma vez, elaboradas até o ponto em que a diferença desejada é esmagada ("a tendência de preencher todos os espaços", como escreve Prinzhorn, "contradiz completamente a essência da representação que tem como objetivo a individualização" - 1972, p. 233). Um exemplo significativo da coleção de

\footnotetext{
${ }^{30}$ Dubuffet prefere o animalesco em detrimento do mecânico, ao passo que Klee por vezes combina ambos, como na sua célebre Máquina cantante (1922).
} 
Prinzhorn é a carta escrita por Emma Hauck, diagnosticada com demência precoce, que escureceu as suas páginas tonando-as quase ilegíveis com um apelo repetido ao seu marido para que "viesse" até ela, ainda que "ela" não estivesse aparentemente nem um pouco segura ou estável (Figura 7). Aqui vemos como o próprio desejo de manter as relações humanas se torna outra expressão do "isolamento autista".

Esse declínio da ordem em desordem também ocorre quando a ordem é explicitamente o tema da obra, como no caso das projeções paranóicas de fantasias megalomaníacas. Como freqüentemente acontece na coleção de Prinzhorn, as descrições de eventos milagrosos e de maquinações hostis, o mapeamento de espaços institucionais e de sistemas cósmicos - nos quais o anseio "metafísico" (1972, p. 241) da arte dos doentes mentais se torna mais aparente - são articulados de forma tão obsessiva que constituem uma ordem para o mundo que se desconstrói por si só, uma vítima de sua própria sistematicidade super-elaborada. Um bom exemplo é o compêndio de Josef Heinrich Grebing, um vendedor também diagnosticado com demência precoce. Grebing reagrupou uma ordem simbólica por meio dos escombros atribuídos à ordem oficial: ele publicou certificados financeiros, pinturas de ícones religiosos, desenhou "mapas- múndi" e, extraordinariamente, desenvolveu um calendário completo do Século XX - "uma cronologia para donzelas e jovens católicos" repleto de tabelas astrológicas (Figura 8). O que Freud destaca acerca do sistema paranóico de Schreber também parece verdadeiro aqui: "A formação da ilusão, que consideramos um produto patológico, é, na verdade, uma tentativa de recuperação, um processo de reconstrução" (1963, p. 174). ${ }^{31}$

O colapso da imagem e do fundo também se difunde nas obras dos três modernistas em questão, onde se torna mais próximo das representações psicóticas do que das desconstruções formais dessa relação em outros modernistas (para testar essa afirmação, poderíamos comparar os quadriculados de Klee e os de Mondrian). Na pequena aquarela Perspectiva de uma sala com habitantes (1921, Figura 9), Klee destrói a figura e o fundo permitindo a fusão, efetivamente, do sujeito e do espaço. Nessa imagem, as ortogonais conduzem a um enigma formado por salas, uma flecha aponta para lugar nenhum, e um graal fantasmagórico nos oferece pouca esperança de salvação. A perspectiva faz com que os vetores dos poucos objetos que existem na sala se tornem transparentes, e esse é o

${ }^{31}$ Esse processo também se encontra em operação das imagens de August Natterer discutidas no capítulo 7. 
mesmo destino das figuras achatadas sobre o chão e ao longo da parede como espectros diagramáticos. É como se eles não habitassem propriamente a sala, mas fossem habitados por ela - de uma perspectiva que parece traçar um "mundo intermediário" (utilizando as suas próprias palavras). Dessa forma, Klee leva o velho projeto da perspectiva - que Erwin Panofsky definiu, em seu epítome renascentista, como a reconciliação entre o sujeito e o objeto - ao ponto de um reverso inumano, pois aqui o sujeito e o objeto não se reconciliam como termos equivalentes, mas se dissolvem como entidades distintas (FREUD, 1963, p. 174). ${ }^{32} \mathrm{Em} \mathrm{1937,} \mathrm{Roger} \mathrm{Caillois,} \mathrm{ligado} \mathrm{ao} \mathrm{movimento} \mathrm{surrealista,}$ fez a melhor interpretação da espacialidade horrenda de Perspectiva de uma sala com habitantes, e da sua consideração singular da angústia esquizofrênica e da perda literal do eu no espaço:

O espaço se torna uma força de devoração para essas almas despossuídas. O espaço as persegue, as circunda, as digere em uma fagocitose gigantesca [consumo de bactérias]. Por fim, as substitui. Então, o corpo se separa do pensamento, o indivíduo rompe os limites da sua pele e ocupa o outro lado dos seus sentidos. Ele tenta se observar de qualquer ponto no espaço. Ele sente que está se tornando o espaço, o espaço escuro onde não podemos dispor as coisas. Ele é semelhante, não semelhante a algo, simplesmente semelhante. E cria espaços dos quais ele é a "propriedade convulsiva". (CAILLOIS, 1984, p. 30 - a ênfase é do autor) ${ }^{33}$

Essa terrível condição de mera semelhança e de propriedade convulsiva capta o terror esquizofrênico aos limites destruídos e à espacialidade invasiva freqüentemente evocado pela arte dos doentes mentais. Interessa-nos aqui especialmente $o$ fato de que algumas vezes esse horror parece exigir um contraponto paranóico - uma projeção defensiva de um espaço que agora se torna muito distinto e distante, de um mundo que se torna repentinamente estranho e hostil. Ernst evoca essa alienação paranóica em uma obra como $O$ quarto do mestre, onde o observador se torna o observado, e o livro de história com animais e os objetos da hora de dormir se tornam seres alienígenas. Se contrapusermos, por um momento, os quartos de Klee e de Ernst, veremos que Perspectiva de uma sala com habitantes parece realizar uma dissolução esquizofrênica do sujeito no espaço, ao passo que o quarto do pintor

\footnotetext{
32 Ver Erwin Panofsky (1991). Klee também deturpa aqui um velho projeto seu, estabelecido quase vinte anos antes, no verão de 1902: "A espiritualização da paisagem, combinação de sua psique com a sensibilidade humana" (KLEE, F., 1962, p.8).

${ }_{33}$ Para considerações semelhantes, ver Louis A. Sass (1992).
} 
parece projetar uma alienação paranóica do sujeito pelo espaço - como se o sujeito esquizofrênico na primeira sala buscasse se centrar novamente, tornar-se novamente um mestre, por meio da projeção paranóica do espaço no segundo quarto, na sua oposição alucinatória entre o eu e o outro. ${ }^{34}$ Dessa forma, a paranóia pode ser entendida como o último refúgio, o manicômio final de um sujeito ameaçado pela perda esquizofrênica do eu. "Eu" ainda sou um "eu" enquanto houver um outro no espaço, talvez um outro como espaço, lá fora para me ameaçar; esse outro me mantém centrado pela sua própria alteridade, pela sua própria ameaça. ${ }^{35}$ Ainda assim, essa projeção paranóica do espaço não garante mais o sujeito do que a construção esquizofrênica de próteses maquínicas mencionadas acima com relação a Ernst. Ambas são tentativas de auto-resgate que apenas ressaltam a perda de si. Essa é a compreensão da arte dos doentes mentais que uma leitura de Ernst permite. ${ }^{36}$

Portanto, não há, propriamente, uma simples oposição entre a esquizofrenia e a paranóia, mas uma ligação contraditória entre os traços pictóricos que podem ser associados a cada uma delas. Na coleção de Prinzhorn, vemos uma oscilação persistente entre as imagens de "catástrofe" esquizofrênicas e as imagens de "reconstrução" paranóicas (de acordo com os termos freudianos): cada anulação do limite é compensada por uma insistência no limite, cada abertura ao caos compensa-se com uma procura pela ordem, e assim por diante. ${ }^{37}$ Essa

\footnotetext{
${ }^{34}$ Algumas vezes estas operações - a dissolução no espaço e a projeção do espaço - ocorrem, aparentemente, ao mesmo tempo, como em algumas imagens do mestre da coleção de Prinzhorn Heinrich Welz, que possivelmente influenciou Paul Klee. Ver James S. Pierce (1977).

35 Freud costumava associar a construção de sistemas da paranóia com a filosofia: "uma ilusão paranóica é uma caricatura de um sistema filosófico", ele escreve em Totem e tabu (1950, p. 73). Teria ele percebido que o inverso dessa analogia também funciona? Pode a própria sistematização da loucura na psicanálise também ser uma defesa contra a loucura? Existe, igualmente, uma dimensão paranóica em toda a filosofia francesa do pós-guerra - a alienação do olhar em Sartre e em Lacan, o poder da vigilância em Foucault, etc. - mas o seu objetivo é outro. Como já sugeri, é possível que a própria crítica ao sujeito por essa filosofia também tenha a missão secreta de resgatá-lo. "Na paranóia", escreveu Leo Bersani, "a função principal do inimigo é fornecer uma definição do real que torne a paranóia necessária. Portanto, devemos suspeitar de que a própria estrutura paranóica seja um dispositivo por meio do qual a consciência mantém a polaridade do eu e do não-eu, preservando, assim, o conceito de identidade" (1989, p. 109).

${ }^{36}$ A mesma interpretação ecoa no ensaio "A arte dos alienados" (1936), do psicanalista e historiador da arte vienense Ernst Kris, que visitou a coleção de Prinzhorn. Influenciado pelas reflexões freudianas sobre a paranóia, Kris censurou a idealização de Prinzhorn da arte dos alienados, interpretada por ele como um projeto de "restituição" falho. Ver o seu Psychoanalytic explorations in art [A psicanálise da arte, 1964].

37 Existe outra tensão nas representações maquínicas: algumas servem para dar suporte a um ego danificado, para defender contra a auto-dissolução esquizofrênica, como discutimos acima; outras descrevem as fantasias paranóicas de controle externo, como propôs Viktor Tausk, um discípulo vienense de Freud, no seu ensaio de 1919 "On the origin of the influencing machine" [Sobre a origem da máquina influenciadora]. De acordo com Tausk, a "máquina influenciadora" é a projeção de um órgão (geralmente da genitália) ou do corpo de forma "a parecer um inimigo externo, uma máquina utilizada para atacar o paciente" (1992, p. 562). Os exemplos gráficos são as "provas" (Beweisse), como os esboçados por Jakob Mohr, diagnosticado como paranóico. Em um dos desenhos ele está literalmente enrolado ao arame da máquina que um inimigo segura - o que talvez seja um indício da natureza tecnológica dessa construção em particular da paranóia.
} 
tensão não existe apenas entre a esquizofrenia e a paranóia, mas também em cada estado, ou seja, em cada paciente fendido pelas visões da perda de si e do auto-resgate. Prinzhorn detectou essa ambivalência na maioria dos pintores, fossem eles diagnosticados como esquizofrênicos ou paranóicos. Essa ambivalência se estende aos objetos externos ("uma cabeça de criança... lembra o desenhista da morte, um rabanete retirado da terra, lembram-no Cristo com o cálice e a hóstia" - 1972, p. 236), bem como aos outros seres ("o médico pode ser cumprimentado como se fosse o carteiro" - idem, p.139), mas é finalmente enraizada no sujeito ("o paciente é um Deus, mas varre o chão de bom grado" - ibid., p.266). A ambivalência do sujeito é mais extrema na identificação recorrente entre os mestres de Prinzhorn e Cristo. A força dessa identificação está em permitir simultaneamente as ilusões de grandeza e de perseguição, um status que é, ao mesmo tempo, "sobrenatural" e "sacrificial", enaltecido e abjeto (Ibid., p. 117). No entanto, mais do que uma posição de dupla autoridade, consiste em uma dupla ligação, na qual o sujeito é pego em um "mundo intermediário", pego em uma crise entre as ordens simbólicas, pego (talvez como Cristo) em um enigma entre tais ordens - entre uma revelação velha e arruinada e uma nova revelação emergente, que ninguém mais percebeu até então e em que muito menos se acredita. ${ }^{38} \mathrm{~A}$ coleção de Prinzhorn é cheia de imagens que parecem relatar uma transgressão profana da religião, ou uma mudança carnavalesca da sociedade. Entretanto, mais do que atos heróicos de recusa ou revolução, o que essas imagens registram são tentativas levadas pelo pânico de restaurar ou de substituir esses sistemas sociais - ou seja, tentativas levadas pelo pânico de registrar a quebra de uma ordem antiga e o projeto de fundação de uma ordem nova.

\section{A ordem simbólica como "Velho libertino com um rifle"}

Gostaria de concluir com uma obra de Ernst, mencionada no capítulo 4, que converte a evocação de um sujeito fracassado em uma crítica de uma ordem simbólica fracassada. É uma obra que se tornou conhecida por meio de uma fotografia de 1920 que mostra Max e Luise Ernst, e Paul e Gala Eluard, em um atelier que o primeiro deles tinha em Colônia; mal se pode ver o pequeno Jimmy Ernst entre eles (Figura 10). É um simples instantâneo que comemora uma nova amizade - que se tornaria em breve um difícil ménage à trois entre Max, Paul e Gala. Eles estão debaixo de uma assemblage estranha, que lembra

38 Ver a nota 27. A respeito da ligação dupla na esquizofrenia, ver Gregory Bateson (1972). Retornarei a esse estado no capítulo 7. 
uma versão tridimensional das "máquinas auto-construídas" de Ernst; é uma das esculturas de sucata feitas ao mesmo tempo que as suas colagens dadaístas, aparentemente inspiradas pelas "esculturas de pães" que ele viu na sua visita ao manicômio próximo a Bonn antes da guerra. Como disse no capítulo 4, a maioria dessas esculturas evoca personagens infelizes cuja autoridade fálica está ameaçada. Assim como a colagem $O$ chapéu faz o homem (1920), a figura estranha em questão é, de fato, um "velho libertino", fixado com varas de madeira, com um capacete, e uma pistola para soldadura (uma colagem posterior com o mesmo título é (des)construída com semelhantes objetos da moda e da guerra).

Ernst também exibiu Velho libertino com um rifle na mostra "Dada Começo da primavera" em abril de 1920, e foi essa escultura que levou os bons cidadãos de Colônia a chamar a polícia para fechar a exposição. (A esse respeito, Velho libertino com um rifle faz um par com a cabeça de porco em gesso, enfiada em uniforme militar e pendurada no teto, que causaria um furor parecido na "Primeira Feira Internacional Dada" em Berlin alguns meses depois). O próprio pai de Ernst rompeu com ele após o acontecimento. Obviamente, essa obra oprimiu uma época que já estava desarticulada.

Ernst atribui uma legenda à escultura formada por uma "salada de palavras" quase-esquizofrênica, comum nas suas colagens da época: "Velho libertino com um rifle protege o vestuário de primavera do museu das intervenções dadaístas" [L'état c'est MOI!] [Escultura monumental]". Está claro que a afirmação é quase sem sentido, mas a sua falta de sentido é sugestiva, pois naquele momento de defesa militar e de caos social o Estado figura como o "velho libertino", cuja única autoridade é a força bruta, "o rifle". E esse Estado patético tenta, ainda, proteger o patrimônio cultural, "os museus", do ataque das "intervenções dadaístas". No entanto, a mágica performativa do poder desse Estado ("I'état c'est MOI!") não funciona mais, pois é ridículo. E agora, o quinteto Ernst-Eluard outrora promíscuo e provocativo, repousa informalmente, quase insolentemente e indiferente ao emblema da força policial. Além disso, o patrimônio cultural que o Estado deseja proteger já está degradado: é um pouco mais do que uma moda, um "vestuário de primavera", uma ostentação de novas mercadorias para cada nova estação, e aparentemente Ernst não exime a vanguarda em geral desse status, nem mesmo Dada em particular. Se Velho libertino é mesmo uma "escultura monumental", consiste no 
monumento ao declínio da monumentalidade simbólica, um monumento ao colapso da autoridade social. É com essa iluminação cega que Max Ernst se depara nessa "terra de ninguém" das representações: a arte dos doentes mentais sugere menos uma expressão pura, uma visão originária, ou a transgressão vanguardista, do que se refere a uma crise existente na ordem simbólica.

\section{Referências bibliográficas:}

BATESON, Gregory. Steps to an ecology of mind. Nova York: Ballantine Books, 1972.

BENJAMIN, Walter. Karl Krauss (1931). In: . On reflexions. Trad. Edmund Jephcott. Nova York: Harcourt Brace Jovanovich, 1978.

. Theses on the philosophy of history (1940). In: . Illuminations.

Trad. Harry Zohn. Nova York: Schocken Books, 1969, p.257-258.

[Edição brasileira: BENJAMIN, Walter. Sobre o conceito de história. In:

Magia e técnica, arte e política: ensaios sobre arte e história da cultura. Trad.

Sérgio Paulo Rouanet. Pref. Jeanne Marie Gagnebin. $7^{a}$ ed. São Paulo:

Brasiliense, 1994 (Obras Escolhidas, v. 1, p. 222-232)].

BERSANI, Leo. Pynchon, paranoia, and literature. Representations, n 25, 1989.

BLEULER, Eugen. Dementia praecox, or the group of schizophrenias. Trad. J. Zinken. Nova York: International Universities Press, 1950.

BRAND-CLAUSSEN, Bettina. The collection of works of art in the psychiatric clinic, Heidelberg - from the beginnings until 1945. In: BRAND-CLAUSSEN et al. (Orgs.). Beyond reason: art and psychosis - Works from the Prinzhorn collection. Londres: Hayward Gallery, 1996.

BRETON, André. Artistic genesis and perspective of surrealism (1941). In:

Surrealism and painting. Trad. Simon Watson Taylor. Londres: Macdonald, 1972.

BURGIN, Victor. Diderot, Barthes, Vertigo. In: . The end of art theory.

Atlantic Highlands, NJ: Humanities Press International, 1986.

CAILLOIS, Roger. Mimicry and legendary psychasthenia (1937). October, $n^{\circ} 31$, 1984.

DUBUFFET, Jean. Prospectus et tous écrits suivants. Paris: Gallimard, 1967. . Honneurs aux valeurs sauvages. In: . Prospectus et tous écrits suivants. Paris: Gallimard, 1967, v. 1, p. 213.

. Positions anticulturelles. In: Prospectus et tous écrits suivants. Paris: Gallimard, 1967, v. 1, p. 94. 
. Art brut in preference to the cultural arts (1949). Trad. Paul Foss e Allen S. Weiss. Art \& Text 27, dez./fev. 1988. . Jean Dubuffet. Nova York, 1960. . L'Homme du commun à l'ouvrage. Paris: Gallimard, 1973.

ERNST, Max. Beyond painting. Nova York: Wittenborn \& Schultz, 1948. . Notes pour une biographie. Écritures. Paris: Le Point du Jour, 1970.

FOUCAULT, Michel. A preface to transgression. In: Language, countermemory, practice. Org. Donald F. Bouchard. Ithaca: Cornell University Press, 1977.

[Edição brasileira: Prefácio à transgressão. In: Estética: literatura e pintura, música e cinema. Org. Manoel Barros da Motta. Trad. Inês Autran Dourado Barbosa. Rio de Janeiro: Forense Universitária, 2001, p. 28-46 (Ditos e Escritos III)].

FOSTER, Hal. Compulsive Beauty. Cambridge, Mass.: MIT Press, 1993.

FREUD, Sigmund. Psychoanalytic notes on an autobiographical account of a case of paranoia (dementia paranoides). In: RIEFF, Phillip (org.). Three case histories. Nova York: Collier Books, 1963.

[Edição brasileira: Freud, S. (1911). Notas psicanalíticas sobre um relato autobiográfico de um caso de paranóia. (dementia paranoides). In:

Edição standard brasileira das obras completas de Sigmund Freud. Rio de Janeiro: Imago, 1996 (v. XII)].

. Totem and taboo ((1913) Trad. James Strachey. Nova York: W W Norton, 1950.

[Edição brasileira: Freud, S. (1913). Totem e tabu. In: Edição standard brasileira das obras psicológicas completas de Sigmund Freud. Trad. Jayme Salomão. Rio de Janeiro: Imago, 1996 (v. XIII)].

KLEE, Paul. The inward vision. Trad. Norbert Guterman. Nova York: Harry Abrams, 1959.

[Versão brasileira do "Credo criativo" de Paul Klee em: HB Chipp (Org.). Teorias da arte moderna. São Paulo: Martins Fontes, 1996].

. Tagerbücher 1898-1918. Stuttgart: Verlag Gerd Hatje, 1988, nº 905 (p. 320-322).

KLEE, Felix. Paul Klee: His life and work in documents. Nova York: George Braziller, 1962.

KRAEPELIN, Emil. Dementia praecox and paraphrenia. Trad. R. M. Barclay. Huntington, Nova York: Robert E. Krieger, 1971. 
[Edição portuguesa: Obras de Kraepelin: A demência precoce. 20 Parte: Parafrenias. Climepsi Editores. Lisboa. 2005].

KRAUSS, Rosalind. The master's bedroom. Representations, $n^{\circ} 28,1989$.

KRIS, Ernst. Psychoanalytic explorations in art. Nova York: Schocken Books, 1964. [Edição brasileira: Psicanálise da arte. Trad. Marcelo Corção. São Paulo: Brasiliense, 1968].

LOMBROSO, Cesare. Genio e follia. Milão, 1864.

MACGREGOR, John. The discovery of the art of the insane. Princeton: Princeton University Press, 1989.

MAN, Paul de. Blindness and insight. Minneapolis: University of Minnesota Press, 1971.

[Edição portuguesa: O ponto de vista da cegueira. Trad. Miguel Tamen. Braga: Angelus Novus; Lisboa: Cotovia, 1999].

PANOFSKY, Erwin. Perspective as symbolic form (1924-25). Trad. Christopher Wood. Nova York: Zone Books, 1991.

[Edição portuguesa: A perspectiva como forma simbólica. Lisboa: Edições 70, 1993].

PIERCE, James S. Paul Klee and Baron Welz. Arts Magazine, Set. 1977.

POLLOCK, Griselda. Avant-garde gambits 1888-1893. Londres: Thames \& Hudson, 1992.

PRINZHORN, Hans. Artistry of the mentally ill. Trad. Eric von Brockdorff. Nova York: Springer Verlag, 1972.

SANTNER, Eric. My own private Germany: Daniel Paul Schreber's secret history of modernity. Princeton: Princeton University Press, 1996.

[Edição brasileira: A Alemanha de Schreber: Uma história secreta da modernidade. Rio de Janeiro: Jorge Zahar, 1997].

SASS, Louis A. Modernism and madness. Nova York: Basic Books, 1992.

SCHLEMMER, Oskar. The letters and diaries of Oskar Schlemmer. Org. Tut

Schlemmer. Middletown, Conn.: Wesleyan University Press, 1972.

SCHREYER, Lothar. Erinnerungen an Sturm und Bauhaus. Munique: Langen \& Müller, 1956.

TAUSK, Viktor. On the origin of the influencing machine. Psychoanalytic Quarterly, 1933, reimpresso. In: Zone, $\mathrm{n}^{\circ}$ 6, 1992.

WERCKMEISTER, O. K. Walter Benjamin, Paul Klee, and the angel of history, Oppositions, 1982. 


\section{Blinded insights Hal Foster}

The revaluation of the art of the mentally ill followed the reassessment of the arts of "primitives" and children in both time and logic. Long viewed as meaningless or symptomatic, the art of the mentally ill was due for rethinking by the late 1910s and early 1920s. Yet, as with these other arts, interested modernists saw this art only according to their own ends - as expressive of an essence of art, a purity of vision, or a defiance of convention - and for the most part it was none of these things. Rather, these three readings - I will call them "expressionist," "visionary," and "transgressive" respectively - bespeak modernist fantasies either of a simple origin of art or of an absolute alterity to culture, and they tend to obscure rather than to illuminate the art of the mentally ill.

The romantics had also viewed the art of the mentally ill as an epitome of creative genius, but they focused on verbal rather than visual productions. Thereafter the value of this art was downgraded dramatically, to a point in the late nineteenth century when it had become little more than a symptom of psychological "degeneration." As noted in chapter 2, the key figure in this discourse of degeneration was the Italian psychiatrist Cesare Lombroso, who, along with his Hungarian follower, Max Nordau, spread this ideological notion from psychiatric practice to cultural interpretation. Lombroso understood madness as a return to a primitive stage of development, and this account prepared the phobic association of the mentally ill, the primitive, and the child that continued into the twentieth century, where it vied with the idyllic association of the three as innocent visionaries that was a legacy of the romantics ${ }^{1}$. Already in Genius and Madness (1864), a study of 107 patients, half of whom drew or painted, Lombroso detected such degeneration in representations that he deemed "atavistic" and/or "absurd"2

The discourse of degeneration is not strong in psychoanalysis, but it did survive in residual form in the notion of "regression"; the diagnostic approach to the art

\footnotetext{
1 Today this particular trio of exotics might strike us as odd, but at the time they were seen as necessary guides in the modernist search for "primal beginnings in art" (Paul Klee). Straightaway, then, we face the old modernist paradox that artistic primacy and expressive immediacy were pursued through the mediation of representations as complex as psychotic images, tribal objects, and the drawings of children.

${ }^{2}$ See Cesare Lombroso, Genio e follia (Milan, 1864); translated into French in 1889, English in 1891, and German in 1894. On the historical reception of the art of the mentally ill, see especially John MacGregor, The Discovery of the Art of the Insane (Princeton: Princeton University Press, 1989).
} 
of the mentally ill also persisted. Like his French teacher Jean Martin Charcot, Freud continued the diagnostic approach through reversal, as it were, as he searched for signs of psychic disturbance in the art of sane masters like Leonardo and Michelangelo (his analyses of these artists date from 1910 and 1914 respectively). Only gradually was the diagnostic approach to the art of the mentally ill countered with accounts attuned to the intrinsic qualities of the work. Here, the two landmarks are L'art chez les fous (1907) by Marcel Réja, the pseudonym of the French psychiatrist Paul Meunier, who examined the art of the mentally ill for insight into the nature of artistic activity as such, and Bildnerei der Geistekranken (Artistry of the Mentally IIl, 1922) by the German art historian Hans Prinzhorn, who extended this inquiry into the fundaments of "configuration" (Gestaltung) in ways that influenced several modernists directly.

This last revaluation of the art of the mentally ill came in the midst of great debate about the definition of the psychoses. By 1898 the German psychiatrist Emil Kraepelin had presented his typology of "dementia praecox" that included paranoid, catatonic, and hebephrenic forms. By 1911 the Swiss psychoanalyst Eugen Bleuler had introduced his category of "schizophrenia," which he defined as the broken relation to self and world as manifest in a dissociation of thought, action, or affect - that is, as a disruption of subjectivity often marked by a disruption in representation (the Greek root of "schizophrenia" means "split mind"). Bleuler offered a compromise position between Kraepelin and Freud: like Kraepelin, he connected paranoia and schizophrenia, and, like Freud, he stressed a splitting (Spaltung) of the mind as key. Nevertheless, Freud offered his own term, "paraphrenia", as an alternative to "schizophrenia" and as a complement to "paranoia" (obviously "schizophrenia" prevailed). Although he sometimes found schizophrenia and paranoia combined, as in his celebrated case study of Judge: Schreber (1911), Freud treated them as symptomatically distinct: in his view, the schizophrenic is overwhelmed by hallucinations that only deepen his sense of catastrophe within and without, while the paranoid constructs delusions of personal grandeur to counter the internal crisis, and projections of world order to counter the external crisis ${ }^{3}$. This distinction between schizophrenia and paranoia is important to my own reading of the art

\footnotetext{
${ }^{3}$ Of course, the very distinction between internal and external is also at stake in paranoia. See Sigmund Freud, "Psychoanalytic Notes on an Autobiographical Account of a Case of Paranoia (Dementia Paranoides)," in Phillip Rieff, ed., Three Case Histories (New York: Collier Books, 1963); Emil Kraepelin, Dementia Praecox and Paraphrenia, trans. R. M. Barclay (Huntington, NY: Robert E. Krieger, 1971); and for Eugen Bleuler, Dementia Praecox, or the Group of Schizophrenias, trans. J. Zinken (New York: International Universities Press, 1950). In Anti-Oedipus, Deleuze and Guattari oppose schizophrenia and paranoia too, which they also relate to limits - crises - in the social order, but there is an anti-Freudian voluntarism in this great text, residual from the antipsychiatric movement of the 1960 s, that I do not share.
} 
of the mentally ill here, the modernist reception of which centers on the work of Prinzhorn.

\section{Configuration according to Hans Prinzhorn}

Prinzhorn had studied art history at the University of Vienna before he turned first to psychiatry and then to psychoanalysis. It was this unique training that led Karl Wilmanns, the director of the Heidelberg Psychiatric Clinic from 1916 to 1933, to appoint him in February 1919 to oversee its collection of the art of the mentally ill. Begun when Kraepelin had directed this clinic from 1890 to 1903, the collection was developed under Wilmanns and extended under Prinzhorn to some 4,500 works by some 435 patients from various institutions, mostly in Germany; seventy-five percent of the represented artists were diagnosed as schizophrenic in one way or another. (Although women outnumbered men in these institutions, they hardly did so in the: collection; only sixteen percent of the works were made by women [fig. 5.1].)

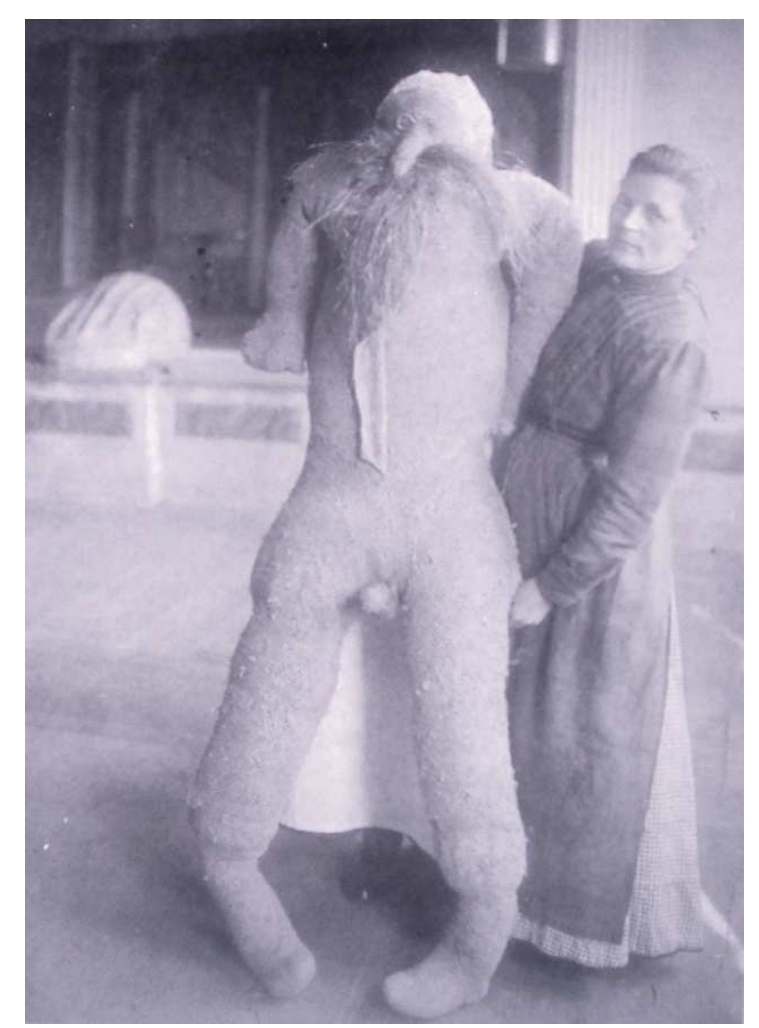

Hal Foster 1. Katharina Detzel com um boneco empalhado que ela mesma fez. Photo Manfred Zentsch.

Prinzhorn left the clinic abruptly in July 1921, even before the publication of the Artistry. Clearly he had great ambitions for the book, for he lectured widely 
thereafter, including a seminar at the Vienna Psychoanalytical Society presided over by Freud, as well as several talks in Germany attended by various modernists.

The Artistry includes a "theoretical part," ten case studies of "schizophrenic masters", and a summary of "results and problems"; with 187 reproductions, it is very selective of the overall collection ${ }^{4}$. Although several works show affinities with symbolism and expressionism, few of the patients were interested in art, though they were sometimes encouraged to draw for diagnostic or therapeutic reasons, which might render the results less spontaneous than Prinzhorn claims. In any case, the selection offered in the Artistry is too disparate in material, technique, and style to fit any one theory, and the theory that Prinzhorn does present is somewhat contradictory.

On the one hand, Prinzhorn does not want to be only diagnostic in his interpretation ("a purely psychiatric approach is insufficient" [AMI 240]), and he does not see the works as direct expressions of illness. Although he proposes six "drives" as dominant in psychotic representation, he regards them as active in all other art as well. Indeed, he argues that "the components of the configurative process" appear "unadulterated" in such work [AMI 269] $)^{5}$. On the other hand, Prinzhorn also does not seek to be only aesthetic in his interpretation, and he cautions against any simple equation of the "pictures" with art. Although he calls his ten favorites "masters," he uses the archaic term Bildnerei or "artistry" ("image-making" is more exact) rather than the usual Kunst or "art." At the same time, Prinzhorn does refer to Van Gogh, Rousseau, Ensor, Kokoschka, Nolde (whom he knew personally), Max Pechstein, Erich Heckel, and Alfred Kubin (the only significant artist of the period to see the collection in person), and he does stress "the particularly close relationship of a large number of our pictures to contemporary art," primarily expressionism (AMI 270). Of course, interested modernists also made connections of this sort, as did equally interested enemies of modernism. The 1937 Nazi exhibition "Degenerate 'Art'" attacked modernists such as Paul Klee and Max Ernst precisely through this association with the mentally ill, and it drew on images from the Prinzhorn collection to do so (ironically, this show also offered the greatest exposure of such art, modernist and mentally ill, in

\footnotetext{
${ }^{4}$ Hans Prinzhorn, Artistry of the Mentally ill, trans. Eric von Brockdorff (New York: Springer Verlag, 1972); hereafter abbreviated $A M I$.

5 For Prinzhorn this "configurative process" is universal, but many works in the Artistry are historically specific - with particular German script, personae (e.g. Wilhelm II), institutions, and so on.
} 
Germany to date $)^{6}$. In this way, a reversibility haunts the modernist revaluation of the art of the mentally ill, for if this art could be revealed as somehow modernist in affinity, the art of the modernists could also be branded as somehow pathological in tendency ${ }^{7}$.

Prinzhorn had studied with the art historian August Schmarsow, who was known for his ontological approach to art (for instance, he liked to define each discipline according to its essential vector: the horizontality of painting, the verticality of sculpture, the depth of architecture; and so on). Prinzhorn then wrote his dissertation under the psychologist Theodor Lipps, whose idea of "empathy" informed this entire generation of Germanic art historians (see chapter 3). In the Artistry, Prinzhorn was also guided by the formalist aesthetics of the art historian Conrad Fiedler, as well as the psychology of expression of the philosopher Ludwig Klages. In effect, he attempted to reconcile the autonomy of visual form stressed by Fiedler with the expressivity of the psyche stressed by $\mathrm{Klages}^{8}$. As his artistic allusions also suggest, Prinzhorn was intrigued by expressionism; despite his own caveats, he claimed for the art of the mentally ill a profound affinity with the "emotional attitude" of such art, with its "renunciation of the outside world" and its "turn inward upon the self" (AMI 271) 9

Taken together, these influences led Prinzhorn to his theory of six drives that he held to govern the art of the mentally ill, but also to inform all other art - drives toward expression, play, ornamental elaboration, patterned order, obsessive copying, and symbolic systems. Here too, however, he courted contradiction, for his drives toward expression and play imply a subject open to the world in a way that the other drives do not. On the contrary, compulsive ornamenting, ordering, copying, and system-building imply a subject in rigid, even paranoid defense against the world. Perhaps

\footnotetext{
6 As early as 1921, a Hamburg professor named Wilhelm Weygrandt used a condemnatory juxtaposition of insane and modernist art, a device extended by Paul Schultze-Naumburg in Kunst und Rasse in 1935 and then, of course, in Entartete "Kunst" in 1937. In 1933 the Nazis installed Carl Schneider as director of the Heidelberg clinic; it was he who provided materials for the 1937 exhibition. Schneider became scientific director of the Nazi extermination program of mental patients, and many of the patients in the Prinzhorn collection met this fate. See Bettina BrandClaussen, "The Collection of Works of Art in the Psychiatric Clinic, Heidelberg - from the Beginnings until 1945," in Brand-Claussen et al., eds., Beyond Reason: Art and Psychosis - Works from the Prinzhorn Collection (London: Hayward Gallery, 1996).

7 Already in the Artistry Prinzhorn sees the danger here:"Such comparisons ... are vulgar and sensational .... it is superficial and wrong to infer an equality of the underlying psychic conditions from external similarities" (AMI271).

8 This tension between Kantian and Hegelian imperatives - between, say, "configuration" and "drive" -was felt throughout the discipline of art history. Incidentally, Prinzhorn took his doctorate in 1908, the same year that a fellow Lipps student, Wilhelm Worringer, published his influential dissertation Abstraction and Empathy (see chapter 3).

9 On this point Brand-Claussen is severe but exact: "Prinzhorn's notion of unconscious creativity stands revealed as a case of Expressionist wishful thinking" (Beyond Reason, 12).
} 
Prinzhorn sensed this contradiction, for he was led to propose that the drives of expressive play were correctives to the drives of obsessive ordering (as we will see, his initial blindness here might point to an eventual insight into the opposed imperatives often at work in this art) ${ }^{10}$. Moreover, in the end he admitted this fundamental difference between the artist and the schizophrenic:

The loneliest artist still remains in contact with humanity, even if only through desire and longing, and the desire for this contact speaks to us out of all pictures by "normal" people. The schizophrenic, on the other hand, is detached from humanity, and by definition is neither willing nor able to reestablish contact with it. If he would he would be healed. We sense in our pictures the complete autistic isolation and the gruesome solipsism that far exceeds the limits of psychopathic alienation, and believe that in it we have found the essence of schizophrenic configuration. (AMI 266)

Even as Prinzhorn cautioned against an equation between image and psyche, he often assumed it (as he does in the above passage), and it is this lack of mediation that allowed him to claim, in the art of the mentally ill, the "essential features" of artistic configuration as such ( $A M I 11)^{11}$. His inculcation of formalist aesthetics, empathy theory, and expressive psychology (including the notions of expressive urges, intrinsic drives, and eidetic images) predisposed him to this sort of aesthetic essentialism. A similar equation between image and psyche also allowed modernists influenced by Prinzhorn - in particular Klee, Ernst, and Jean Dubuffet - to see "essential features" of art in the art of the mentally ill. All three knew the Artistry well, though not the Prinzhorn collection as such. Aware of the art of the mentally ill early in his career, Klee heard Prinzhorn lecture before his book appeared. As noted in chapter 4, Ernst also discovered this art independently, perhaps during his prewar studies at the University of Bonn. Younger than the others, Dubuffet encountered the Artistry in 1923, only a year after its publication, when he was not yet active as an artist. Although the art of the mentally ill is only one influence on these modernists, it affected their distinctive elaboration of stylistic devices and aesthetic models alike.

\footnotetext{
10 The notion of an insight that stems from a blindness is drawn, of course, from Paul de Man, Blindness and Insight (Minneapolis: University of Minnesota Press, 1971).

${ }^{11}$ As we have seen, Prinzhorn warns against this equation between image and psyche at the end of the Artistry (see note 7). At the outset, however, he claims it: "we therefore posit the realm of expressive facts, in which psychical elements appear directly and are apprehended equally directly, without the juxtaposition of any intellectual apparatus" (AMI 13). At other moments he is less sure: "what and how much of the psyche expresses itself in such an autocratic world of form?" (AMI 72). This uncertainty appears irreducible in many psychoanalytic accounts of art - including, perhaps, my own here.
} 


\section{Vision according to Paul Klee}

Klee begins his "Creative Credo" (1920) with these well-known words: "Art does not reproduce the visible; rather, it makes visible."12 This text comes at the height of his engagement with the art of the mentally ill, and in this makingvisible he credits "the child, the madman and the savage" with special power, for they "can still, or again, look into" the "in-between world" that "exists between the worlds our senses perceive." ${ }^{13}$ Clearly this power is visionary for Klee - it concerns "the realm of the unborn and the dead" - and as early as 1912 , in a review of the Blaue Reiter expressionists (with whom he would soon be associated), he deems it necessary to any modernist "reformation" of art. ${ }^{14}$ Some Klee experts see the influence of the art of the mentally ill on his work as early as 1904-05. Others speculate that he came across the now-celebrated art of Adolf Wölffli, a patient in a institution near Bern, while Klee still lived there; but the Wölffli images were not published until 1921, and Klee makes no mention of such an encounter at the time. We do know from Oskar Schlemmer, his colleague at the Bauhaus, that Klee knew of the Prinzhorn collection before Prinzhorn lectured near Stuttgart in July $1920 .{ }^{15}$ Certainly his work shows the strongest effects of the art of the mentally ill in this period, with the heteroglossic markings and obsessive orderings that Prinzhorn ascribed to such representation. We also know from another Bauhaus colleague, Lothar Schreyer, that Klee identified deeply with the Artistry on its publication in 1922 (he kept. a copy of the book in his studio), and did so in the context of an institution, the Bauhaus, soon to be renowned for its rationalism. "You know this excellent piece of work by Prinzhorn, don't you?," Schreyer has Klee remark as he flips through the Artistry: "This picture is a fine Klee. So is this, and this one, too. Look at these religious paintings. There's a depth and power of expression that I never achieve in religious subjects. Really sublime art. Direct spiritual vision." ${ }^{16}$ There is much to unpack in this rhetoric of celebration that moves between hubris ("a fine Klee") and humility ("I never achieve ..."), a rhetoric that is also characteristic of the modernist rapport with primitive art. Most important is the casting of the art of the mentally ill almost in the register of the sublime, as a

\footnotetext{
12 Paul Klee, The Inward Vision, trans. Norbert Guterman (New York: Harry Abrams, 1959), 5.

${ }^{13}$ Felix Klee, Paul Klee: His Life and Work in Documents (New York: George Braziller, 1962), 184. The ambiguity between "still" and "again" is telling of the difficulty of placing this vision temporally.

${ }^{14}$ Ibid.; Paul Klee, Tagerbücher 1898-1918 (Stuttgart: Verlag Gerd Hatje, 1988), no. 905, 320-322.

15 Oskar Schlemmer, The Letters and Diaries of Oskar Schlemmer, ed. Tut Schlemmer (Middletown, Conn.: Wesleyan University Press, 1972), 83. Klee might also have seen a selection of the collection in January 1921 at Zinglers Kabinett in Frankfurt, where he would show a year later.

${ }^{16}$ Felix Klee, Paul Klee, 183; quoted from Lothar Schreyer, Erinnerungen an Sturm und Bauhaus (Munich: Langen \& Müller, 1956). How much we can trust this memory of a conversation is open to dispute.
} 
matter of "direct spiritual vision." Yet Klee is accurate here in his self-appraisal: when he simply illustrates "religious subjects," as in his various "angels" and "demons," "ghosts" and "seers," he does not achieve the "power of expression" often found in the Artistry; but when he evokes "direct spiritual vision," he does sometimes approach this power, as in his celebrated watercolor known as Angelus Novus (1920; fig. 5.2).

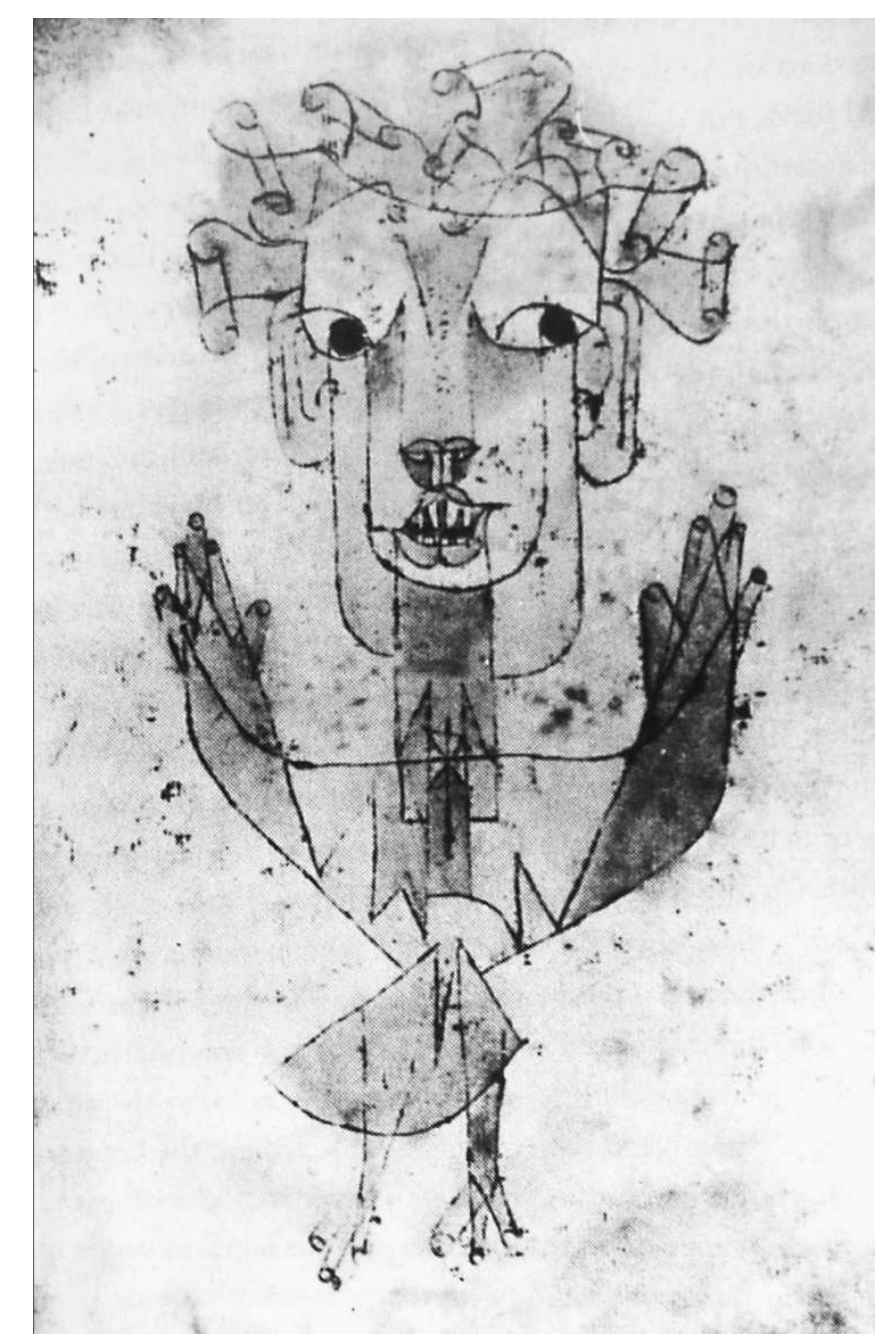

Hal Foster 2. Paul Klee, Angelus Novus, 1920

With its quasi-schizophrenic patterning, its strange elaboration of wreaths as hair and scrolls as fingers, its immense head with averted gaze and ambiguous mouth, this figure who presses toward us does seem to "make visible," as if it did have the power to make us behold. At least the figure appeared so to its onetime owner Walter Benjamin, for whom it was an allegorical angel of historyas-catastrophe that "preferred to free men by taking from them." ${ }^{17}$ But what

17 Walter Benjamin, "Karl Kraus" (1931), in On Reflections, trans. Edmund Jephcott (New York: Harcourt Brace Jovanovich, 1978), 273. His allegorical account appears in "Theses on the 
exactly is this "direct spiritual vision" that Klee invokes? Might it run the risk of a mental state that, far from innocent, is hallucinatory, even horrific - a vision that comes to possess its subject with a sudden annunciation, as glimpsed in this angel by both Klee and Benjamin? This state - too direct, too sublime - is evoked in some representations in the Artistry that are akin to Angelus Novus, such as Monstrance Figure by Johann Knopf (fig. 5.3),

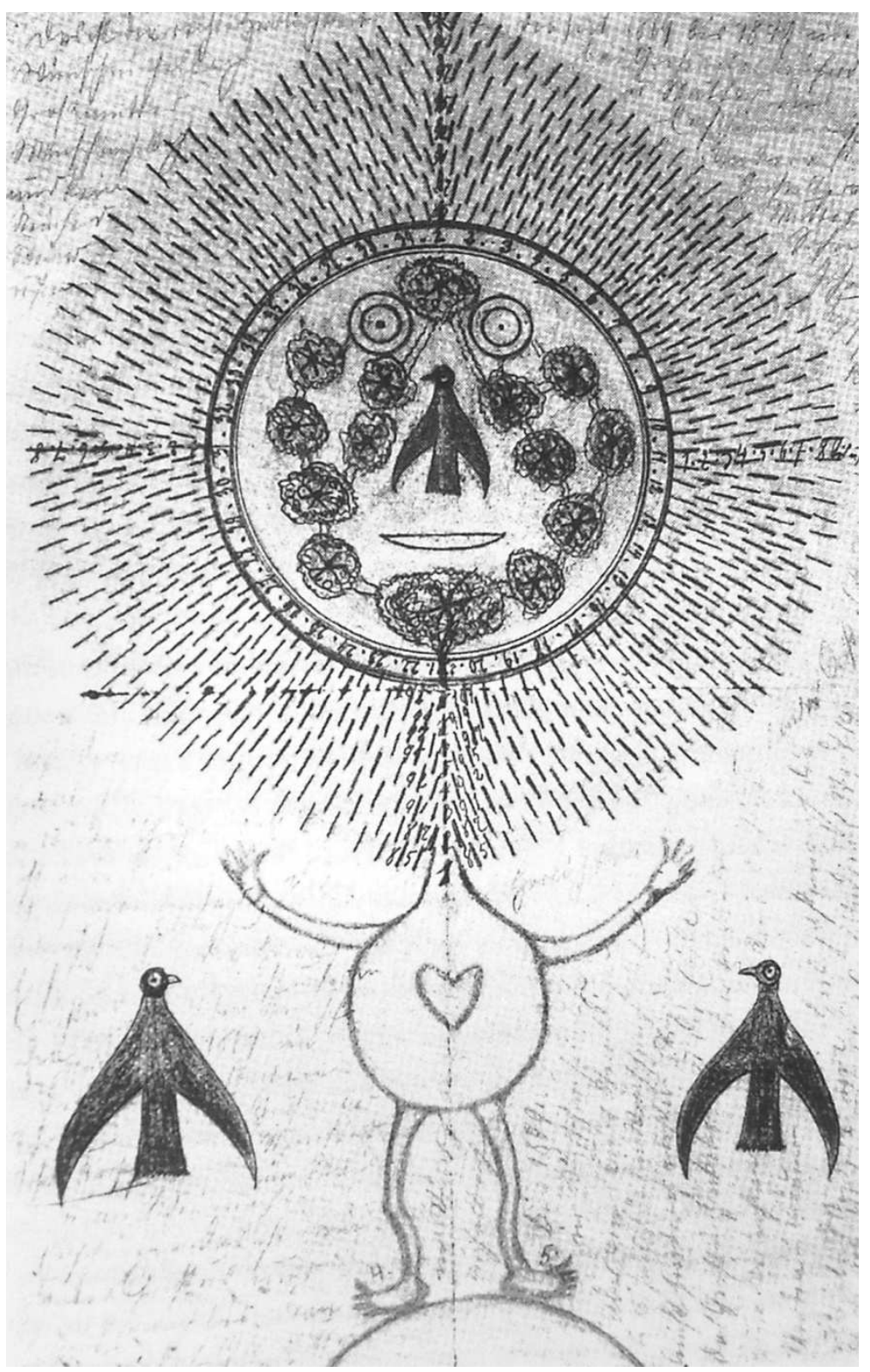

Hal Foster 3. Johan Knopf (Knüpfer), Imagem de custódia. Foto Manfred Zentsch

one of the ten schizophrenic masters whose work Klee would have known

Philosophy of History" (1940), in Illuminations, trans. Harry Zohn (New York: Schocken Books, 1969), 257-258. There are many accounts of this angel, among them O. K. Werckmeister, "Walter Benjamin, Paul Klee, and the Angel of History," Oppositions (Fall 1982): "He first saw it as an allegory of metaphysical experience, then of opposition, and finally of survival in the midst of a historical catastrophe where texts and images were no longer of any use" (115). 
(Prinzhorn gives him the pseudonym "Knüpfer," and his diagnosis is listed as "paranoid form of dementia praecox"). ${ }^{18} \mathrm{~A}$ "monstrance" is indeed a "making visible": in the Roman Catholic Church, it is an open or transparent vessel in which the Host is displayed for veneration. But this "monstrance figure" is also monstrous - an image that, however obscure it may seem to us, appears too open, too transparent, to the "religious vision" of its paranoid maker, which shines through with some of the untamed intensity of the Lacanian real (see chapter 7).

Klee catches a glimmer of this intensity in several of his works of the time, such as Man is the Mouth of the Lord (1918), the title of which alone suggests a paranoid vision, and The Saint of the Inner Light (1920), a figure whose "inner light" is evoked through a blinded visage. The ironic play with pictographic systems, which is active in other Klees but foreign to the art of the mentally ill, is also absent here. ("Irony is by its very nature totally excluded," Prinzhorn writes, "because it always refers to commonly accepted conventions, the very thing that the schizophrenic has excluded from his thought" [AMI 245].) More importantly, the innocent idea of the art of the mentally ill cherished by Klee is burned away in these works. Just as Prinzhorn wanted to see this art as expressive, only to discover that it is often radically inexpressive, that is, expressive only of schizophrenic withdrawal, so Klee wanted to see an innocence of vision in this art, only to discover an intensity that sometimes borders on paranoid terror - an Angelus Novus of catastrophe. Here, as with Prinzhorn, the initial blindness of his model of the art of the mentally ill produces an eventual insight for us, whereby the artistic vision projected onto these patients is revealed as the psychological terror that it often is.

\section{Transgression according to Jean Dubuffet}

The horrific dimension of this hallucinatory vision does not make it less immediate for Klee; on the contrary, it makes it more so, and it is this heightened immediacy that allows him to seek the modernist grail of pure vision in the art of the mentally ill. Another kind of immediacy is projected by Dubuffet, who develops a transgressive model of modernist art based in part

\footnotetext{
18 This particular work is not in the Artistry, but related images are included. For one image Knüpfer provided this gloss (as extrapolated by Prinzhorn): "The large circle with the wreath of rays is intended to be a monstrance, as we know from other drawings, to which the tiny body is a handle. At the same time the circle is the face of a clock, the sun, and the face of the little man according to the inscription represents the lamb of God, i.e., Christ, with whom Knüpfer usually identifies himself, so that we have to assume at least five or six meanings" (AMI 174). As readers of Judge Schreber know, rays often figure paranoid influence, as do the birds in the image that speak to him. Also quintessentially paranoid is the identification with Christ, more on which below.
} 
on this art. Again, he encountered the Artistry early in his formation; it was given to him in 1923, at which time he studied other publications of visionary art as well. Yet his own work in this vein did not develop until the early 1940s, and then his first inspiration was the drawing of children: his figures of this time recall the stick-people of such art, presented frontally or in profile, or (paradoxically) both at once. In the interim, however, Dubuffet corresponded with patients and doctors in various asylums, and this contact culminated in 1945 in a three-week tour of psychiatric hospitals in Switzerland, (where he encountered the work of Wölffli, among others). This experience prompted him to two signal acts: to destroy most of his art prior to 1942 , and to begin a collection of "irregular" art (including primitive, naïve or folk, and mentally ill productions) under the rubric of art brut-brut as in "raw," "crude," "uncivilized." In 1948, along with André Breton, Jean Paulhan, Charles Ratton, Henri-Pierre Roché, and Michel Tapié, Dubuffet formed the Compagnie de l'Art Brut, and in 1949 he presented the first exhibition of its holdings (which totaled roughly 2000 works by sixty-three artists) at the Galerie René Drouin in Paris. The show was accompanied by his important text on the subject, "L'Art Brut préferé aux arts culturels," in which Dubuffet first presents the brut artist as a radical version of the romantic genius free of all convention:

We understand by this term works produced by persons unscathed by artistic culture, where mimicry plays little or no part (contrary to the activities of intellectuals). These artists derive everything - subjects, choice of materials, means of transposition, rhythms, styles of writing, etc. - from their own depths, and not from the conceptions of classical or fashionable art. We are witness here to a completely pure artistic operation, raw, brute, and entirely reinvented in all of its phases solely by means of the artist's own impulses. ${ }^{19}$

In a subsequent essay Dubuffet transforms this category of brut into a criterion of all modernist art: "a work of art is of no interest to me unless it is an absolutely immediate and direct projection of the depths of the individual."20 This idealization of the art of the mentally ill is similar to those of Prinzhorn and Klee: it, too, assumes the notions of an essential "expression" and a direct "vision." Yet for Dubuffet, the nature of this art is less formal (as it is for

\footnotetext{
19 Jean Dubuffet, Prospectus et tous écrits suivants (Paris: Gallimard, 1967); "Art Brut in Preference to the Cultural Arts" (1949), trans. Paul Foss and Allen S. Weiss, Art \& Text 27 (December-February 1988), 33.

${ }^{20}$ Dubuffet, "Honneurs aux valeurs sauvages, Prospectus, vol. 1, 213.
} 
Prinzhorn) or spiritual (as it is for Klee) than transgressive: "I believe very much in the values of savagery; I mean: instinct, passion, mood, violence, madness." 21 So too, as with the others, his idealization is a kind of primitivism: Dubuffet also believes in a return to "depths." Yet, unlike the others, he defines these depths not as an origin of art, which one can reclaim redemptively, so much as an outside to art, which breaks into its cultural spaces disruptively. Nevertheless, like other primitivists before him, Dubuffet targets academic art first and last; in this regard his outsider logic is also an insider move, one that, intentionally or not, works to win him a place within avant-gardist lineages. ${ }^{22}$ Moreover, even as he seeks to undo the opposition between normal and abnormal ("this distinction between normal and abnormal seems quite untenable: who, after all, is normal?"), Dubuffet affirms an opposition between brut and culturel, between civilized and noncivilized. ${ }^{23}$ In this way his transgression might come to support the very law that it purports to contest. Indeed, as Michel Foucault remarked of Georges Bataille, such transgression might serve to reimagine the "sacred" basis of this law that modern secularization has eroded. "Profanation in a world which no longer recognizes any positive meaning in the sacred," Foucault writes. "Is this not more or less what we may call transgression ... a way of recomposing its empty form, its absence, through which it becomes all the more scintillating?"24

Yet right here, like Prinzhorn and Klee before him, Dubuffet might point to an insight into the art of the mentally ill in the very blindness of his anticultural conception of it - two insights, in fact. The first one involves the subjective order: far from "unscathed," the psychotic is scarred by trauma, and this psychic disturbance might be registered in the bodily distortions that pervade the art of the mentally ill. For in this art, significant parts of the body, especially eyes and mouths, are often grossly enlarged, and sometimes disruptively plunged into other parts of the body, so that eyes become breasts, say, or mouths double as vaginas (fig. 5.4). ${ }^{25}$

\footnotetext{
${ }^{21}$ Dubuffet, "Positions anticulturelles," in Prospectus, vol. 1, 94; Jean Dubuffet (New York, 1960), 2.

22 By his own later admission: "I quite agree that no art form exists that is not in some way dependent on cultural givens" (L'Homme du commun à l'ouvrage [Paris: Gallimard, 1973], 439). On such gambits see Griselda Pollock, Avant-Garde Gambits 1888-1893 (London: Thames \& Hudson, 1992).

${ }^{23}$ Dubuffet, "Art Brut in Preference," 33.

24 Michel Foucault, "A Preface to Transgression," in Language, Counter-Memory, Practice, ed. Donald F. Bouchard (Ithaca: Cornell University Press, 1977), 30. The essay first appeared in "Hommage à Georges Bataille," Critique 195-196 (1963).

${ }^{25}$ Both in horror and in delight, the body is sometimes transformed into a kind of sex machine, often with sacramental or sacrilegious overtones - and sometimes both at once.
} 


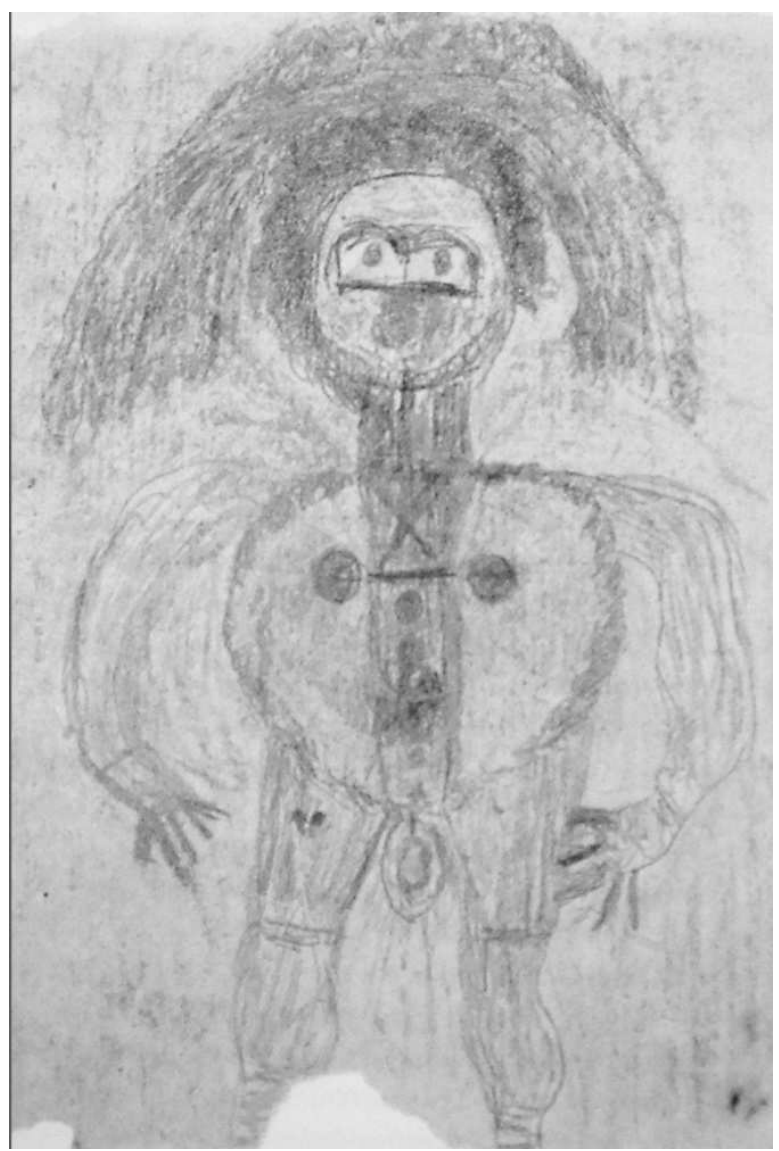

Hal Foster 4. Herman Beehle (Beil), Sem título

Klee also experimented with such derangements of the body image, but Dubuffet did so more extremely, and occasionally in ways that correspond to works in the Artistry (fig. 5.5). 


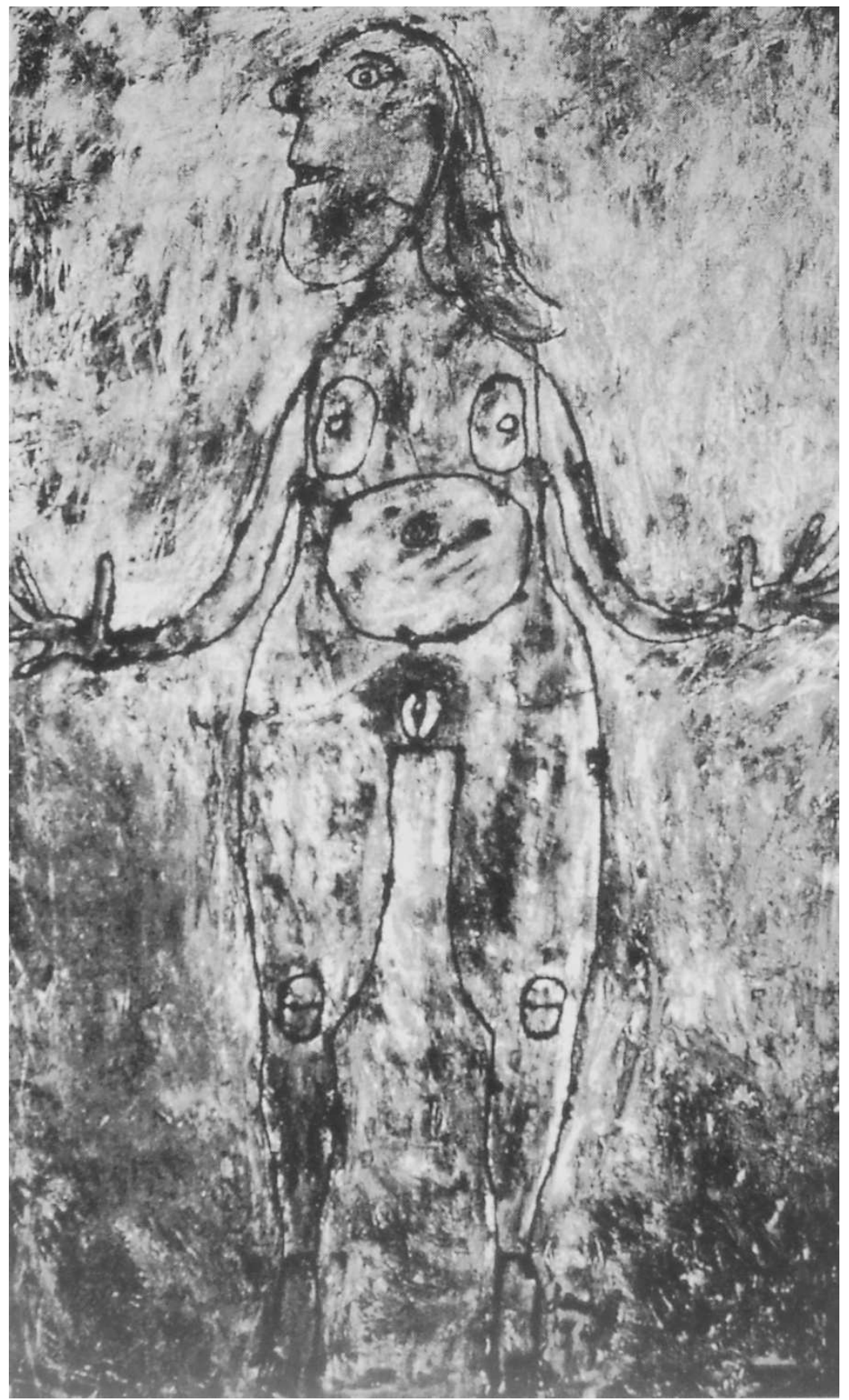

Hal Foster 5. Jean Dubuffet, Grand nu charbonneux, 1944.

His affinity with Hermann Beehle, known as Beil; is uncannily (or is it consciously?) close: they share a frontal presentation of schematic nudes sometimes rearranged, often splayed, and always embedded in the support (which for Beil tended to be toilet paper). Through such devices in his own work Dubuffet evokes a schizophrenic sense of literal self-dislocation, which is far from the "completely pure artistic operation" that he otherwise wished to project onto the art of the mentally ill.

If his first insight concerns subjectivity, his second involves the status of the 
symbolic order as imagined in the art of the mentally ill. The bodily derangements in this art imply a world that is more desperate, even debilitated, than empowered, and despite his assertions to the contrary, this is sometimes true in Dubuffet as well. In this way both bodies of work might point to a different kind of transgression, one conceived along the lines less of the avantgardist logic of Dubuffet than of the immanent logic of Foucault on Bataille. In other words, rather than attack artistic convention and symbolic order, the art of the mentally ill seems concerned to find such aesthetic laws again -perhaps to found a symbolic order again; at the very least (as Foucault remarks), to "recompose its empty form, its absence." For, to their horror, this is what these artists often seem to see: not a symbolic order that is too stable, that they wish to contest as such (again as posited by avant-gardist logic), but, rather, a symbolic order that is not stable at all, that is in crisis or corruption. Far from anticivilizational heroes, as Dubuffet wanted to imagine them ("insanity represents a refusal to adopt a view of reality that is imposed by custom"), these artists are desperate to construct a surrogate civilization of their own, a stopgap symbolic order in default of the official one that, like the Angelus Novus of Klee and Benjamin, they perceive to be in ruins. ${ }^{26}$ This hypothesis suggests a further speculation: that the schizophrenic and paranoid visions recorded in the Prinzhorn collection might be symptomatic of a crisis in the symbolic order specific to the capitalist modernity of the time; more, that this crisis prepared the explosion of psychosis in this period (of which the Prinzhorn collection is but one archive); and, finally, that some modernists found in the art of the mentally ill a perspective on this crisis. ${ }^{27}$

Thus far I have sketched three creative misreadings of the art of the mentally

${ }^{26}$ Dubuffet as quoted by MacGregor in The Discovery of the Art of the Insane, 303. For a graphic account of this apprehension of crisis in the symbolic order, see chapter 7 below.

27 This speculation was first proposed in chapter 4. My line of thought here is indebted to Eric Santner's brilliant text My Own Private Germany: Daniel Paul Schreber's Secret History of Modernity (Princeton: Princeton University Press, 1996). "The social and political stability of a society as well as the psychological 'health' of its members," Santner writes, "would appear to be correlated to the efficacy of these symbolic operations - to what we might call their performative magic - whereby individuals "become who they are," assume the social essence assigned to them by way of names, titles, degrees, posts, honors, and the like. We cross the threshold of modernity when the attenuation of these performatively effectuated social bonds becomes chronic, when they are no longer capable of seizing the subject in his or her self-understanding. The surprise offered by the analysis of paranoia... is that an "investiture crisis" has the potential to generate not only feelings of extreme alienation, anomie, and profound emptiness, anxieties associated with absence; one of the central theoretical lessons of the Schreber case is precisely that a generalized attenuation of symbolic power and authority can be experienced as the collapse of social space and the rites of institution into the more intimate core of one's being. The feelings generated thereby are, as we shall see, anxieties not of absence and loss but of overproximity, loss of distance to some obscene and malevolent presence that appears to have a direct hold on one's inner parts" (xii). In this regard, the art of the mentally ill does possess an immediacy, but an immediacy less to the symbolic (to an artistic essence) than to the real (to a primal condition that the symbolic screens from us and for us). Perhaps one can view this art diagnostically after all - but in relation to a sick symbolic order 
ill: the Prinzhorn model of expression, the Klee model of vision, and the Dubuffet model of transgression. All three are modernist projections that use the art of the mentally ill to propose a metaphysical essence of art. Although each model locates the artist differently, they all presuppose an ego that is intact enough - indeed, self-present enough - to be expressive, visionary, or transgressive in the first place. Even more oddly, they imagine this ego in radical discontent with artistic convention and symbolic order alike, rather than in "autistic isolation" from both. ${ }^{28}$ In this way they project a symbolic order against which this radical discontent is posed - one that is stable, solid, set. And none of this projection seems true of the art of the mentally ill; instead, this projection conforms to avant-gardist ideologies of rupture, immediacy, purity, and so on. Far from self-present, the psychotic artist is profoundly dislocated, often literally lost in space. And far from avant-gardist in its revolt against artistic convention and symbolic order, psychotic representation attests to a frantic desire to reinstate convention, to reinvent order, which the psychotic feels to be broken, and so in desperate need of repair or replacement. In short, the obsessive elaborations of this art are not made to break the symbolic order; on the contrary, they are made in its apparent breach. And here, perhaps, is a further lesson for us all: the seeming intractability of the symbolic order might lie less in any grounded fixity that it possesses (it is we semi-paranoics who project this fixity, at least in part) than in the fragile arbitrariness that it works to conceal at all costs - and which the mentally ill glimpse at their cost. This has significant implications for a rethinking of transgression as a primary objective of avant-garde art.

\section{Hallucination according to Max Ernst}

Ernst had few illusions about the innocence of the art of the mentally ill expressive, visionary, transgressive, or otherwise. On the contrary, he sought to exploit its disturbances in order "to escape the principle of identity." ${ }^{29}$ Again, Ernst encountered this art almost as early as Klee, perhaps during his prewar studies in psychology at the University of Bonn, where he read Kraepelin as well as Freud (at some point, too, he must have seen the Schreber case study, for

\footnotetext{
${ }^{28}$ As we have seen, Prinzhorn oscillates between these readings. According to Brand-Claussen: "The whole avant-garde concept of willfully violating pictorial convention - a practice that emerged unscathed from any amount of hostile comparisons with the art of the mentally ill - finds its ultimate expression in Prinzhorn's model, according to which the autistic, mad artist makes visible, in the 'unio mystica with the whole world', what it is that marks out the genuine artist" (Beyond Reason, 14). ${ }_{29}$ Max Ernst, Beyond Painting (New York: Wittenborn \& Schultz, 1948), 13; hereafter abbreviated $B P$. Beyond Painting consists of several fragments, versions of which were first published in surrealist journals from the late 1920s through the middle 1930s. The phrase "to escape the principle of identity" is a quotation from a review by Breton of a 1921 show of early Ernst collages (BP 177).
} 
he uses Freudian tropes of paranoia in Beyond Painting, his extraordinary arttreatise-cum-self-analysis). As noted in chapter 4, Ernst claims that he visited a collection of art of the mentally ill at an asylum near Bonn while a student, and that he once planned a book on the subject. "They profoundly moved the young man", he writes of such art works in his "Biographical Notes." "Only later, however, was he to discover certain 'procedures' that helped him penetrate into this 'no-man's-land.'"30 As much as Ernst discovered these procedures "beyond painting" - his own versions of collage called frottage and grattage - he also extrapolated them from the art of the mentally ill.

As we saw in chapter 4, his first Dadaist collages of mechanistic figures, made in Cologne before the publication of the Artistry, allude to the psychological damage produced by World War I. Such images as Self-Constructed Little Machine (1919; fig. 4.2) resemble a particular kind of schizophrenic representation, a genre of machinic structures that seem intended as ego-supports but only serve to debilitate the ego all the more (there are several dysfunctional machines in the Prinzhorn collection; see fig. 4.3). In such alienated portraits, Ernst evokes a regression to disordered drives and deathly functions, a regression that resonates with the reactionary events of the time; in this way he seems to adapt the art of the mentally ill into an indirect critique of the symbolic order of his age.

His Dadaist work impressed young surrealists-to-be when it was first shown in Paris in May 1921, but André Breton and Louis Aragon were struck less by his collages of disjunctive figures than by his "overpaintings" of found illustrations (figs. 5.6, 4.15, 4.16, pls. 7, 8). These weird palimpsests of painted pages from teaching-aid catalogues "introduced an entirely original scheme of visual structure," Breton later remarked; "at the same time [they] corresponded exactly to the intentions of Lautréamont and Rimbaud in poetry," the designated precedents of surrealism. ${ }^{31}$ In effect, the overpaintings demonstrated how visual art could advance the surrealist poetics of "the coupling of two realities, irreconcilable in appearance, upon a plane which apparently does not suit them;" as Ernst defines collage in Beyond Painting, essentially in a paraphrase of Lautréamont, Pierre Reverdy, and others ( $B P$ 13). Crucial here is the connection that Ernst draws between disruptions in

\footnotetext{
${ }^{30}$ Max Ernst, "Notes pour une biographie," in Écritures (Paris: Le Point du Jour, 1970), 20.

${ }^{31}$ André Breton, "Artistic Genesis and Perspective of Surrealism" (1941), in Surrealism and Painting, trans. Simon Watson Taylor (London: Macdonald, 1972), 64. Of course, the allusion to Lautréamont is to his "chance encounter of a sewing machine and an umbrella on a dissecting table" that surrealism adopted as its motto, and the allusion to Rimbaud is to his "alchimie du verbe" in $A$ Season in Hell, which Ernst terms "the miracle of total transfiguration" in Beyond Painting.
} 
image and in subjectivity, a connection supported by the example of the art of the mentally ill. This art emerges, then, as a necessary point of mediation between Dadaist and surrealist aesthetics, one that often disappears in accounts of this passage. When Ernst moved to Paris in 1912, he brought the Artistry as a gift for Paul Eluard, who in the same year collaborated with Breton on Immaculate Conception, a poetic simulation of madness that is an inaugural text of surrealist writing.

Ernst connects disruptions in image and in subjectivity explicitly in Beyond Painting. In "Some Data on the Youth of M.E.," he recounts his earliest memories in a way that correlates symbolic crises with psychic disturbances. In one memory his little sister dies on the same night as his pet bird, a coincidence to which he ascribes his later "confounding of the images of human beings with birds and other creatures" (BP 26). More important, however, is his "vision of half-sleep" (dated "from 5 to 7 years") that opens Beyond Painting: here, little Max watches his roguish father, a Sunday painter, make "joyously obscene" marks on a panel (BP 3 ). This is a first encounter with painting cast in terms of a primal scene, which Freud defines as a traumatic fantasy of parental intercourse through which a child teases out the riddle of origins (see chapter 1 ). ${ }^{32}$ Ernst evokes the trope of the primal scene in the origin stories of all his procedures "beyond painting" - a repetition that again underscores his desire to open up aesthetic order to psychic disruption. Just as Freud describes his psychologically foundational scenes in visual terms, so Ernst seems to describe his pictorially originary scenes in psychoanalytic terms.

More is involved here than a desublimatory device, however, for Ernst develops this notion of traumatic fantasy into a theory of aesthetic practice. "It is as a spectator that the author assists... at the birth of his work," he argues in Beyond Painting. "The role of the painter is to ... project that which sees itself in him" (BP 8; original emphasis). ${ }^{33}$ Apparently with the primal scene again in mind, Ernst positions the artist as both inside and outside the scene of his art, as both active creator of his fantasy and passive voyeur of its images. The visual fascinations and sexual confusions of the primal scene inform not only his definition of collage ("the coupling of two realities irreconcilable in appearance") but also his sense of its purpose (to disturb "the principle of identity"). And he

\footnotetext{
${ }^{32}$ For more on the primal scene in Ernst, see my Compulsive Beauty (Cambridge, Mass.: MIT Press, 1993), from which a few paragraphs here are adapted.

33 Compare Prinzhorn on one of his masters: "He composes completely passively, almost as a spectator" (AMI 143). Here again there might be echoes of the passivity of Schreber.
} 
puts this model into practice as early as The Master's Bedroom (1920; fig. 5.6, pl. $8)$,

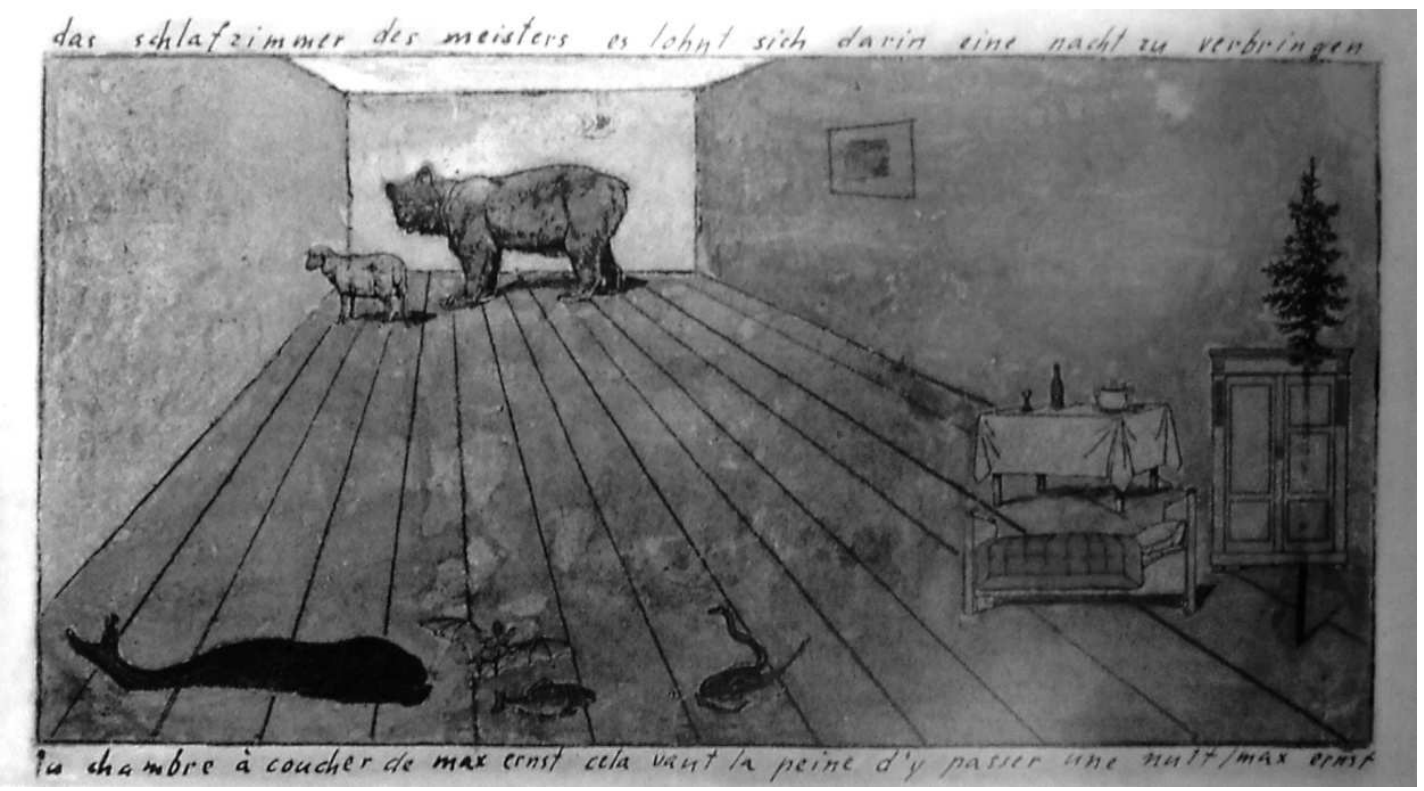

Hal Foster 6. Max Ernst, O quarto do mestre, 1920

a celebrated overpainting of a catalogue chart of fifty objects used for elementary instruction in perception, speech, and writing (note the brilliance of this particular subversion of rationalist training). All but ten of the original items are painted over (table, bed, cabinet, tree, whale, bat, fish, snake, sheep, bear); wildly out of scale, they are set in a bizarre bedroom that Ernst sketches in with only enough lines and tints to evoke a schizophrenic theater mundi. Strange occupants and skewed space alike seem to gaze back at the artistviewer, as if a traumatic fantasy, long repressed, had suddenly returned to threaten its master, a hallucination that might "unmaster" him altogether. Although the title alone suggests a primal scene, it is in the formal disconnections of the image - its play with mad juxtaposition, contradictory scale, and anxious perspective - that traumatic fantasy is evoked and paranoid affect produced. These are the "procedures" that helped Ernst penetrate the "no-man's-land" of psychotic representation, and thereby to pass from the more social residues evident in Dadaist collage to the more psychic traces at work in surrealist images.

As one model of the surrealist image, the surrealists liked to cite the exemplum used by Leonardo to describe how artistic genius can discern, in a mere stain on a wall, an entire landscape, battle scene, or other such invention. ${ }^{34}$ Often,

\footnotetext{
${ }^{34}$ Ernst alludes to it in Beyond Painting (BP 7), as does André Breton in L'Amour fou; so too, for that matter, does Prinzhorn in the Artistry (AMI 18-19).
} 
however, this canonical allusion seems like a bid for artistic respectability; the more insistent model of the surrealist image, as Ernst states in Beyond Painting, is "the simple hallucination" (BP 12). "I was surprised," he writes in one version of his primal scene of art, "by the sudden intensification of my visionary capacities and by the hallucinatory succession of contradictory images superimposed, one upon the other, with the persistence and rapidity characteristic of amorous memories" (BP 14). Although the "mechanism" of his procedures remains the "chance meeting" of images, the "technique" is not as materially blatant as in most Dadaist collages (BP 13). As we saw in chapter 4, Ernst tended to obscure his means of production:"ce n'est pas la colle qui fait le collage," he remarks in Beyond Painting (BP 13). That is, he tended to burn away the material support so that the resultant image might appear as immaculate - indeed, as hallucinatory as a psychic vision. "The drawings thus obtained," Ernst writes of his frottages, "lost more and more... the character of the material interrogated... and took on the aspect of... the first cause-of the obsession, or produced a simulacrum of that cause" ( $B P$ 8). This burning away of the material support replicates the oneiric intensity of the psychic vision - of the dream, the screen memory, or the primal scene (as noted in chapter 1, the dream of the Wolf Man - another Freud case study that Ernst must have known - is all three at once). As in these psychic visions, so in the Ernst collages: singular intensity is produced through a multiple layering of visual scenes that appear as "psychic readymades." 35 With images in superimposition that sometimes seep through one another, the medium of overpainting is well suited to evoke this field of psychic readymades. Indeed, the overpainting suggests a visual correlative of the very "scenography" of the psyche: the juxtaposition of incongruous images as in a dream, the return of the familiar estranged through repression as in the uncanny, the conflation of two events distant in time as in trauma. And, again, this model of art as hallucinatory vision appears to be underwritten by the art of the mentally ill. ${ }^{36}$

\footnotetext{
35 See Rosalind Krauss, "The Master's Bedroom," Representations 28 (Fall 1989). "What is projected here is a visual field that is not a latency, an ever renewed upsurge of the pure potentiality of the external, but instead a field that is already filled, already - to say the word - readymade" (65). On the staging of the image in a way that seems to burn away its support, see Victor Burgin, "Diderot, Barthes, Vertigo," in The End of Art Theory (Atlantic Highlands, NJ: Humanities Press International, 1986). As we saw in chapter 1, the apparent burning away of the support produces an oeneric intensity (as in the Wolf Man), yet the image remains a palimpsest, a screen made up of multiple screens. In a sense, if late modernist abstraction suggests a "strictly optical" space (according to Clement Greenberg), the overpaintings suggest a "strictly psychical" space.

${ }^{36}$ Compare the transformational illogic of the Prinzhorn master, August Natterer, discussed in chapter 7. For Krauss, the closest analogue of the overpaintings is the screen memory, "an apparatus by means of which vision is retrojected, projected after the fact onto the fully saturated ground of the readymade" ("The Master's Bedroom," 69).
} 
In his early Dadaist collages, then, Ernst evokes a damaged subject in the manner of some schizophrenic representations, in particular those of machinic structures devised as ego-supports. Soon thereafter he develops a surrealist aesthetic in the manner of some paranoid representations, in particular those governed by a "hallucinatory succession of contradictory images." In this way Ernst not only elaborates the art of the mentally ill stylistically; he seems to understand it almost diagnostically, and to turn the symptomatology of its representations to critical purposes. ${ }^{37}$ This understanding makes his use of the art of the mentally ill different from the avant-gardist uses represented by Klee and Dubuffet. Unlike them, Ernst does not position such images as a redemptive origin of art or as a radical outside to civilization; again, that is to project a symbolic order that is intact, even solid. Rather, he points to the more radical insight that the symbolic order is somehow already cracked, and that this crack might not only precipitate a crisis in the subject but also prepare a new kind of critical art, one that rethinks both the site and the stake of transgression.

\section{A patient is God but sweeps the floor willingly}

As we have seen, both Klee and Dubuffet often derange the image of the body, as if in keeping with a schizophrenic apprehension of ego-damage or selfdislocation, and, like Ernst, they sometimes figure the body as a dysfunctional mechanism as well. ${ }^{38}$ These distortions of the body image are also pronounced in the Prinzhorn collection, and they point to a common characteristic of its art - a paradoxical treatment of boundary lines and figure-ground relationships. Sometimes borders are effaced, as if in schizophrenic dissolution; sometimes, on the contrary, they are exaggerated, as if in paranoid defense. And sometimes, too, boundaries are exaggerated to the point where they are effaced again - as if, in the very attempt to underscore the distinction between self and world necessary to an image of autonomy, this very distinction were undone. The failure of the boundary in this art takes as many forms as the drives posited by Prinzhorn: figure-ground relationships are confused in

\footnotetext{
37 This aesthetic was later made programmatic, almost rote, in the "paranoid-critical method" of Salvador Dali. Beyond Painting can be read as a passage from Dadaist strategies that mime preOedipal regression to surrealist stories of Oedipal riddling. In his work of the early 1920s, Ernst does pass from late Dadaist collages sometimes evocative of a primal scene to early surrealist paintings that are often Oedipal in theme. He also moves from the autistic persona "Dadamax" to the hybrid figure "Loplop," who functions sometimes as an external superego (especially when identified with a castrative father). In a sense, Ernst moves from a position of Dadaist negativity to one of surrealist redemption, an aesthetic of restorative self-fashioning more than of "convulsive identity."

38 Dubuffet favors the animalistic over the mechanistic, while Klee sometimes combines the two, as in his well-known Twittering Machine (1922).
} 
ornamental ordering, obsessive copying, systematic fantasies, and so on. In all these modes, the will to order is often so insistent that it overbears the device designed to deliver it, and the image is plunged back into chaos.

A recurrent instance of this paradoxical disordering of figure and ground is the compulsive inscription of the pictorial field with repeated numbers and/or letters, words and/or phrases. Here a longing for any difference seems to be pronounced not only in the primordial marking of a figure against a ground, but also in the fundamental nature of the signs that are used. Yet, again, these marks are often elaborated to the point where the desired difference is overwhelmed ("the tendency to fill in each area," Prinzhorn writes, "contradicts completely the essence of representation which aims at individualization" [AMI233]). A poignant example in the Prinzhorn collection is the letter-writing of Emma Hauck, diagnosed with dementia praecox, who darkened her pages into near illegibility with a repeated plea for her husband "to come" to her, even though this "her" seems far from secure or stable (fig. 5.7).

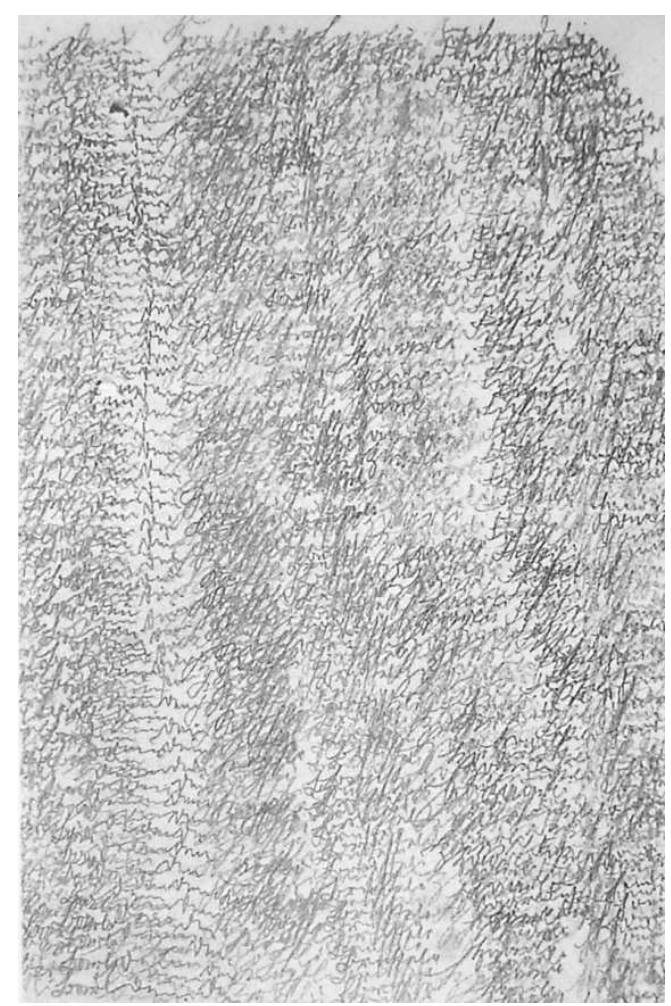

Hal Foster 7. Emma Hauck, Querido venha (carta ao marido), 1909

Here the very desire for human connection becomes another expression of "autistic isolation."

This tipping of order into disorder also occurs when order is the explicit subject of the work, as in paranoid projections of grandiose fantasies. Often in the 
Prinzhorn collection, depictions of miraculous events and hostile machinations, mappings of institutional spaces and cosmic systems - in which the "metaphysical urge"(AMI241) of the art of the mentally ill is most apparent are so obsessively articulated that the order that they construct for the world deconstructs on its own, a casualty of its own overelaborate systematicity. A good example is the compendious work of Josef Heinrich Grebing, a commercial clerk also diagnosed with dementia praecox. Grebing reassembled a symbolic order out of the perceived debris of the official one: he issued financial certificates, painted religious icons, drew "world maps," and, most extraordinarily, developed an entire calendar of the twentieth century - "a chronology for Catholic youths and maidens" - replete with astrological tables (fig. 5.8).

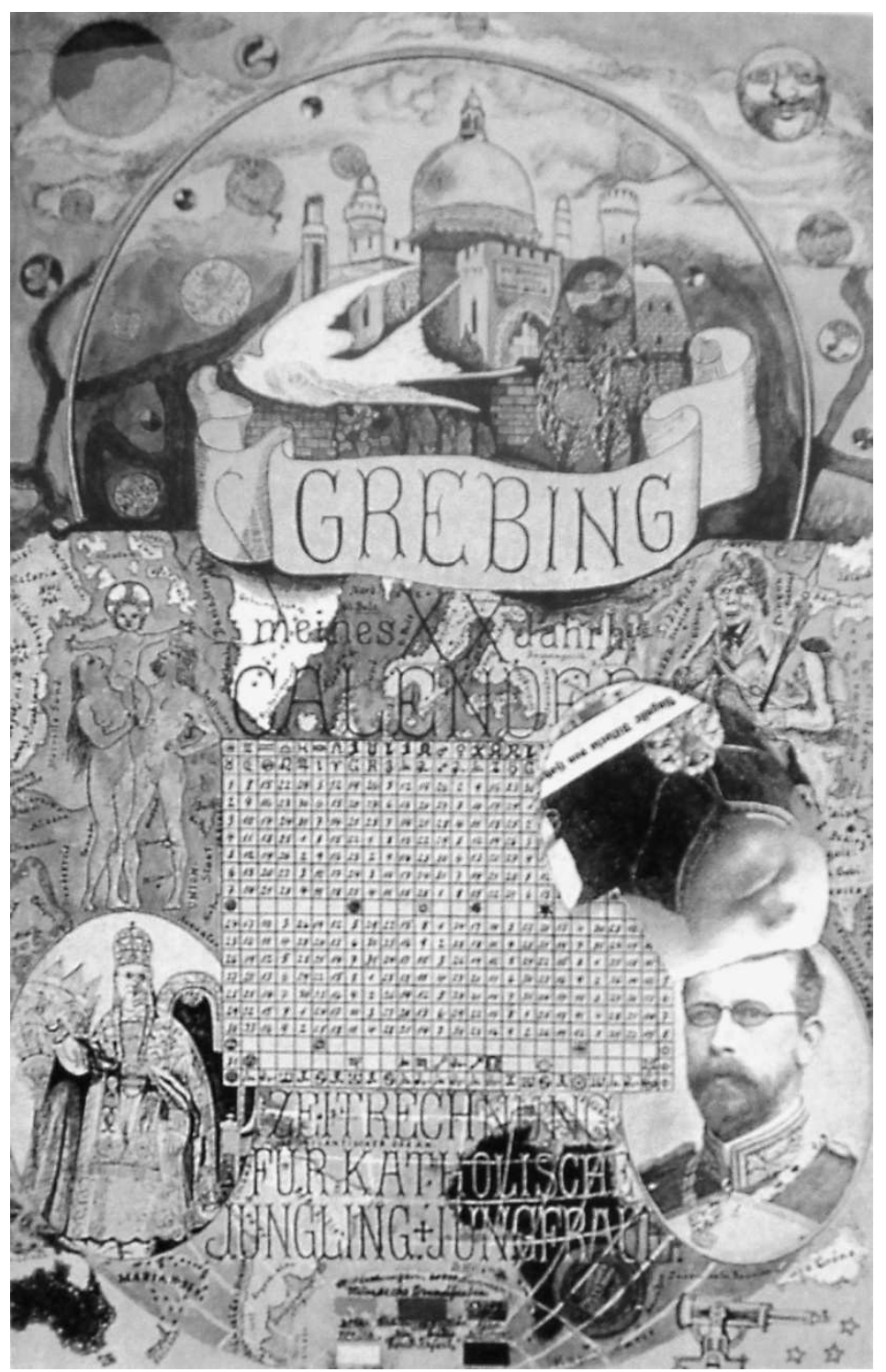

Hal Foster 8. Josef Heinrich Grebing, Calendário do meu século XX _ Cronologia para jovens católicos e donzelas, Foto Manfred Zentsch. 
What Freud remarks of the paranoid system of Judge Schreber seems true here as well: "The delusion-formation, which we take to be a pathological product, is in reality an attempt at recovery, a process of reconstruction." 39

The collapsing of figure and ground is also pervasive in the related work of our three modernists, where it is closer to such psychotic representations than to the formal deconstructions of this relationship in other modernists (one can compare the grids of Klee with the grids of Mondrian as a test of this point). In the small watercolor Room Perspective with Inhabitants (1921; fig. 5.9),

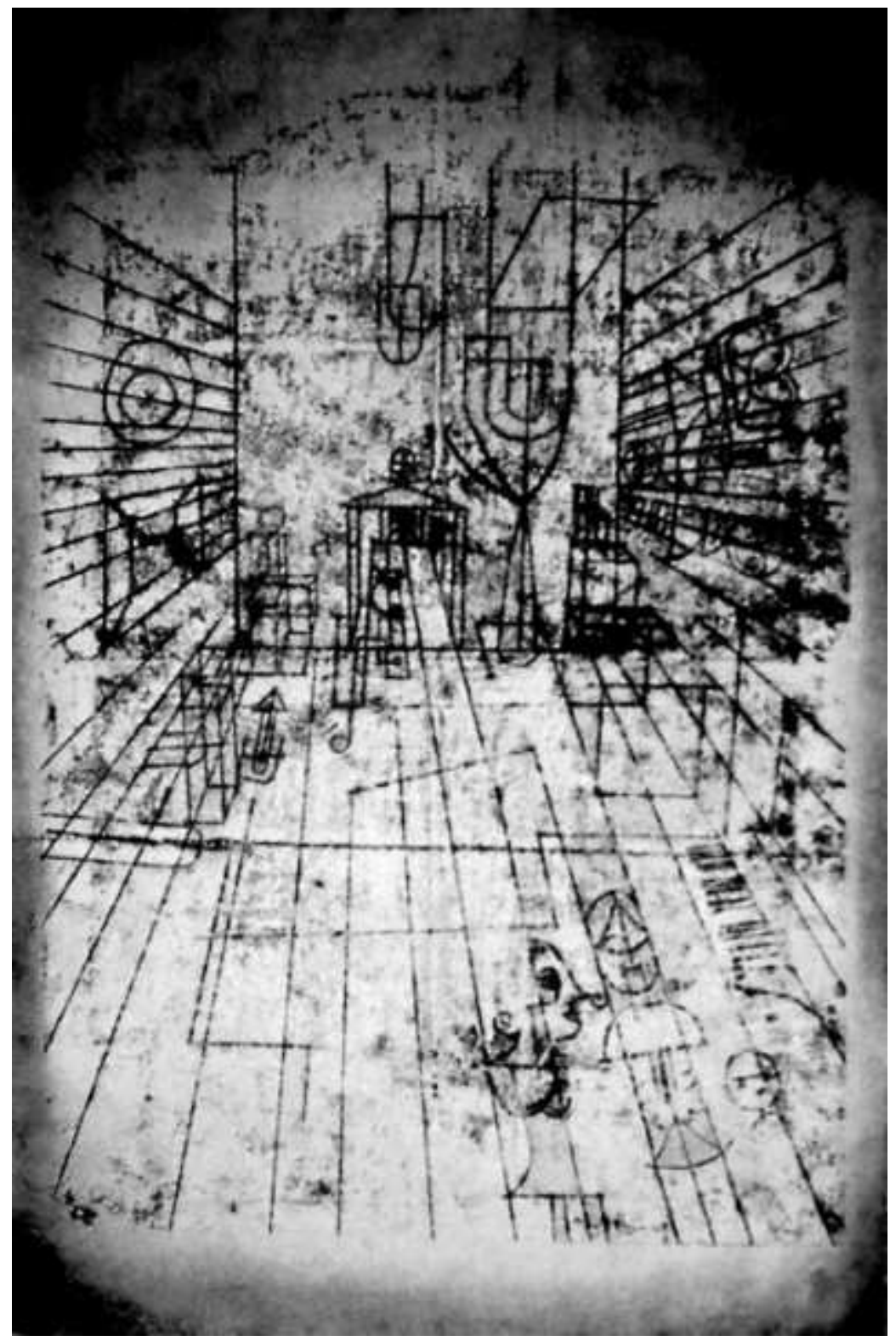

Hal Foster 9. Paul Klee, Perspectiva de uma sala com habitantes, 1921.

\footnotetext{
${ }^{39}$ Freud, "Psychoanalytic Notes on an Autobiographical Account of a Case of Paranoia," 174. This process is also at work in the images of August Natterer discussed in chapter 7.
} 
Klee collapses figure and ground in a way that effectively merges subject and space. In this image orthogonals lead to a conundrum of rooms, an arrow points nowhere, and a ghostly grail offers little hope of salvation. The few objects in the room are vectored into transparency by the perspective, and the same fate befalls the figures that are flattened in the floor and along the wall like schematic spectres. They less inhabit the room than are inhabited by it - by a perspective that seems to trace an "in-between world" (to use his own term). In this way, Klee pushes the old project of perspective - which Erwin Panofsky once defined, in its Renaissance epitome, as the humanist reconciliation of subject and object - to the point of an inhuman reversal, for here subject and object are not reconciled as equal terms so much as dissolved as distinct entities. ${ }^{40}$ The best gloss on the horrific spatiality of Room Perspective with Inhabitants is this singular account of schizophrenic anguish, of a literal losing of self in space, by the surrealist associate Roger Caillois in 1937:

To these dispossessed souls, space seems to be a devouring force. Space pursues them, encircles them, digests them in a gigantic phagocytosis [consumption of bacteria]. It ends by replacing them. Then the body separates itself from thought, the individual breaks the boundary of his skin and occupies the other side of his senses. He tries to look at himself from any point whatever in space. He feels himself becoming space, dark space where things cannot be put. He is similar, not similar to something, but just similar. And he invents spaces of which he is "the convulsive possession." ${ }^{41}$

This awful condition of mere similarity and convulsive possession captures the schizophrenic terror of collapsed boundaries and invasive spatiality that is often evoked in the art of the mentally ill. Of special interest here is that sometimes this horror seems to call out for a paranoid counter - a defensive projection of a space that now becomes too distinct and distant, of a world that is suddenly estranged and hostile. Ernst evokes this paranoid alienation in a work like The Master's Bedroom,

\footnotetext{
40 See Erwin Panofsky, Perspective as Symbolic Form (1924.-25), trans. Christopher Wood (New York: Zone Books, 1991). Here, too, Klee perverts an old project of his own, set nearly twenty years before in summer 1902: "Spiritualization of landscape, mingling of its psyche with human sensibility" (Felix Klee, Paul Klee, 8).

${ }^{41}$ Roger Caillois, "Mimicry and Legendary Psychasthenia" (1937), October 31 (Winter 1984), 30; original emphasis. For other such evocations, see Louis A. Sass, Modernism and Madness (New York: Basic Books, 1992).
} 
where the viewer becomes the viewed, and the storybook animals and bedtime things turn into alien beings (fig. 5.6, pl. 8). If we can juxtapose the two rooms of Klee and Ernst for a moment, Room Perspective with Inhabitants seems to perform a schizophrenic dissolution of the subject into space, while The Master's Bedroom seems to project a paranoid alienation of the subject by space - as if the schizophrenic subject imagined in the first room sought to be recentered, made master again, by the paranoid projection of space in the second room, in its hallucinated opposition of self and other. ${ }^{42}$ In this way paranoia might be understood as the last refuge, the final asylum of a subject threatened by schizophrenic self-loss: "I" am still an "I" as long as there is an other in space, perhaps an other as space, out there to threaten me; this other keeps me centered by its very alterity, in its very threat. ${ }^{43}$ Yet this paranoid projection of space is no more guarantee of the subject than the schizophrenic construction of machinic prostheses mentioned above in relation to Ernst. Both are attempts at self-rescue that only underscore self-loss. Such is the understanding of the art of the mentally ill that a reading after Ernst allows. ${ }^{44}$

Rather than a simple opposition between schizophrenia and paranoia, then, there is a contradictory connection between the pictorial traits that might be associated with each. In the Prinzhorn collection one sees a persistent oscillation between images of schizophrenic "catastrophe" and images of paranoid "reconstruction" (to use the Freudian terms): every cancellation of boundary seems countervailed by an insistence on boundary, every opening to chaos by a groping at order, and so on. ${ }^{45}$ This tension exists not only between

\footnotetext{
${ }^{42}$ Sometimes these two operations - dissolution into space and projection of space - seem to occur at once, as in some images by the Prinzhorn master Heinrich Welz, who may have influenced Klee. See James Smith Pierce, "Paul Klee and Baron Welz," Arts Magazine (September 1977).

${ }^{43}$ Freud liked to associate the system-building of paranoia with philosophy:"a paranoiac delusion is a caricature of a philosophical system," he writes in Totem and Taboo (1913; trans. James Strachey [New York: W W Norton, 1950], 73). Did he sense that the analogy might run the other way too? Might the systematizing of madness in psychoanalysis be a defense against madness? There is a paranoid dimension in much postwar French philosophy as well - the alienation of the gaze in Sartre and Lacan, the power of surveillance in Foucault, and so on - but its stake is different. As suggested above, perhaps the very critique of the subject in such philosophy is also a secret mission to rescue it. "In paranoia," Leo Bersani has argued, "the primary function of the enemy is to provide a definition of the real that makes paranoia necessary. We must therefore begin to suspect the paranoid structure itself as a device by which consciousness maintains the polarity of self and nonself, thus preserving the concept of identity" ("Pynchon, Paranoia, and Literature;' in Representations 25 [Winter 1989], 109).

44 This understanding is echoed in a 1936 essay "The Art of the Mentally Ill" by the Viennese psychoanalyst and art historian Ernst Kris, who visited the Prinzhorn collection. Influenced by Freud on paranoia, Kris was critical of the Prinzhorn idealization of this art, which he read instead as a failed project of "restitution," See his Psychoanalytic Explorations in Art (New York: Schocken Books, 1964).

45 There is another tension between machinic representations: some seem designed to shore up a damaged ego, to defend against schizophrenic self-dissolution, along the lines discussed above; others to depict paranoid fantasies of external control, along the lines proposed by Viktor Tausk, a
} 
schizophrenia and paranoia but also within each condition, that is, within each patient torn between visions of self-loss and visions of self-rescue. Prinzhorn detected such ambivalence in most of his masters, whether they were diagnosed as schizophrenic or paranoid. This ambivalence extends to external objects ("a child's head ... reminds the drawer of death, a radish pulled from the earth reminds him of Christ with chalice and host" [AMI236]) as well as to other beings ("the physician may be greeted as if he were the mailman" [AMI39]), but it finally rooted in the subject ("a patient is God but sweeps the floor willingly" [AMI266]). This ambivalence in the subject is most extreme in the recurrent identification among the Prinzhorn masters with Christ. The force of this identification is that it allows for simultaneous delusions of grandeur and persecution, for a status that is at once "supernatural" and "sacrificial," exalted and abject (AMI 117). However, rather than a position of a double authority, this is a position of a double bind, in which the subject is indeed caught in an "inbetween world," caught in a crisis between symbolic orders, caught (perhaps like Christ) as the crux between such orders - between a ruined old dispensation and an emergent new dispensation that no one else yet perceives, let alone believes in. ${ }^{46}$ The Prinzhorn collection is full of images that seem to recount a blasphemous transgression of religion, or a carnivalesque overturning of society. But rather than heroic acts of refusal or revolution, what these images might register are panicked attempts to restore or to replace such social systems - panicked attempts, that is, both to record the breaking of an old order and to project the founding of a new one.

\section{The symbolic order as "old lecher with riffle"}

I want to conclude with a work by Ernst, mentioned in chapter 4, that turns an evocation of a failed subject into a critique of a failed symbolic order. It is a work now known through a photograph that shows Max and Luise Ernst, and Paul and Gala Eluard, in the Cologne studio of the former in 1920; the infant Jimmy Ernst is barely visible between them (fig. 5.10).

\footnotetext{
Viennese associate of Freud, in his 1919 paper "On the Origin of the Influencing Machine" (Psychoanalytic Quarterly [1933], reprinted in Zone 6 [1992]). According to Tausk, the "influencing machine" is a projection of an organ (usually the genitals) or the body in such a way that it "appears as an outer enemy, a machine used to attack the patient" (Zone, 562). Graphic examples are the "proofs" (Beweisse) drawn by Jakob Mohr, who was indeed diagnosed as paranoid. In one drawing he is literally wired to the machine held by an enemy - perhaps an indication of the technological nature of this particular construction in paranoia.

${ }^{46}$ See note 27 . On the double bind in relation to schizophrenia, see Gregory Bateson, Steps to an Ecology of Mind (New York: Ballantine Books, 1972). I return to this condition in chapter 7.
} 


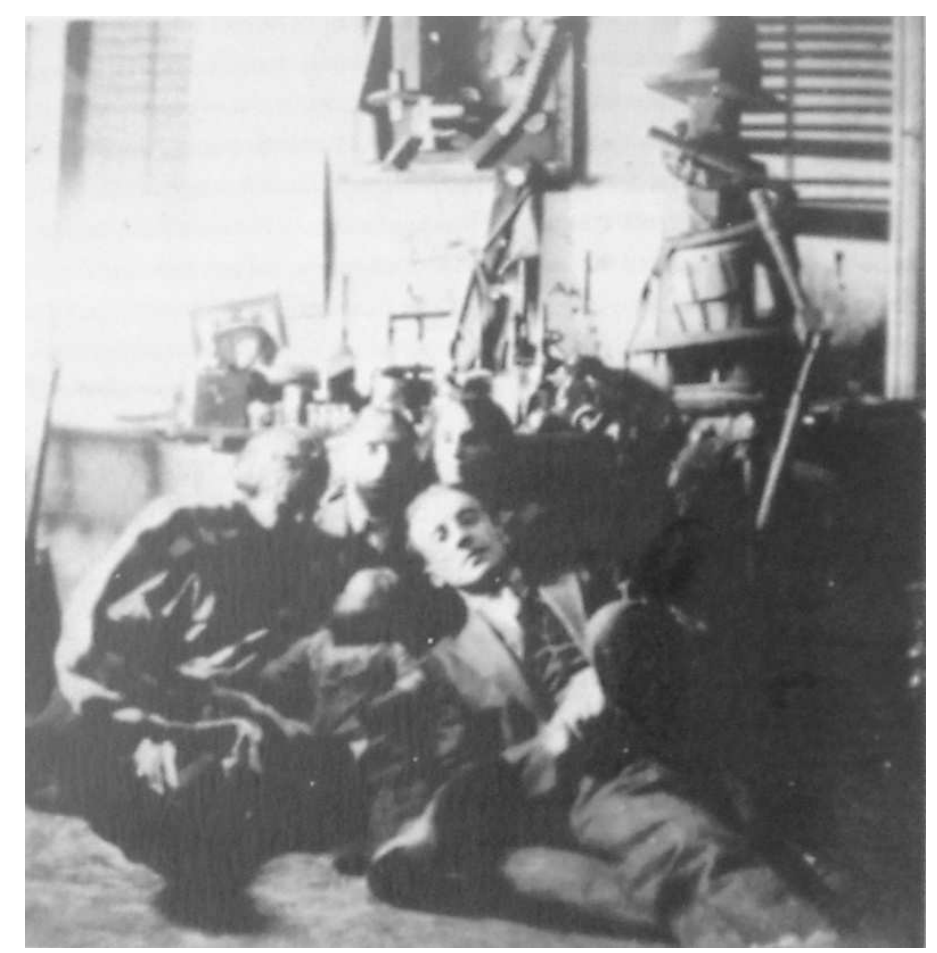

Hal Foster 10. Louise Straus-Ernst, Max Ernst, e o filho Jimmy com Gala e Paul Eluard no atelier de Ernst, Colônia, Nov. 1921, em frente ao Velho Libertino com um rifle

It is a simple snapshot that commemorates a new friendship - a friendship that would soon become a difficult Max-Paul-Gala menage à trois. They appear under a strange assemblage that resembles a three-dimensional version of the "selfconstructed machines" of Ernst; it is one of the junk sculptures made at the same time as his Dadaist collages, apparently inspired by the "bread sculptures" seen on his prewar visit to the asylum near Bonn. As I argued in chapter 4, most of these sculptures evoke hapless personages of phallic authority in trouble. Akin to the collage The Hat Makes the Man (1920; fig. 4.12), the strange figure here is indeed an "old lecher," stuck together with wood rods, a helmet hat, and a stick-gun (a later collage with the same title is de/constructed out of similar items of fashion and war).

Again, Ernst presented Old Lecher with Rifle in the "Dada-Early Spring" show in April 1920, and it was this sculpture that provoked the good citizens of Cologne to call out the police to close the exhibition. (In this regard, Old Lecher with Rifle is partner to the plaster pig head, stuck on a military uniform and hung from a ceiling, that caused a similar furor at the "First International Dada Fair" in Berlin a few months later.) His own father brake with Ernst over the event. Clearly this work pressured a time that was already out of joint.

Ernst gives the sculpture a caption in the quasi-schizophrenic "word salad" 
common in his contemporaneous collages: "Old Lecher with Rifle Protects the Museum's Spring Apparel from Dadaist Interventions [L'état c'est MOI!] [Monumental Sculpture]." This is near nonsense, to be sure, but it is pointed nonsense, for in this moment of military defeat and social chaos the state is figured as an "old lecher" whose only authority is sheer force, "the rifle." And yet this pathetic state still attempts to protect the cultural patrimony, "the museums," from the attack of "Dadaist interventions." However, the performative magic of this state power ("I'état c'est MOI!") no longer functions; it is ridiculous, and here the Ernst-Eluard quintet, at once promiscuous and provocative, lies casually, almost insolently, indifferent to this emblem of police force. Moreover, the cultural patrimony that the state wishes to protect is already degraded: it is little more than fashion, "spring apparel," an array of new commodities for each new season, and Ernst does not seem to exempt the avant-garde in general, or Dada in particular, from this status. If Old Lecher is indeed a "monumental sculpture," it is thus a monument to the failure of symbolic monumentality, a monument to the collapse of social authority. It is this blinded insight that the art of the mentally ill might point less to pure expression, originary vision, or vanguard transgression than to a given crisis in the symbolic order - that Ernst discovers in "the no-man's-land" of its representations. 